\title{
UHF RFID ANTENNA IMPEDANCE MATCHING TECHNIQUES
}

\author{
A Thesis \\ presented to \\ the Faculty of California Polytechnic State University, \\ San Luis Obispo
}

\author{
In Partial Fulfillment \\ of the Requirements for the Degree \\ Master of Science in Electrical Engineering
}

by

Kamron Sockolov

March 2017 
(C) 2017

Kamron Sockolov

ALL RIGHTS RESERVED 
COMMITTEE MEMBERSHIP

TITLE:

UHF RFID Antenna Impedance Matching Techniques

AUTHOR:

Kamron Sockolov

DATE SUBMITTED:

March 2017

COMMITTEE CHAIR:

Dean Arakaki, Ph.D.

Associate Professor of Electrical Engineering

Advisor

COMMITTEE MEMBER:

Dennis Derickson, Ph.D.

Department Chair of Electrical Engineering

COMMITTEE MEMBER:

Xiaoying Rong, Ph.D.

Associate Professor of Graphic Communication 


\author{
ABSTRACT \\ UHF RFID Antenna Impedance Matching Techniques \\ Kamron Sockolov
}

Radio Frequency Identification (RFID) systems use electromagnetic signals to wirelessly identify and track RFID-tagged objects. A reader transmits a carrier wave request signal to an RFID tag, which then transmits a unique identification signal back to the reader. Applications include supply chain inventory management, automated toll booth fee systems, sports event timing, restricted access control, pet monitoring and retail theft prevention. An RFID tag includes an antenna connected to a Radio Frequency Integrated Circuit (RFIC). RFID tags in the ultra-high frequency (UHF), industrial, scientific and medical (ISM) $902-928 \mathrm{MHz}$ band and global Electronic Product Code (EPC) $860-960 \mathrm{MHz}$ band are powered passively (power extracted from carrier wave) and cost less than 15 cents per tag. Low cost UHF ISM RFID tags are an effective solution for tracking large inventories. UHF ISM tag antennas are typically planar dipoles printed onto a plastic dielectric substrate (inlay). Power exchange and transmit range is maximized when a tag antenna's input impedance is conjugate matched to the RFIC input impedance. Since RFIC input impedance includes capacitive reactance, optimized antenna input impedance includes compensating inductive reactance.

The T-match network (Figure 0-1) [2] adds inductive matching microstrips to conjugate match the RFIC. Narrowband ( $\pm 1.5 \%$ of center frequency) and broadband ( $\pm 5 \%$ of center frequency) lumped element designs [3] also use inductive matching strips. Narrowband, lumped element design is accomplished through Smith Chart matching assuming lumped antenna elements. The broadband lumped element design is accomplished through a circuit transformation to an equivalent network and tuning the transformed circuit to resonate from $865 \mathrm{MHz}$ to $955 \mathrm{MHz}$, with a center frequency of $910 \mathrm{MHz}$. 


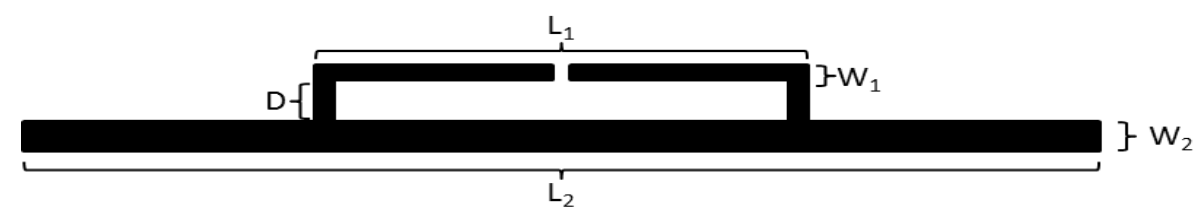

Figure 0-1. T-Match Network

This thesis demonstrates a start-to-finish design process for narrow $( \pm 1.5 \%$ of center frequency) and broadband ( $\pm 5 \%$ of center frequency) RFID tag antennas [3]. Furthermore, antenna matching element geometries are parametrically swept to characterize input impedance frequency response. Thesis accomplishments include (a) narrow and broadband antenna designs, (b) Keysight's Advanced Design System (ADS) Momentum simulations, (c) antenna fabrication, and (d) differential probe impedance setup and antenna impedance measurements. Additional items include (e) impedance adjustments ( $\mathrm{f}$ ) tag range testing and $(\mathrm{g}$ ) narrow vs. broadband matching technique comparisons. Antennas were fabricated in Cal Poly's Graphic Communication Department by silk-screening silver conductive ink onto DuPont Melinix Polyethylene Terephthalate (PET) plastic. Impedance simulations are compared to fabricated antenna impedance measurements and range testing results. 


\section{ACKNOWLEDGMENTS}

Thank you, Dr. Dean Arakaki for your countless hours reviewing and editing my thesis and for developing Cal Poly's Radio Frequency and Antennas programs, which has made this thesis possible. Also, thank you for pushing me to produce high quality work - I believe it has made me both a better engineer and technical writer. Thank you, Dr. Xiaoying Rong (Cal Poly's Graphic Communication Department) for printing my antenna designs and sitting on my thesis committee. Thank you, Dr. Dennis Derickson for sitting on my thesis committee and giving me a chance by accepting me into the Cal Poly's Electrical Engineering Master's Degree Program. I have enjoyed my time and learned a tremendous amount during my enrollment.

I am eternally grateful to my parents for supporting my sister and me through every step of our educations. Without your support, Mom and Dad, my academic career and subsequent success would not be possible. I am also forever grateful to my sister, Leila, for her everlasting friendship and support. 


\section{TABLE OF CONTENTS}

Page

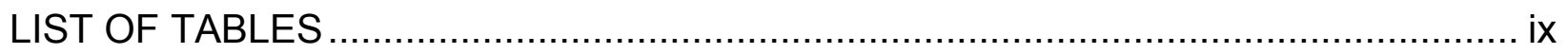

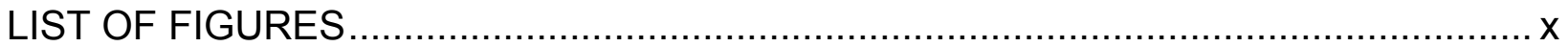

\section{CHAPTER}

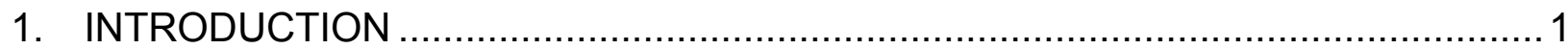

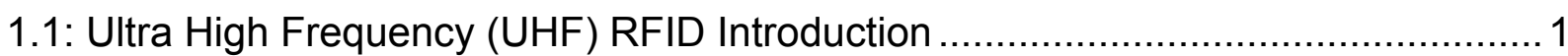

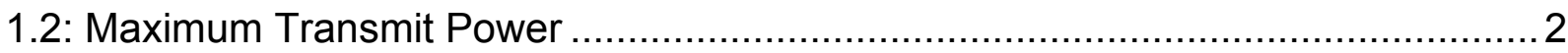

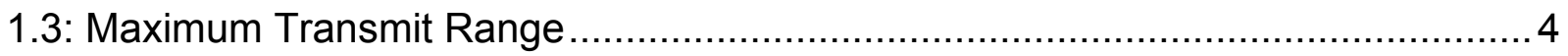

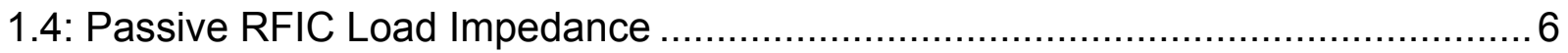

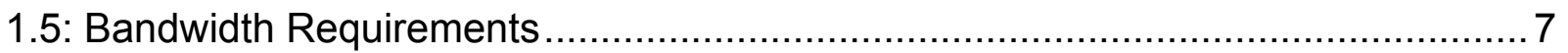

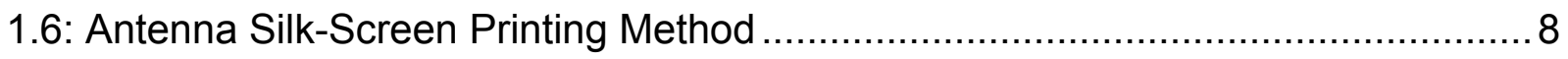

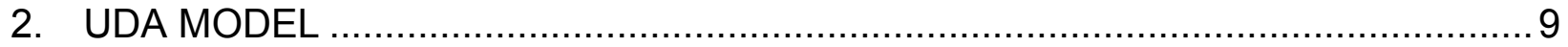

2.1: T-Match Antenna Input Impedance Using Even/Odd Mode Analysis ................ 10

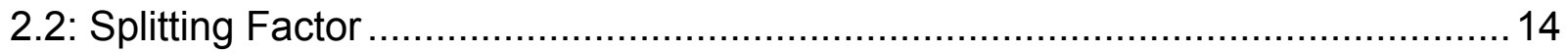

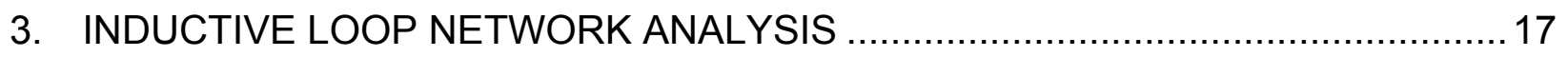

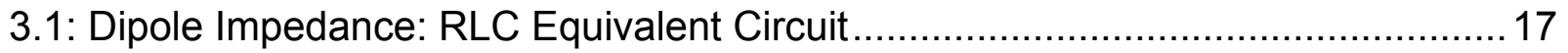

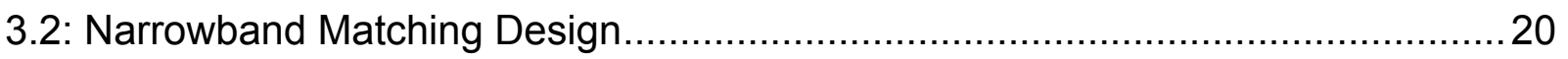

3.3: Broadband Matching Design........................................................... 21

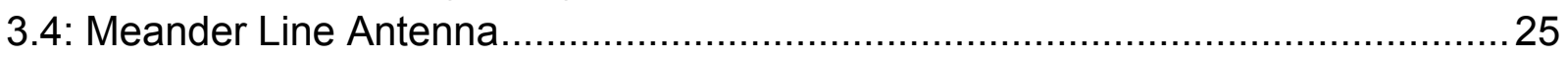

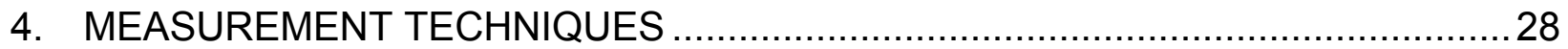

4.1: Patch Antennas for Range Testing and Sleeve Balun Verification .....................28

4.2: RFID Antenna Input Impedance Measurement Methods............................. 31

4.2.1: Sleeve Balun Probe .................................................................. 31

4.2.2: Differential Impedance Probe .......................................................... 36

4.2.3: Sleeve Balun and Differential Probe Verification ................................. 38

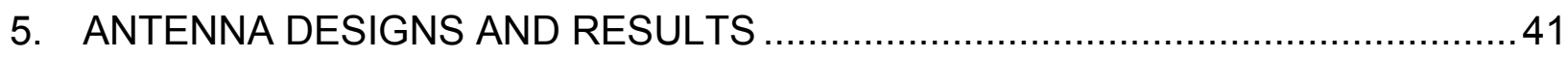

5.1: Load Characterization ......................................................................... 41

5.2: Narrowband 902-928MHz Design, Measurement and Range Testing ..............43

5.3: Broadband 865-955MHz Design, Measurement and Range Testing .................50

5.4: Narrowband vs. Broadband Frequency Response ...................................57

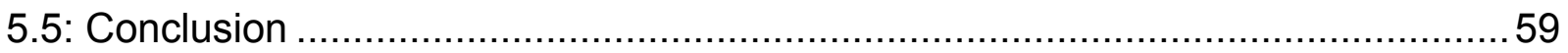

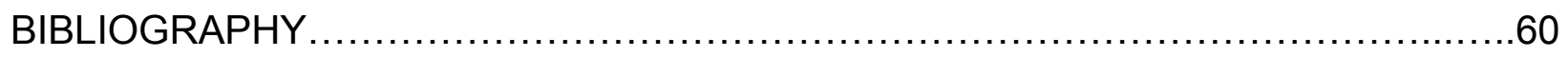

APPENDICES

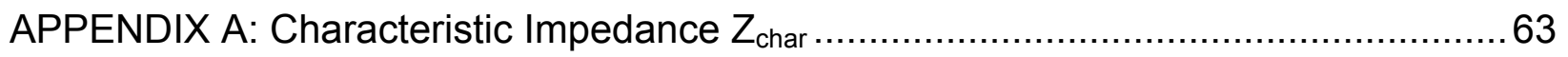

APPENDIX B: Capacitance Per Unit Length for Two Cylindrical Conductors...............65 
APPENDIX C: $\cosh ^{-1}(x)=\ln \left(x+\left(x^{2}-1\right)^{1 / 2}\right)$

APPENDIX D: Splitting Factor in Odd Mode, Two-Port Network Analysis of T-Match

Structure. 


\section{LIST OF TABLES}

Table

Page

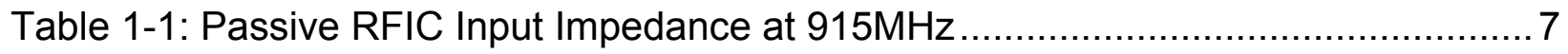

Table 1-2: RFID UHF Global Bands [10] ....................................................... 7

Table 4-1: Air Dielectric Patch Antenna (902MHz-928MHz) Dimensions ......................29

Table 5-1: Narrowband Antenna Dimensions ......................................................... 43

Table 5-2: Narrowband Antenna Range Testing Conditions at $915 \mathrm{MHz}^{*} \ldots \ldots \ldots \ldots \ldots \ldots . . . . . . . . .49$

Table 5-3: Narrowband Antenna/ Higgs-4 RFIC Range ............................................. 49

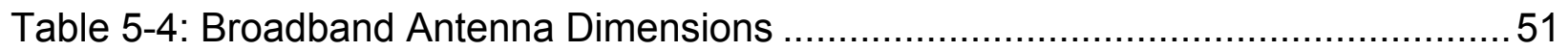

Table 5-5: Broadband Antenna Range Test Conditions at $910 \mathrm{MHz} \ldots \ldots \ldots \ldots \ldots \ldots \ldots \ldots . . . . . . \ldots 56$

Table 5-6: Broadband Antenna/RFIC Range Read Range .......................................56 


\section{LIST OF FIGURES}

Figure

Figure 0-1. T-Match Network

Figure 1-1: (a) Reader Transmitting Carrier to Tag, (b) Tag Backscattering to Reader... 1

Figure 1-2: RFID Tag: Antenna RFIC and Inlay ............................................ 2

Figure 1-3: Maximum Power Transfer Theorem ................................................. 2

Figure 1-4: Thevenin Equivalent Generator $V_{A}$ and Antenna Impedance $Z_{A} \ldots \ldots \ldots \ldots \ldots 3$

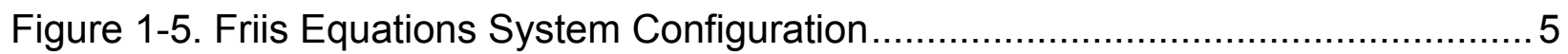

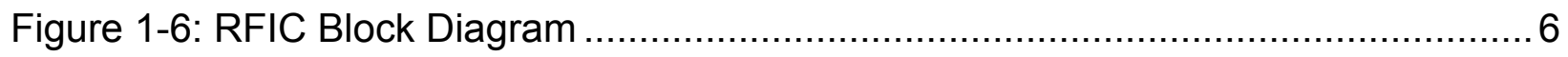

Figure 1-7: RFIC Input Impedance, (a) Norton Equivalent, (b) Thevenin Equivalent....... 6

Figure 1-8: ATMA Semi-Auto Screen Printing Press, Roller and 305 Mesh Polyester

Silk-Screen on an Aluminum Frame at the Cal Poly Graphic Communications Lab....... 8

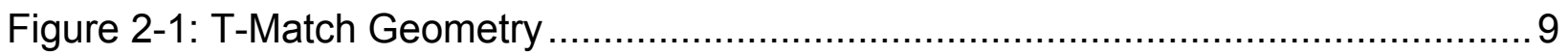

Figure 2-2: Alien Squig ${ }^{\mathrm{TM}}$ Inductive Shunt Series Matching Network ........................9

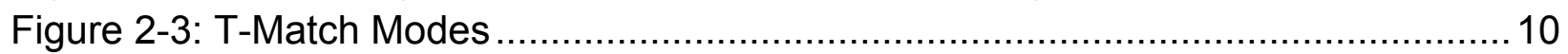

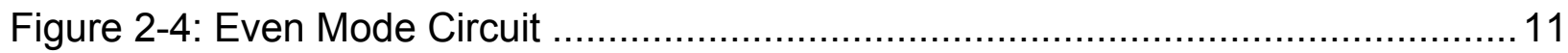

Figure 2-5: (a) Even Mode Circuit Redrawn and (b) Radiating Antenna Equivalent......11

Figure 2-6: (a) Odd-mode Circuit, (b) Circuit Redrawn with Divided Sources,

(c) Circuit with Equipotential Line between Sources ......................................... 12

Figure 2-7. Transmission Line Model for Half of Odd-Mode Impedance ..................... 12

Figure 2-8: (a) Even Modes, (b) Odd Modes, (c) Total Modes ................................. 13

Figure 2-9: T-Match Antenna Equivalent Circuit ........................................... 14

Figure 2-10: Two Parallel, Cylindrical Conductor Cross-Sections with Unequal Radii .. 15

Figure 2-11: Top View of Asymmetric Coplanar Strip ....................................... 15

Figure 3-1: Inductive Loop with Series and Shunt Inductance [17] ......................... 17

Figure 3-2: Lumped Element Matching Network for RFID Tag [16] .......................... 17

Figure 3-3: RLC Impedance Equivalent [18] Dipole Impedance as Lumped Element

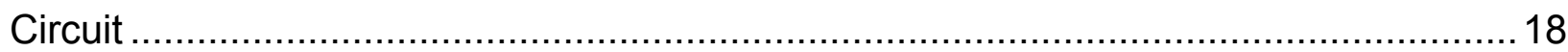

Figure 3-4: Simplified RLC Network; Dipole Reactance as Lumped Element Circuit ....18

Figure 3-5: Series RLC Response Fit to ADS Simulated Dipole Reactance ................19

Figure 3-6: RFID Tag Lumped Element Matching Network .................................21

Figure 3-7: Smith Chart Impedance Matching; IC Load to Conjugate Dipole

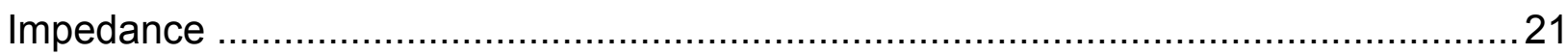

Figure 3-8: Transformed Lumped Element Matching Network, Broadband Match ........22

Figure 3-9: Lumped Element RLC Band-Pass Filter, Broadband Match ....................22

Figure 3-10: Current Distributions and Geometry, Meander Line Dipole .....................25

Figure 4-1: Air Dielectric, Probe Fed Patch Antenna Geometry: (a) Patch Antenna Front View, (b) Patch Antenna Side View ................................................... 28

Figure 4-2: Patch Antenna to Ground Electric Fields and Fringing Areas ..................29

Figure 4-3: Air Dielectric Patch Antenna, 902MHz-928MHz ................................. 29 
Figure 4-4: Air Dielectric Patch Antenna $\left|\mathrm{S}_{11}\right|(\mathrm{dB})$ vs. Frequency $(\mathrm{MHz}), 902 \mathrm{MHz}-$

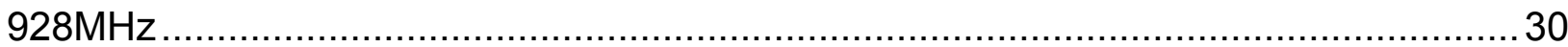

Figure 4-5: Measured Air Dielectric Patch Antenna Gain (dB) vs. Frequency (MHz),

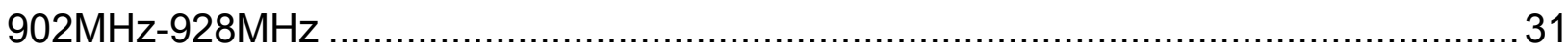

Figure 4-6: Dipole and Cable without Balun........................................................ 32

Figure 4-7: Sleeve Balun, $\lambda / 4$ Metal Sleeve Soldered to Outside of Outer Conductor... 33

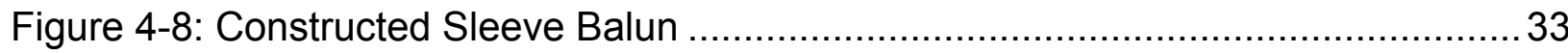

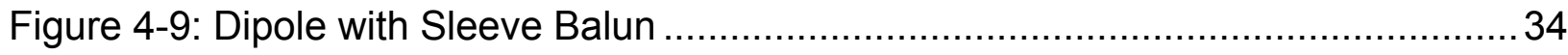

Figure 4-10: Anechoic Chamber Pattern Measurement Setup, Top View .....................35

Figure 4-11: Dipole With and Without Sleeve Balun, E-Plane ( $\theta)$ Field Pattern, dB ......35

Figure 4-12: Differential Probe, Tag Antenna Input Impedance Measurements .............36

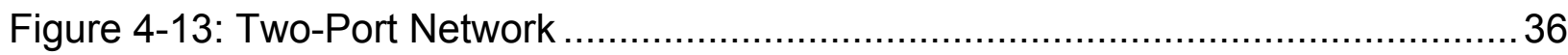

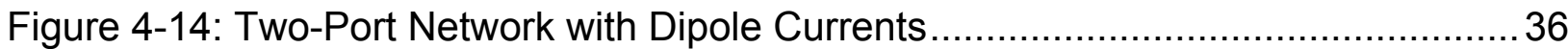

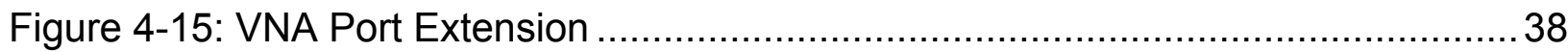

Figure 4-16: PET Substrate Bounded Above and Below by Air Dielectric, Side View ... 39

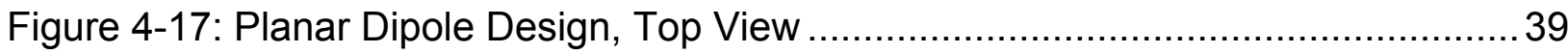

Figure 4-18: Printed Planar Dipole Input Resistance $(\Omega)$ vs. Frequency $(\mathrm{MHz}) \ldots \ldots \ldots \ldots . . . .39$

Figure 4-19: Printed Planar Dipole Input Reactance $(\Omega)$ vs. Frequency $(\mathrm{MHz}) \ldots \ldots \ldots \ldots . . .40$

Figure 5-1: Higgs-4 Strap Dimensions (Millimeters) [9] ........................................... 41

Figure 5-2: RFIC Input Shunt Capacitance and Resistance ........................................42

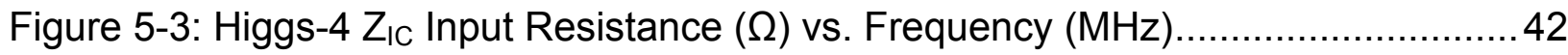

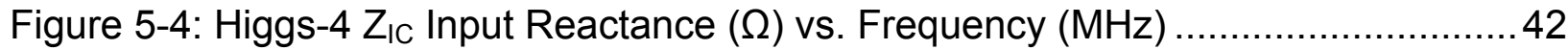

Figure 5-5: Narrowband Antenna Dimensions ...................................................... 43

Figure 5-6: Simulated Narrowband Input Resistance $(\Omega)$ vs. Frequency $(\mathrm{MHz}) \ldots \ldots \ldots . . .44$

Figure 5-7: Simulated Narrowband Input Reactance $(\Omega)$ vs. Frequency $(\mathrm{MHz}) \ldots \ldots \ldots \ldots . . .44$

Figure 5-8: Simulated Narrowband Input Resistance $(\Omega)$ vs. Frequency $(\mathrm{MHz}) \ldots \ldots \ldots \ldots . . .45$

Figure 5-9: Simulated Narrowband Input Reactance $(\Omega)$ vs. Frequency $(\mathrm{MHz}) \ldots \ldots \ldots \ldots . . . .45$

Figure 5-10: Measured Narrowband Input Resistance $(\Omega)$ vs. Frequency $(\mathrm{MHz}) \ldots \ldots \ldots . . .46$

Figure 5-11: Measured Narrowband Input Reactance $(\Omega)$ vs. Frequency $(\mathrm{MHz}) \ldots \ldots \ldots . . .46$

Figure 5-12: Simulated Narrowband $\left|\mathrm{S}_{11}\right|(\mathrm{dB})$ vs. Frequency $(\mathrm{MHz}) \ldots \ldots \ldots \ldots \ldots \ldots \ldots \ldots . . . . . . \ldots \ldots$

Figure 5-13: Higgs-4 RFIC Strap Attached to Narrow Band Antenna ...........................48

Figure 5-14: RFID Tag Range Testing Setup, E-Plane aligned with $\mathrm{f} . \ldots \ldots \ldots \ldots \ldots \ldots \ldots \ldots . . . . . . . . . . . . .48$

Figure 5-15: Simulated Narrowband $915 \mathrm{MHz}$ Antenna E-Field Pattern (f) in dB ...........48

Figure 5-16: Broadband Simulated Input Resistance $(\Omega)$ vs. Frequency $(\mathrm{MHz}) \ldots \ldots \ldots \ldots . . .50$

Figure 5-17: Broadband Simulated Reactance $(\Omega)$ vs. Frequency $(\mathrm{MHz}) \ldots \ldots \ldots \ldots \ldots \ldots \ldots . . .50$

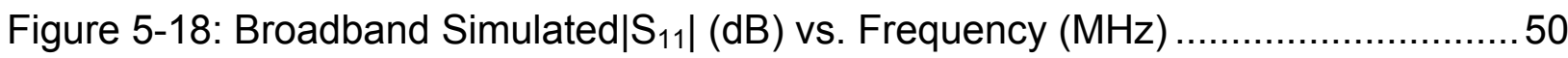

Figure 5-19: Broadband MLA Antenna Design ....................................................51

Figure 5-20: Calculated Broadband Input Resistance $(\Omega)$ vs. Frequency $(\mathrm{MHz}) \ldots \ldots \ldots . .51$

Figure 5-21: Calculated Broadband Input Reactance $(\Omega)$ vs. Frequency $(\mathrm{MHz}) \ldots \ldots \ldots \ldots . . .52$

Figure 5-22: Simulated Broadband Input Resistance $(\Omega)$ vs. Frequency $(\mathrm{MHz}) \ldots \ldots \ldots \ldots . . .53$ 
Figure 5-23: Simulated Broadband Input Reactance $(\Omega)$ vs. Frequency $(\mathrm{MHz}) \ldots \ldots \ldots \ldots . . . .53$ Figure 5-24: Measured Broadband Feed Input Resistance $(\Omega)$ vs. Frequency (MHz)...54 Figure 5-25: Measured Broadband Feed Input Reactance $(\Omega)$ vs. Frequency $(\mathrm{MHz}) \ldots 54$ Figure 5-26: Measured Broadband Feed $\left|\mathrm{S}_{11}\right|(\mathrm{dB})$ vs. Frequency $(\mathrm{MHz}) \ldots \ldots \ldots \ldots \ldots \ldots . . . . . . . .55$ Figure 5-27: $915 \mathrm{MHz}$ Simulated Broadband Antenna E-Field Pattern $(\phi)$ in dB 56 Figure 5-28: Simulated Antenna Resistance $(\Omega)$ vs. Frequency $(\mathrm{MHz})$ for Varying Shunt Inductor $\mathrm{I}_{\mathrm{H}}$ Lengths 58

Figure 5-29: Simulated Antenna Resistance $(\Omega)$ vs. Frequency $(\mathrm{MHz})$ for Varying Shunt Inductor $I_{H}$ Lengths 58 


\section{INTRODUCTION}

\section{1: Ultra High Frequency (UHF) RFID Introduction}

Radio Frequency Identification (RFID) is a wireless identification and tracking system. Applications include manufacturing supply chain inventory tracking, animal tracking, retail theft prevention, toll fees and sporting event timing. An RFID system includes a reader that tracks one or more tags (i.e.: transponders). The reader wirelessly transmits a carrier wave (uplink) to the tag (Figure 1-1a). A tag is a Radio Frequency Integrated Circuit (RFIC) affixed to a portable antenna. The tag backscatters a unique identification signal (downlink) to the reader (Figure 1-1b).

(a)

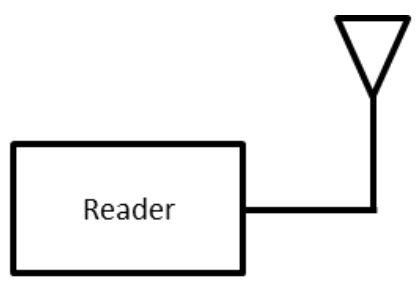

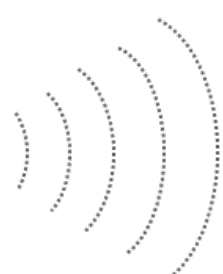

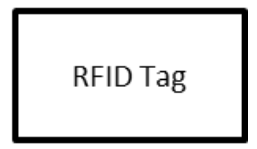

RFID Tag (b)

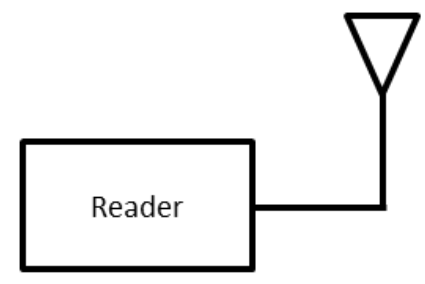

backscattered wave

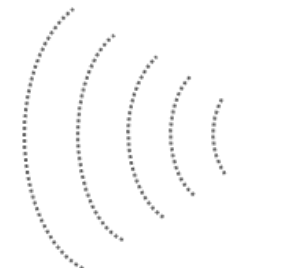

Figure 1-1: (a) Reader Transmitting Carrier to Tag, (b) Tag Backscattering to Reader RFID tags are classified into three types: active, semi-active and passive. An active tag is battery powered and periodically transmits identification information without a reader's request. A semi-active tag transmits a battery-powered identification signal at the reader's request. A passive tag (Figure 1-2) uses the reader's carrier wave to power the RFIC and transmit the backscatter signal. Passive tags include a passively powered RFIC attached to an antenna. The antenna is printed onto a dielectric substrate; an "inlay." Passive RFICs require $6 \mu \mathrm{W}-30 \mu \mathrm{W}$ to operate internal circuitry. Read range is limited to $\sim 4 \mathrm{~m}$ while maintaining reader transmit power levels within 4W EIRP Federal Communications Commission (FCC) regulations. By comparison, semi-active and 
active tags communicate over a $100 \mathrm{~m}$ read range. However, passive tags are cost effective (5 to 15 cents per tag) and disposable. Semi-active tags cost $\$ 10$ to $\$ 50$ and active tags cost $\$ 15$ to $\$ 100$ per tag. This thesis focuses on passive tags operating in the ultra-high frequency (UHF), industrial, scientific and medical (ISM) $902 \mathrm{MHz}-928 \mathrm{MHz}$ band and the global Electronic Product Code (EPC) $860 \mathrm{MHz}-960 \mathrm{MHz}$ band.

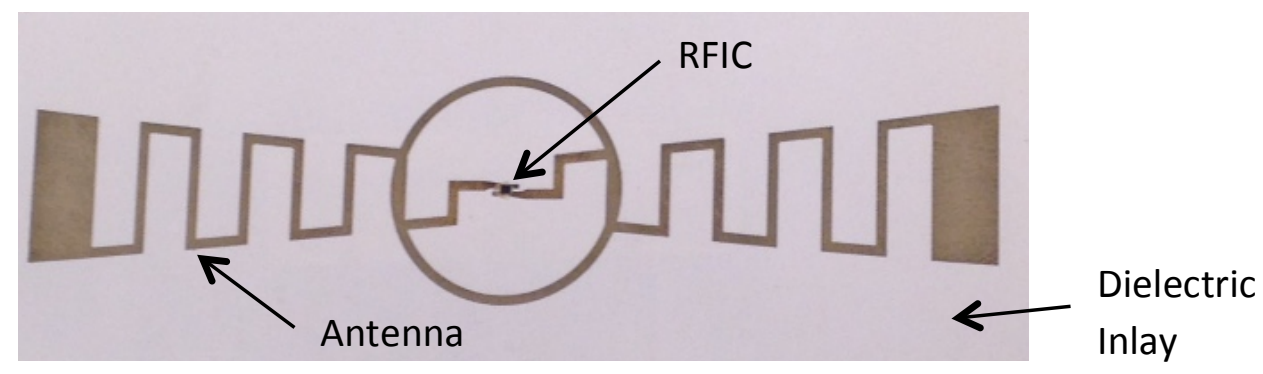

Figure 1-2: RFID Tag: Antenna RFIC and Inlay

\section{2: Maximum Transmit Power}

Power transfer is maximized to a finite, reactive load when the generator input impedance equals the load impedance complex conjugate [4] (Figure 1-3). For passive tags, the generator and load impedances correspond to the antenna and RFIC, respectively.

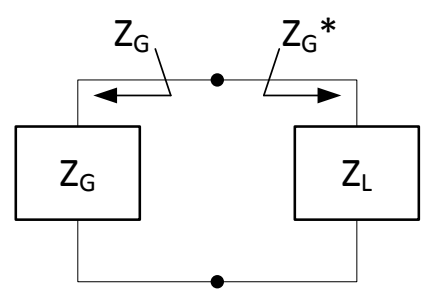

Figure 1-3: Maximum Power Transfer Theorem

Antenna input impedance is denoted $Z_{A}=R_{A}+j X_{A}$ where $R_{A}$ and $X_{A}$ are the input resistance and reactance, respectively. RFIC input impedance is $Z_{I C}=R_{I C}+j X_{I C}$. The antenna generator, modeled as a Thevenin equivalent circuit, and RFIC load are shown in Figure 1-4. Circuit current I is [5]:

$$
I=\frac{V_{A}}{\left(R_{A}+R_{I C}\right)+j\left(X_{A}+X_{I C}\right)}
$$

The maximum power delivered to the RFIC load (when $\left.Z_{I C}=Z_{A}^{*}\right)$ is: 


$$
P_{M A X}=\frac{|I|^{2}}{8} \frac{\left|Z_{A}\right|^{2}}{R_{A}}=\frac{\left|V_{A}\right|^{2}}{8} \frac{1}{R_{A}}
$$

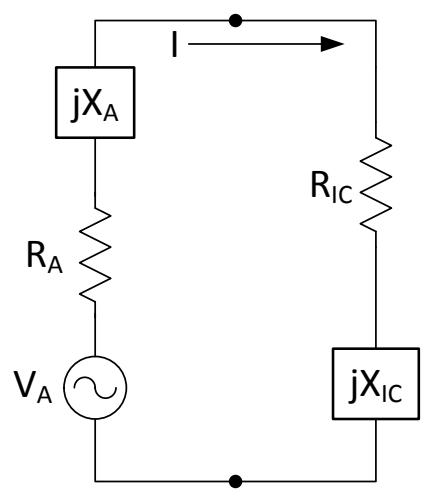

Figure 1-4: Thevenin Equivalent Generator $V_{A}$ and Antenna Impedance $Z_{A}$

The actual power delivered to the RFIC is:

$$
P_{I C}=\frac{1}{2}|I|^{2} R_{I C}=\frac{1}{2} \frac{\left|V_{A}\right|^{2}}{\left[\left(R_{A}+R_{I C}\right)^{2}+\left(X_{A}+X_{I C}\right)^{2}\right]} R_{I C}
$$

Power transmission coefficient ' $T$ ' is the ratio of actual RFIC delivered power ( $\left.P_{I C}\right)$ to the maximum power $\left(\mathrm{P}_{\mathrm{MAX}}\right)[5]$ :

$$
\tau=\frac{P_{I C}}{P_{M A X}}=\frac{4 R_{A} R_{I C}}{\left[\left(R_{A}+R_{I C}\right)^{2}+\left(X_{A}+X_{I C}\right)^{2}\right]}
$$

Using the identity:

$$
4 R_{A} R_{I C}=\left|Z_{I C}+Z_{A}\right|^{2}-\left|Z_{I C}-Z_{A}^{*}\right|^{2}
$$

and substituting (1-2), (1-3) and (1-5) into (1-4) yields:

$$
\tau=1-\left|\frac{Z_{I C}-Z_{A}^{*}}{Z_{I C}+Z_{A}}\right|^{2}, \quad 0 \leq \tau \leq 1
$$

Power that is reflected back to the antenna does not reach the RFIC. Reflected power $\left(P_{\text {REFL }}\right)$ is:

$$
P_{R E F L}=P_{M A X}-P_{I C}
$$


The power reflection coefficient $\theta$ is the ratio of reflected power $\left(P_{\text {REFL }}\right)$ to the maximum power available to the RFIC ( $\left.P_{\text {MAX }}\right)$ :

$$
\theta=\frac{P_{R E F L}}{P_{M A X}}=1-\tau
$$

Substituting the t coefficient from (1-6) into (1-8), the power reflection coefficient is:

$$
\theta=\left|\frac{Z_{I C}-Z_{A}^{*}}{Z_{I C}+Z_{A}}\right|^{2}, \quad 0 \leq \theta \leq 1
$$

Voltage reflection coefficient $s_{r}$ for lumped element and non-traveling wave interfaces, originally introduced by [6], is the square root of the power reflection coefficient:

$$
s_{r}=\frac{Z_{I C}-Z_{A}^{*}}{Z_{I C}+Z_{A}}, 0 \leq s_{r} \leq 1
$$

Voltage reflection coefficient $s_{r}$ for lumped elements should not be confused with the well-known voltage traveling wave reflection coefficient gamma $(Г)$. The reflection coefficient $s_{r}$ is used at lumped element interfaces (see Figure 1-3). $\Gamma$ quantifies reflections when a wave traveling on a transmission line (a controlled impedance environment) encounters either another transmission line or a mismatched lumped element load.

\section{3: Maximum Transmit Range}

Maximum transmit range $\mathrm{R}$ (Figure 1-5) is calculated via the Friis Equation [5]. This relation for free space environments is:

$$
P_{R}=P_{T} G_{T} G_{R} L\left(1-\left|s_{r}\right|^{2}\right)\left(\frac{\lambda}{4 \pi R}\right)^{2}
$$

where $P_{R}$ is received power, $P_{T}$ is transmitted power, $G_{R}$ is receiver antenna gain, $G_{T}$ is transmitter antenna gain, $L$ is cable loss and $\lambda$ is operating frequency wavelength. 


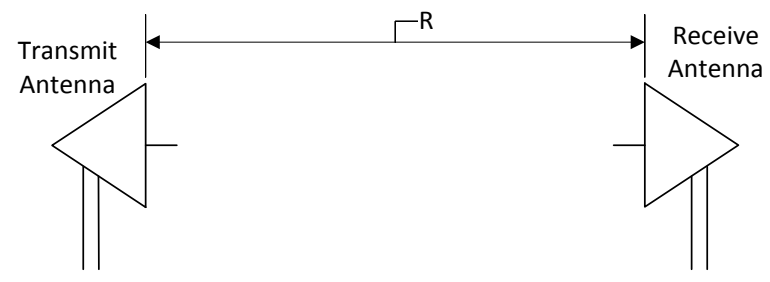

Figure 1-5. Friis Equations System Configuration

Read range is:

$$
R=\frac{\lambda}{4 \pi} \sqrt{\frac{P_{T} G_{T} G_{R} L\left(1-\left|s_{r}^{2}\right|\right)}{P_{R}}}
$$

Tag read operations require two transmission modes - uplink and downlink. In uplink mode, the tag receives the reader signal. In downlink mode, the tag transmits back to the receiver. Minimum required RFID reader received power is $-60 \mathrm{dBm} ;-15 \mathrm{dBm}$ to $-22.5 \mathrm{dBm}$ for the RFIC. Hence, the uplink limits transmit distance. RFID tag antennas are low gain $(<2 \mathrm{~dB})$, omnidirectional dipoles to minimize read range dependency on tag orientation. Transmit antennas are circularly or linearly polarized patch antennas with gain ranging $5-9 \mathrm{~dB}$. Maximum transmit power $\mathrm{P}_{\mathrm{T}}$ is limited by the $\mathrm{FCC}$ to $4 \mathrm{~W}$ Equivalent Isotropic Radiated Power (EIRP) to minimize electrical interference in nearby electrical systems. EIRP is defined as [5]:

$$
E I R P=P_{T} G_{T} L
$$

Maximum read range in terms of EIRP is [5]:

$$
R=\frac{\lambda}{4 \pi} \sqrt{\frac{E I R P * G_{R}\left(1-\left|s_{r}^{2}\right|\right)}{P_{R}}}
$$

Three parameters available to antenna designers to maximize transmit range include antenna efficiency, impedance matching, and RFIC sensitivity. This thesis focuses on RFIC/antenna impedance matching and RFIC sensitivity. 


\section{4: Passive RFIC Load Impedance}

Passive RFICs use CMOS circuitry. The simplified block diagram (Figure 1-6) shows a top-level RFIC design. Three circuit blocks at the RFIC's input operate sequentially: (1) The reader transmits a continuous wave (CW) carrier wave, which is rectified and regulated in the RFIC to power its CMOS circuitry, $V_{d d}$. (2) The reader transmits an Amplitude Shift Key (ASK) request which is detected by the RFIC's envelope detector and transferred to the logic unit. (3) Finally, the logic unit transmits a unique identification code that is backscattered through the RFIC's ASK modulator. Both the full-wave rectifier and envelope detector have capacitive input impedances; however, the full-wave rectifier has the largest capacitive reactance $(-j 140 \Omega$ to $-\mathrm{j} 205 \Omega$ for RFICs manufactured by Impinj [7] and Alien [8] [9]).

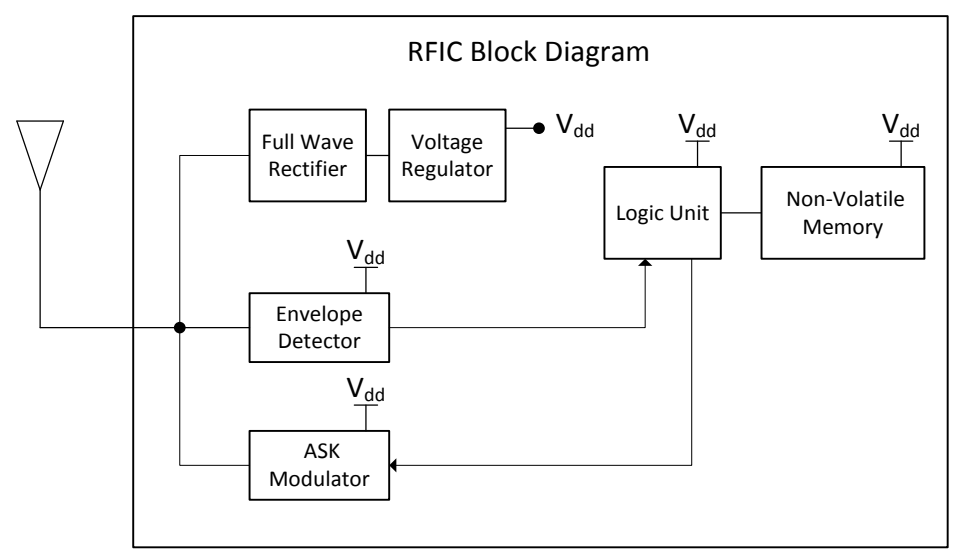

Figure 1-6: RFIC Block Diagram

The equivalent load is a lumped element, shunt resistor and capacitor (Figure 1-7a). Example RFIC input impedances are listed in Table 1-1. Antenna designs require series inductive reactance to conjugate match the RFIC's input capacitance.

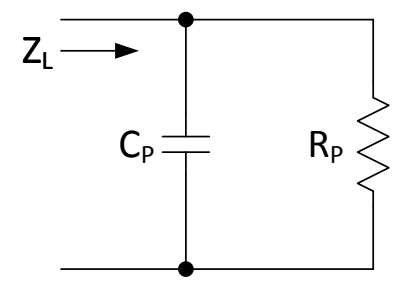

(a) Parallel, Shunt RFIC Input

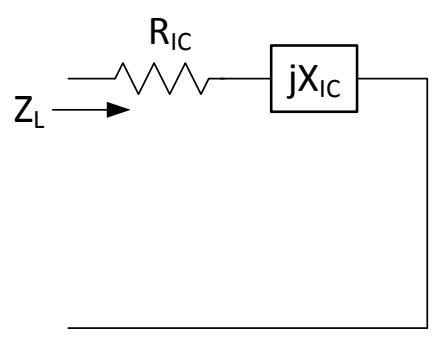

(b) Series RFIC Input

Figure 1-7: RFIC Input Impedance, (a) Norton Equivalent, (b) Thevenin Equivalent 
Table 1-1: Passive RFIC Input Impedance at $915 \mathrm{MHz}$

\begin{tabular}{|c|c|c|c|c|}
\hline \multicolumn{5}{|c|}{ Passive RFIC Input Impedance } \\
\hline \hline RFIC & Vendor & $\begin{array}{c}\text { Shunt } \\
\text { Resistance }(\Omega)\end{array}$ & $\begin{array}{c}\text { Shunt } \\
\text { Capacitance }(\mathrm{pF})\end{array}$ & $\begin{array}{c}\text { Total } \\
\text { Impedance }(\Omega)\end{array}$ \\
\hline Monza 4 & Impinj & 1650 & 1.21 & $12-\mathrm{j} 142$ \\
\hline Monza 5 & Impinj & 1800 & 1.07 & $15-\mathrm{j} 161$ \\
\hline Higgs-3 & $\begin{array}{c}\text { Alien } \\
\text { Technology }\end{array}$ & 1500 & 0.85 & $27-\mathrm{j} 200$ \\
\hline Higgs-4 & $\begin{array}{c}\text { Alien } \\
\text { Technology }\end{array}$ & 1800 & 0.95 & $18-\mathrm{j} 181$ \\
\hline
\end{tabular}

\section{5: Bandwidth Requirements}

The $902 \mathrm{MHz}-928 \mathrm{MHz}$ range is an unlicensed FCC ISM band with maximum allowable 4W EIRP transmit power. Most countries adhere to RFID bands (Table 1-2) within the global Electronic Product Code (EPC) regulatory $865 \mathrm{MHz}-955 \mathrm{MHz}$ band. A commercially viable worldwide tag requires a $90 \mathrm{MHz}$ bandwidth (input return loss > $10 \mathrm{~dB})$.

Table 1-2: RFID UHF Global Bands [10]

\begin{tabular}{|l|l|l|}
\hline \multicolumn{3}{|c|}{ RFID UHF Global Bands } \\
\hline \hline Country & $\begin{array}{l}\text { Frequency } \\
\text { (MHz) }\end{array}$ & Power \\
\hline Australia & $920.0-926.0$ & 4W EIRP \\
\hline Brazil & $902.0-928.0$ & 4W EIRP \\
\hline Canada & $902-928.0$ & 4W EIRP \\
\hline $\begin{array}{l}\text { Central } \\
\text { America }\end{array}$ & \multicolumn{2}{|l|}{ Typically USA Compliant } \\
\hline USA & $902.0-928.0$ & 4W EIRP \\
\hline China & $920.5-924.5$ & 2W EIRP \\
\hline EU & $865.6-867.6$ & 2W ERP \\
\hline Israel & $915.0-917.0$ & 2W EIRP \\
\hline Japan & $952.0-956.4$ & 4W EIRP \\
\hline Korea & $917.0-920.8$ & 4W EIRP \\
\hline Mexico & $902.0-928.0$ & 4W EIRP \\
\hline North Africa & Typically EU Compliant \\
\hline Russia & $916.0-921.0$ & 1W ERP \\
\hline Saudi Arabia & $865.6-867.6$ & 2W ERP \\
\hline South Africa & $915.4-921.0$ & 4W EIRP \\
\hline
\end{tabular}




\section{6: Antenna Silk-Screen Printing Method}

Passive RFID tag commercial advantages include low manufacturing cost; less than 15 cents per tag. One low-cost RFID antenna manufacturing method is silk-screening, which uses a permeable screen mesh to transfer ink onto a substrate. A mask is printed onto the screen to maintain the ink within the mask outline. The silk-screening process is chosen because it is simple, materials are affordable, and inexpensive equipment can be used. Silk-screening is an additive method; the conductor is added to the substrate, rather than removed. Additive methods reduce conductor cost. This project's antenna fabrication method uses silk-screening Dupont 5025 silver ink (sheet resistivity is $12-15 \mathrm{~m} \Omega / \mathrm{sq} / \mathrm{mil}$ ) onto on Dupont Melinex® ST504 polyethylene terephthalate (PET) film (sheet thickness is $150 \mu \mathrm{m}$ and dielectric constant $\varepsilon_{\mathrm{r}}=2.9$ ) (Figure 1-8). The printed silver thickness is approximately 1 mil. Antennas are printed at Cal Poly's Graphic Communication Department. Commercial silver ink cost is $\sim \$ 1$ per gram; a printed antenna requires approximately $1 \mathrm{mg}$ of ink. Silk-screening accuracy is within $100 \mu \mathrm{m}$; sufficient for RFID antenna designs. PET film is also ready available.

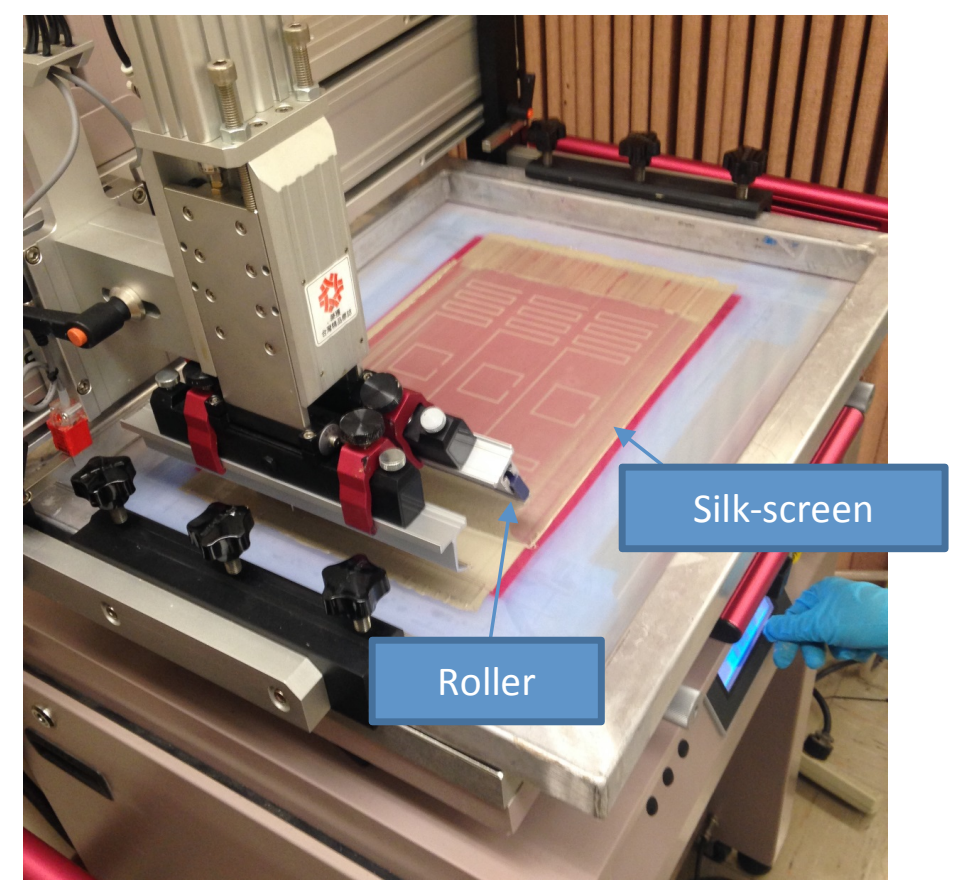

Figure 1-8: ATMA Semi-Auto Screen Printing Press, Roller and 305 Mesh Polyester Silk-Screen on an Aluminum Frame at the Cal Poly Graphic Communications Lab 


\section{UDA MODEL}

The T-match antenna was originally designed by Uda [2] as an impedance matching technique for the driving element of a Yagi-Uda antenna array. It is now predominantly used as a conjugate matching method in RFID and microstrip designs. The matching network is tuned by adjusting the antenna geometry defined in Figure 2-1. An important assumption for the impedance derivation is that widths $\mathrm{W} 1$ and $\mathrm{W} 2$ and spacing $D$ between conductors are electrically small $(<N 10)$. Uda's T-match analysis is described in this chapter.

Uda's original T-match and modern day inductive matching networks are similar but the latter can include complex geometries beyond Uda's analysis methods.

Figure 2-1 displays the traditional T-match geometry - two parallel conductors W1 and W2 (conductors can have differing widths) with a set gap $D$ between the two structures. For Uda's analysis method gap $D$ is electrically small $(D<\lambda / 10)$. Figure 2-2 shows Alien's Squig ${ }^{\mathrm{TM}}$ antenna matching network, which cannot be analyzed with Uda's analysis methods because the conductors are neither parallel nor electrically close.

Designs similar to Figure 2-2 are called "modified T-match" or inductive loop. Modified T-match analysis is presented in Chapter 3.

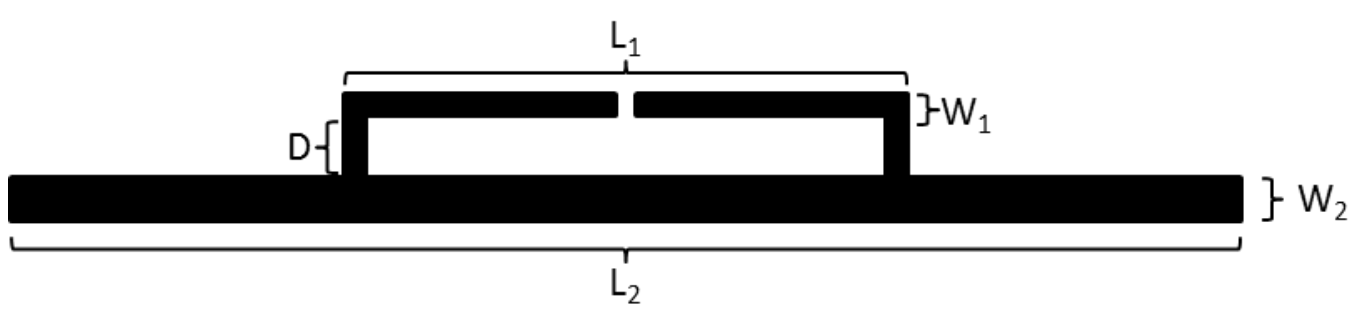

Figure 2-1: T-Match Geometry

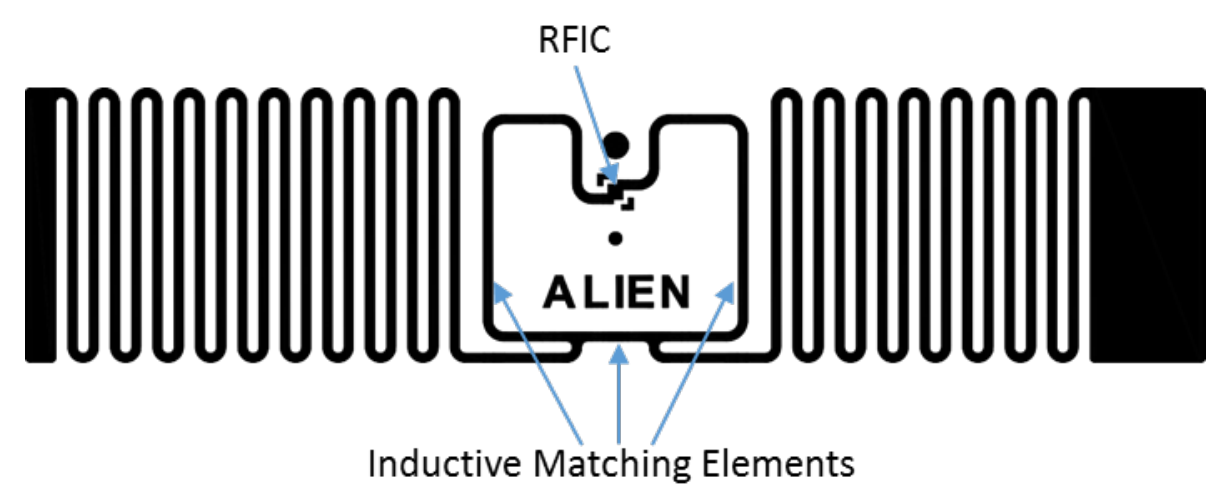

Figure 2-2: Alien Squig тM Inductive Shunt Series Matching Network 


\section{1: T-Match Antenna Input Impedance Using Even/Odd Mode Analysis}

The T-match antenna input impedance, similar to the folded dipole, is derived by analyzing even and odd modes. Even-odd mode analysis is the decomposition of electrical networks into super-imposed in-phase and out-of-phase voltage and current excitations to determine the overall circuit response, see Figure 2-3. In even mode, elements are driven by in-phase signals. In odd mode, elements are driven with out-ofphase signals. Opposing voltage sources on the even and odd mode dipole arms cancel when added together, yielding the original circuit. Hence, even and odd-mode dipole arm voltages must be equal magnitude but opposite polarity. The even mode is also represented as (d) the radiating antenna mode, while (e) the non-radiating transmission line matching network represents the odd mode.

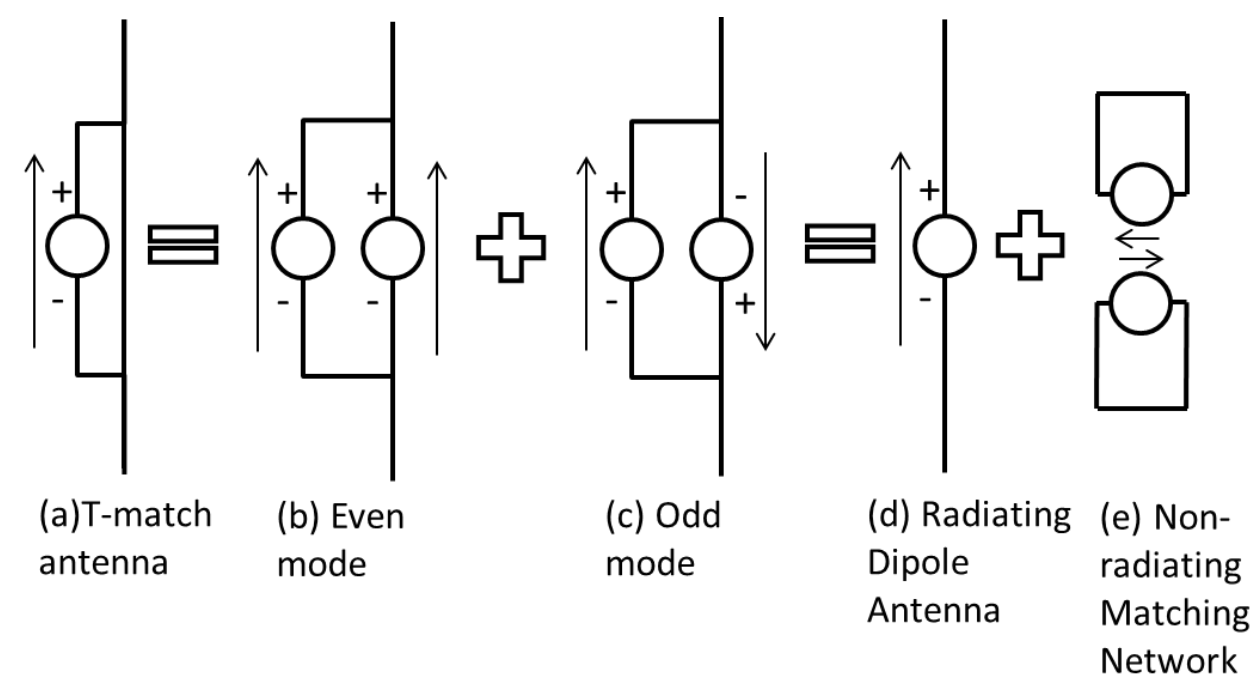

Figure 2-3: T-Match Modes

Even mode branch currents depend on dimensions W1, W2 and D through splitting factor $\alpha$ :

$$
I_{e 2}=\alpha I_{e 1}
$$

where $\mathrm{I}_{\mathrm{e} 1}$ and $\mathrm{l}_{\mathrm{e} 2}$ are currents through the upper matching network and lower antenna element of Figure 2-4, respectively. The splitting factor $\alpha$ is discussed in Section 2.2. The two even mode voltage sources are identical to satisfy even and odd mode 
superposition. The equivalent circuit (redrawn in Figure 2-5a) uses a single voltage supply $\mathrm{V}_{\mathrm{e}}=\mathrm{V}_{\mathrm{e} 1}=\mathrm{V}_{\mathrm{e} 2}$. Adding currents $\mathrm{I}_{\mathrm{e} 1}$ and $\mathrm{I}_{\mathrm{e} 2}$, where $\mathrm{I}_{\mathrm{e} 1}=\mathrm{I}_{\mathrm{e}}$ due to symmetry, Ohm's law is used to define even mode impedance $Z_{e}$ :

$$
V_{e}=Z_{e}\left(I_{e 1}+I_{e 2}\right)=Z_{e}(1+\alpha) I_{e}
$$

The even mode impedance $Z_{e}$ is the radiating dipole input impedance. For a $0.475 \lambda$ length cylindrical dipole, $Z_{\mathrm{e}}$ is approximately $73 \Omega$.

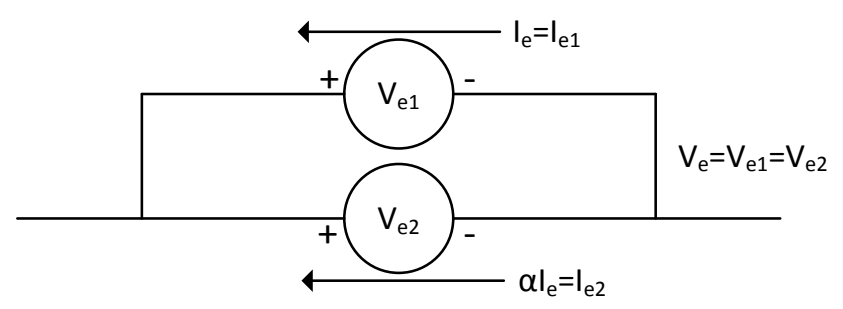

Figure 2-4: Even Mode Circuit

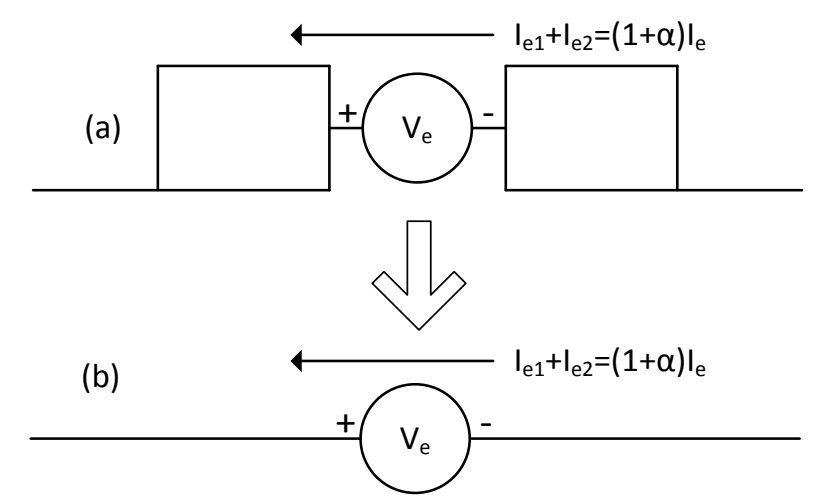

Figure 2-5: (a) Even Mode Circuit Redrawn and (b) Radiating Antenna Equivalent

For odd (transmission line) mode (Figure 2-6a), the two branch currents have equal magnitude and opposite polarities, $\mathrm{I}_{01}=\mathrm{I}_{\mathrm{O}}$ and $\mathrm{I}_{\mathrm{0} 2}=-\mathrm{I}_{0}$, form a closed loop. To satisfy conservation of power in even-odd mode analysis, $\mathrm{V}_{\mathrm{e} 2}+\mathrm{V}_{\mathrm{o} 2}=0$. Odd mode voltage sources are related by splitting factor $\alpha$. From (D.13):

$$
V_{o 1}=-\alpha V_{o 2}=\alpha V_{o}
$$

Each odd-mode, the voltage source is divided into halves (Figure 2-6b) to form an equipotential line on the circuit centerline (Figure 2-6c). The left-half circuit voltage sources $V_{o 1} / 2$ and $V_{o 2} / 2$ are subtracted to form a single voltage source (Figure 2-7). $Z_{\circ}$ 
is the odd-mode input impedance into the transmission line. $Z_{\text {char }}$ is the characteristic impedance along the transmission line. The odd-mode circuit is a closed loop with short-circuit termination $Z_{L}=0$. Ohm's law is applied to determine $Z_{0}$ :

$$
Z_{o} I_{o}=\frac{V_{o 1}-V_{o 2}}{2}=\frac{(1+\alpha) V_{o}}{2}
$$
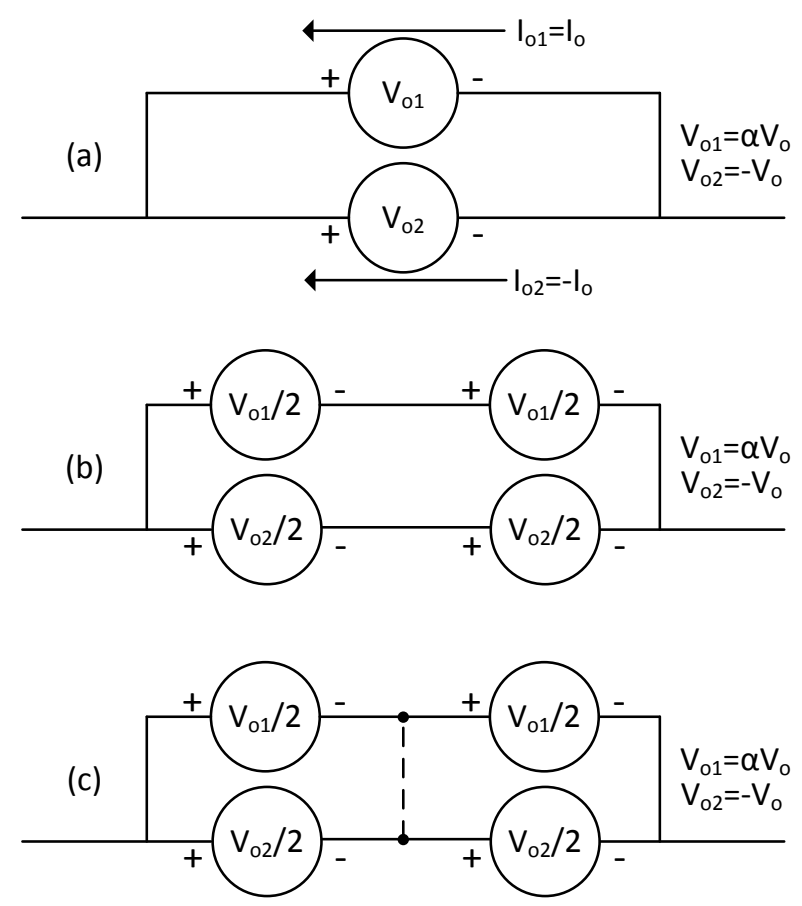

Figure 2-6: (a) Odd-mode Circuit, (b) Circuit Redrawn with Divided Sources, (c) Circuit with Equipotential Line between Sources

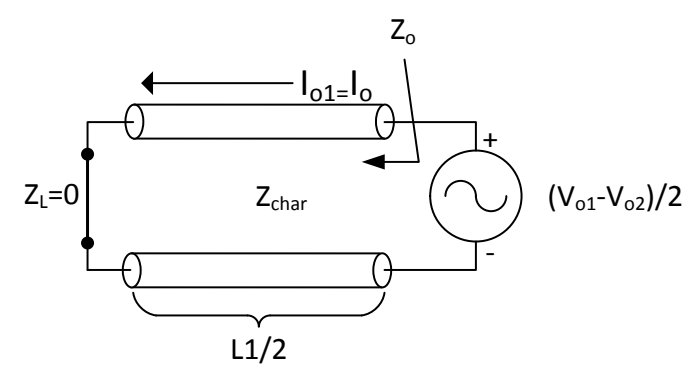

Figure 2-7. Transmission Line Model for Half of Odd-Mode Impedance

The translated input impedance for a lossless transmission line is:

$$
Z_{\text {lossless }}=Z_{\text {char }} \frac{Z_{L}+j Z_{\text {char }} \tan (\beta l)}{Z_{\text {char }}+j Z_{L} \tan (\beta l)}
$$


where characteristic impedance $Z_{\text {char }}$ is derived using asymmetric coplanar strips defined in Appendix $A, \beta$ is the wave number $(2 \pi / \lambda)$, where $\lambda$ is wavelength, $I=L_{1} / 2$ is the transmission line length and $Z_{L}=0$ is the load impedance. The odd mode impedance is:

$$
Z_{o}=j Z_{\text {char }} \tan \left(\beta \frac{L_{1}}{2}\right)
$$

Total voltages and currents (Figure 2-8c) for the matching element $\left(\mathrm{V}_{\mathrm{T} 1}, \mathrm{I}_{\mathrm{T} 1}\right)$ and dipole elements $\left(\mathrm{V}_{\mathrm{T}_{2}}, \mathrm{I}_{\mathrm{T} 2}\right)$ are derived by adding even and odd mode parameters:

$$
\begin{gathered}
V_{T 1}=V_{e 1}+V_{o 1}=V_{e}+\alpha V_{o} \\
V_{T 2}=V_{e 2}+V_{o 2}=V_{e}-V_{o}=0 \\
I_{T 1}=I_{e 1}+I_{o 1}=I_{e}+I_{o} \\
I_{T 2}=I_{e 2}+I_{o 2}=\alpha I_{e}-I_{o}
\end{gathered}
$$

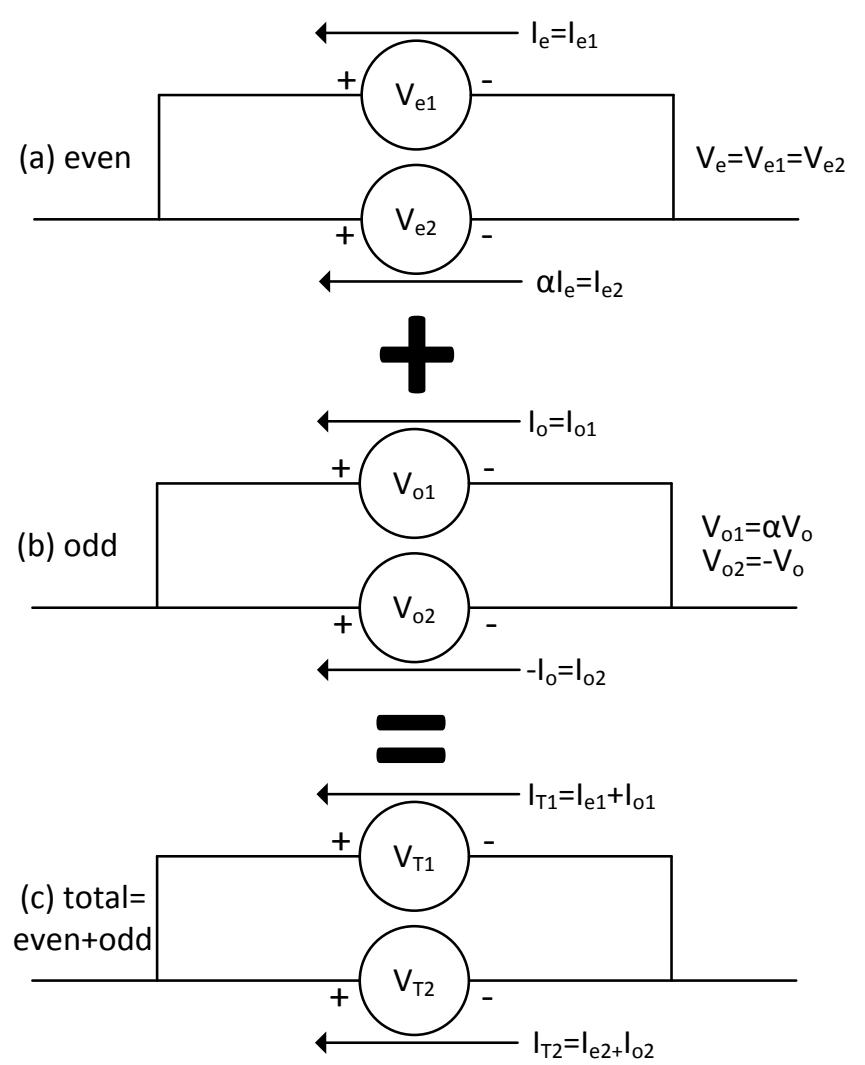

Figure 2-8: (a) Even Modes, (b) Odd Modes, (c) Total Modes 
Input impedance is derived by applying Ohm's law to the matching network elements. Using $V_{\mathrm{e}}=\mathrm{V}_{\mathrm{o}}$ from (2-8) the input impedance is:

$$
Z_{\text {in }}=\frac{V_{T 1}}{I_{T 1}}=\frac{V_{e}+\alpha V_{o}}{I_{e}+I_{o}}=\frac{(1+\alpha) V_{e}}{I_{e}+I_{0}} .
$$

Substituting (2-2) and (2-4) into (2-11), and using (2-8), the input impedance is:

$$
Z_{\text {in }}=\frac{(1+\alpha)^{2} Z_{e} I_{e}}{I_{e}+\frac{\left(1+\alpha V_{o}\right.}{2 Z_{o}}}=\frac{2(1+\alpha)^{2} Z_{e} Z_{o} I_{e}}{2 Z_{o} I_{e}+(1+\alpha) V_{o}}=\frac{2(1+\alpha)^{2} Z_{e} Z_{o} I_{e}}{2 Z_{o} I_{e}+(1+\alpha)^{2} Z_{e} I_{e}} .
$$

The input impedance is:

$$
Z_{\text {in }}=\frac{2(1+\alpha)^{2} Z_{e} Z_{o}}{2 Z_{o}+(1+\alpha)^{2} Z_{e}}
$$

This derivation resembles a product over sum of two impedances; hence, the input impedance can be represented as the parallel combination of $Z_{e}$ and $2 Z_{o}$ through a transformer with turns ratio $=1+\alpha$.

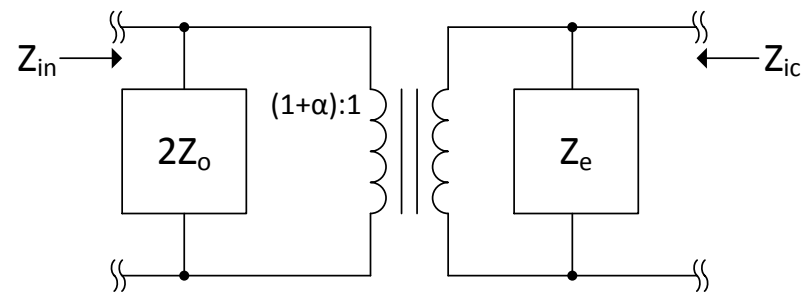

Figure 2-9: T-Match Antenna Equivalent Circuit

\section{2: Splitting Factor}

Uda [2] derives the splitting factor for cylindrical folded dipoles. The splitting factor $\alpha$ is the even (radiating) mode ratio of currents in the matching and antenna elements, or the odd (transmission line) voltage ratio:

$$
\alpha=\frac{I_{e 2}}{I_{e 1}}=-\frac{V_{o 1}}{V_{o 2}}=\frac{\frac{d Q_{2}}{d t}}{\frac{d Q_{1}}{d t}} \approx \frac{Q_{2}}{Q_{1}}
$$

The splitting factor presented by [2] is: 


$$
\alpha=\frac{\cosh ^{-1}\left[\frac{D^{2}-R_{1}^{2}+R_{2}^{2}}{2 D R_{2}}\right]}{\cosh ^{-1}\left[\frac{D^{2}+R_{1}^{2}-R_{2}^{2}}{2 D R_{1}}\right]}
$$

where $D$ is the distance between the two conductors, and $R_{1}$ and $R_{2}$ are two the radii (Figure 2-10). Following extensive literature review, a derivation for (2-15) could not be found, although several papers use the relation. Reference [11] states that the splitting factor is derived from the capacitance of unequal cylinders derived in [12]. The capacitance between two unequal diameter conductors per unit length (see Appendix B) is:

$$
C=2 \pi \varepsilon_{o}\left[\cosh ^{-1}\left(\frac{D^{2}-R_{1}^{2}-R_{2}^{2}}{2 R_{1} R_{2}}\right)\right]^{-1}
$$

This equation resembles, but is not identical to, the numerator and denominator terms of $(2-15)$.

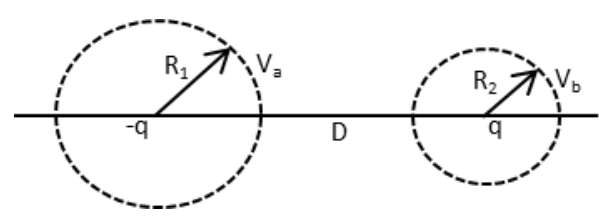

Figure 2-10: Two Parallel, Cylindrical Conductor Cross-Sections with Unequal Radii A useful splitting factor expression for coplanar strips (Figure 2-11) is derived by comparing the charge ratios in the even antenna mode [13]:

$$
\alpha=\frac{Q_{2}}{Q_{1}}=\frac{\ln \left\{4 c+2\left[(2 c)^{2}-\left(W_{1} / 2\right)^{2}\right]\right\}-\ln \left\{W_{1}\right\}}{\ln \left\{4 c+2\left[(2 c)^{2}-\left(W_{2} / 2\right)^{2}\right]\right\}-\ln \left\{W_{2}\right\}}
$$

where $c=\frac{1}{4} W_{1}+\frac{1}{4} W_{1}+\frac{1}{2} D$.

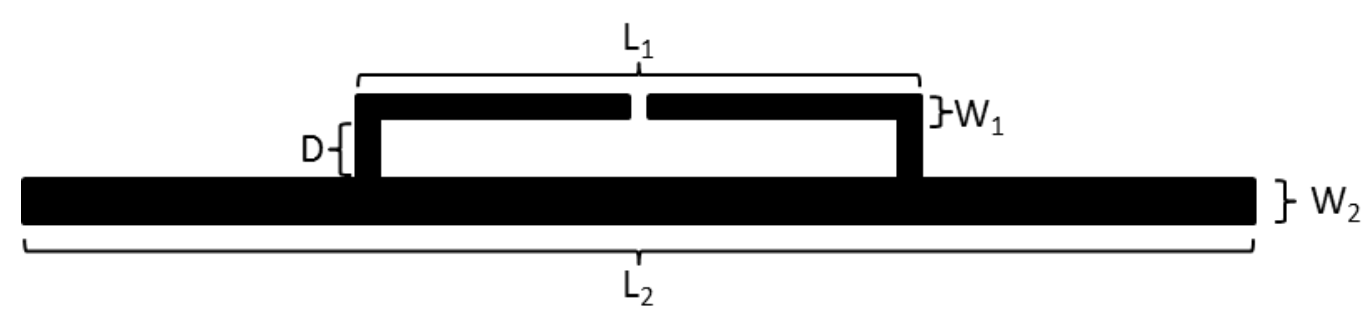

Figure 2-11: Top View of Asymmetric Coplanar Strip 
The assumption that the current ratio is equivalent to the charge ratio is true only when the antenna is in a resonant mode. Otherwise, the currents have unequal phases, resulting in a complex splitting factor and inaccurate input resistance $( \pm 20 \Omega)$ and reactance $( \pm 50 \Omega)$ derivations [14] [15]. To the author's knowledge, there are no splitting factor derivations that consider non-zero phase differences. 


\section{INDUCTIVE LOOP NETWORK ANALYSIS}

Narrow and broadband lumped-element impedance matching methods are applied to RFID antenna designs in [16]. Both techniques represent the dipole antenna, inductive matching strips and RFIC as lumped elements. A symmetric RFID tag is a balanced device with an equipotential line through its center [17] (Figure 3-1). For simplicity, the RFID tag is modeled by its individual components as an unbalanced device [16] (Figure 3-2): an RLC modeled dipole, series and shunt inductor matching elements and an RFIC load comprised of a shunt resistor and capacitor. The shunt inductor and IC load both connect to the equipotential symmetry line. The RLC band-pass filter response is curve-fit to the dipole self-impedance [18] to yield the RFIC equivalent load; a shunt capacitor and resistor.

Equipotential

Symmetry Line

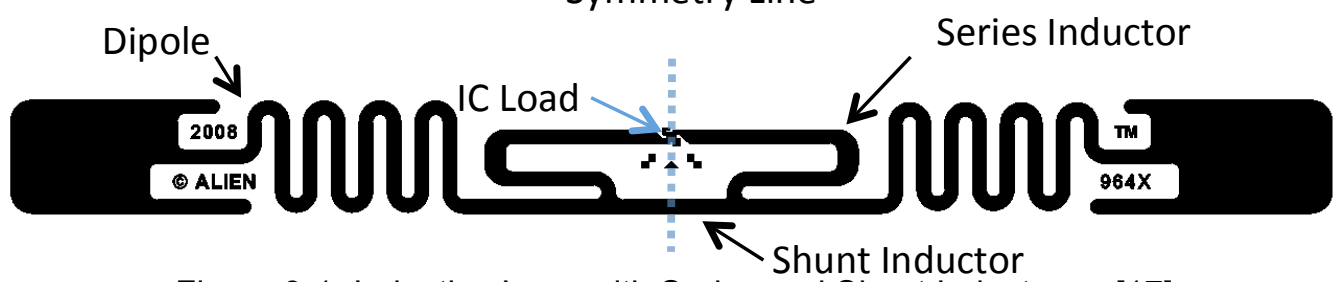

Figure 3-1: Inductive Loop with Series and Shunt Inductance [17]

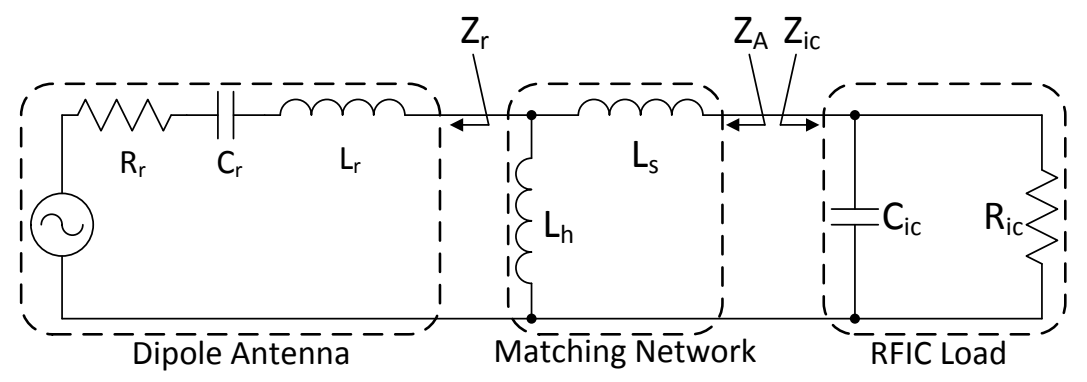

Figure 3-2: Lumped Element Matching Network for RFID Tag [16]

\section{1: Dipole Impedance: RLC Equivalent Circuit}

The dipole antenna input-impedance is curve-fit to a series and shunt RLC circuit [18] (Figure 3-3). The model is simplified [17] to curve-fit the dipole antenna input impedance to a series RLC band-pass filter network (Figure 3-4). 


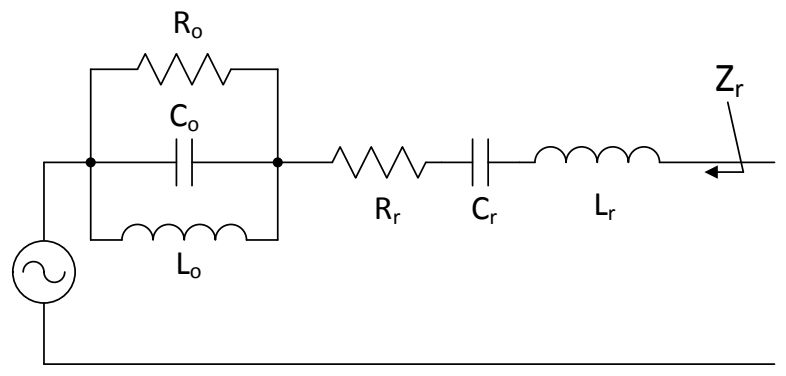

Figure 3-3: RLC Impedance Equivalent [18] Dipole Impedance as Lumped Element Circuit

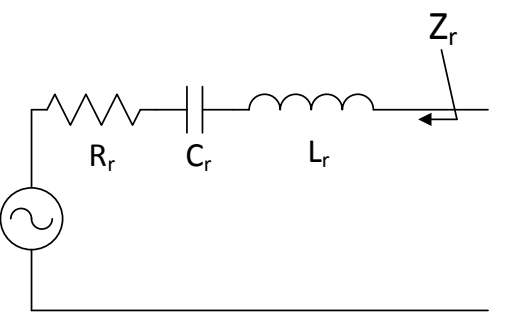

Figure 3-4: Simplified RLC Network; Dipole Reactance as Lumped Element Circuit Input impedance $Z_{\text {in }}$ for the simplified circuit is:

$$
Z_{r}=R_{r}+j \omega L_{r}+\frac{1}{j \omega C_{r}}
$$

The antenna resonant frequency $\mathrm{f}_{\mathrm{r}}(\sim 0.475 \lambda$ dipole length) follows an RLC filter:

$$
f_{r}=\frac{1}{2 \pi \sqrt{L_{r} C_{r}}}
$$

Radiation resistance is assumed constant; deviation is less than $10 \%$ over the operating band. Figure 3-5 shows the RLC fit to simulated dipole reactance is valid only around the first resonance $(0.4<L / \lambda<0.6)$ where $L$ is the antenna length and $\lambda$ is the operating wavelength. 


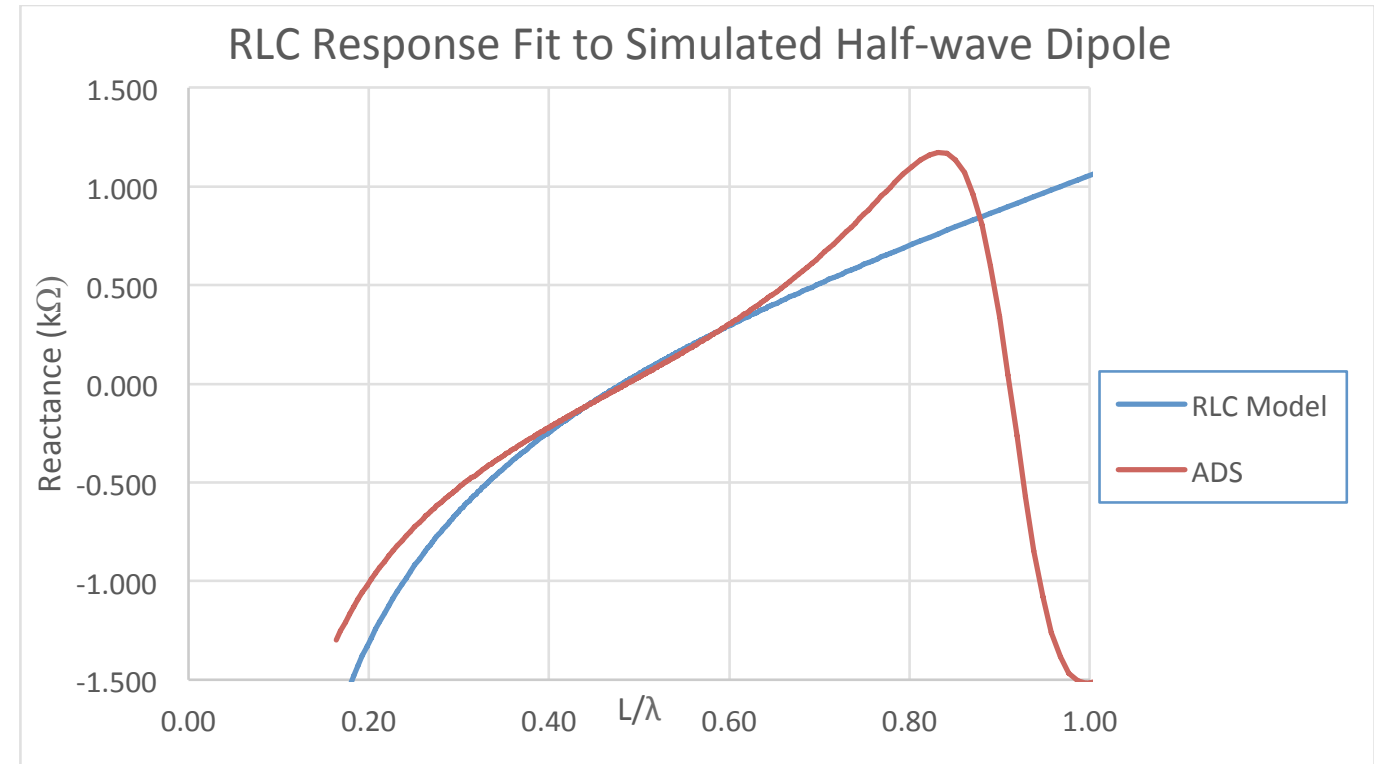

Figure 3-5: Series RLC Response Fit to ADS Simulated Dipole Reactance

Resistance $R_{r}$ is approximated as [19]:

$$
R_{r}=80\left(\frac{\alpha \pi L}{\lambda}\right)^{2}
$$

where $L$ is the antenna length, $\lambda$ is the operating frequency wavelength and $\alpha$ is:

$$
\alpha=\frac{1-\cos \left(\frac{\pi L}{\lambda}\right)}{\frac{\pi L}{\lambda} \sin \left(\frac{\pi L}{\lambda}\right)}
$$

The sine integral $S_{i}(x)$ is:

$$
S_{i}(x)=\int_{0}^{x} \frac{\sin (\tau)}{\tau} d \tau
$$

The cosine integral $C_{i}(x)$ is:

$$
C_{i}(x)=-\int_{x}^{\infty} \frac{\cos (\tau)}{\tau} d \tau
$$

Reactance $X_{r}$ is solved by the Induced EMF Method[20]: 


$$
X_{r}=60\left\{2 S_{i}(\beta L)+\cos (\beta L)\left[2 S_{i}(\beta L)-S_{i}(2 \beta L)\right]-\sin (\beta L)\left[2 C_{i}(\beta L)-C_{i}(2 \beta L)-C_{i}\left(\frac{2 \beta a^{2}}{L}\right)\right]\right\}
$$

where $\beta$ is the wave number $(2 \pi / \lambda)$, and $a$ is dipole radius.

\section{2: Narrowband Matching Design}

Narrow band matching maximizes power transfer at the center design frequency. The goal is to tune the RFIC load to the antenna's complex conjugate input impedance. The matching network path is shown on a Smith Chart (Figure 3-7). The process is as follows:

a. $\quad$ Plot the RFIC input impedance $Z_{i c}$ at the center frequency. The final matching target is the antenna conjugate impedance $Z_{r}{ }^{*}$.

b. From $Z_{i c}$, add series inductance (clockwise rotation on the constant resistance $R_{i c}$ circle) to reach the $G_{r}$ conductance circle.

c. Add shunt inductance (counter-clockwise rotation on the $\mathrm{G}_{\mathrm{r}}$ constant conductance circle) to reach target impedance $Z_{r}^{*}$.

d. Translate shunt and series inductances to microstrip geometry.

To convert between cylindrical radius a and planar antenna width W, [20] approximates a:

$$
a=W / 4
$$

Cylindrical conductor self-inductance is approximated [21]:

$$
L=\frac{\mu_{o}}{2 \pi} l \ln (l / a)=\frac{\mu_{o}}{2 \pi} l \ln (4 l / W)
$$

where $\mu_{o}$ is the permeability of free-space $\left(\sim 4 \pi \times 10^{-7} \mathrm{~N} / \mathrm{A}^{2}\right)$ and $l$ is microstrip length. The inductances define shunt and series inductor lengths in Figure 3-2. Shunt inductors are planar strip lengths from the dipole element center to the series inductor launch. Series inductors terminate at the IC pads. 


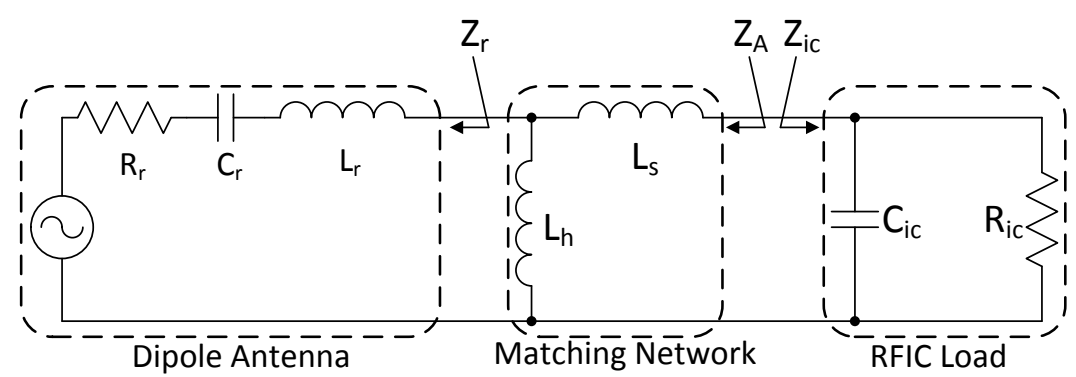

Figure 3-6: RFID Tag Lumped Element Matching Network

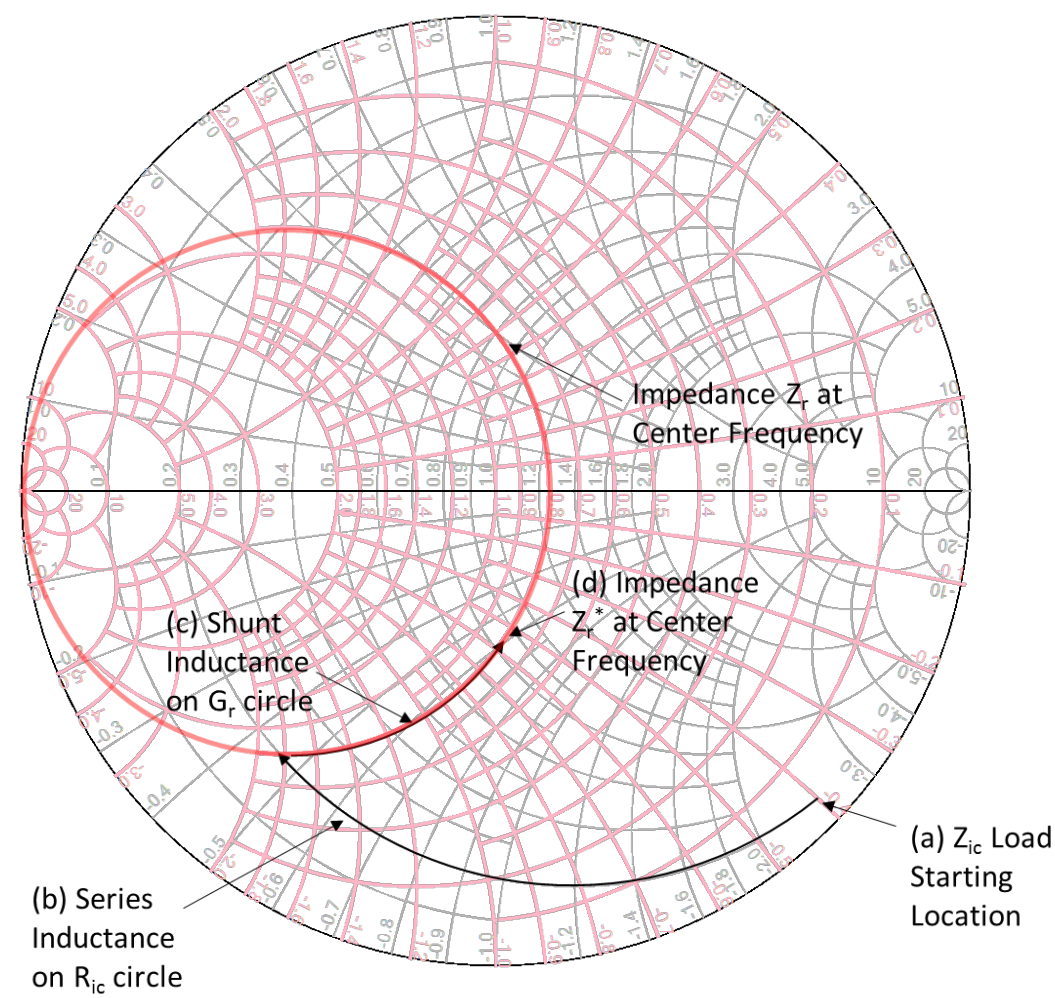

Figure 3-7: Smith Chart Impedance Matching; IC Load to Conjugate Dipole Impedance

\section{3: Broadband Matching Design}

The narrowband design tunes for center frequency matching; however, matching $\left(\left|\mathrm{S}_{11}\right|<-10 \mathrm{~dB}\right)$ over the $90 \mathrm{MHz}$ bandwidth is compromised. A transformed matching network and load present an alternative circuit (Figure 3-8), which includes adjacent series and parallel RLC band-pass filters. Series inductors $L_{r}$ and $L_{b}$ are added to form $a$ single inductor (Figure 3-9). 


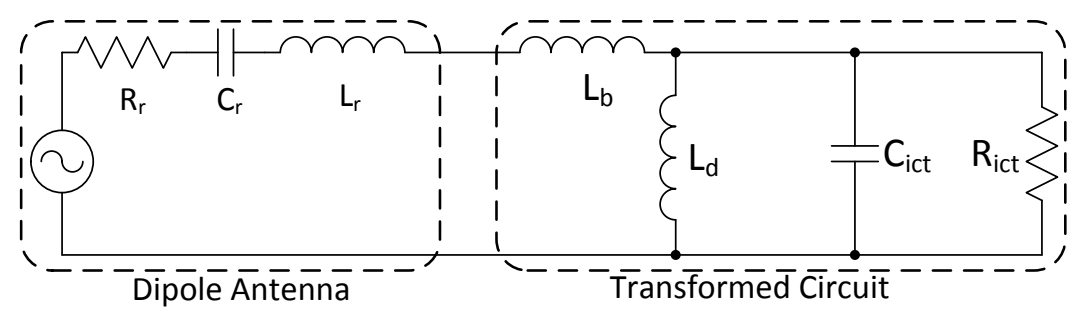

Figure 3-8: Transformed Lumped Element Matching Network, Broadband Match

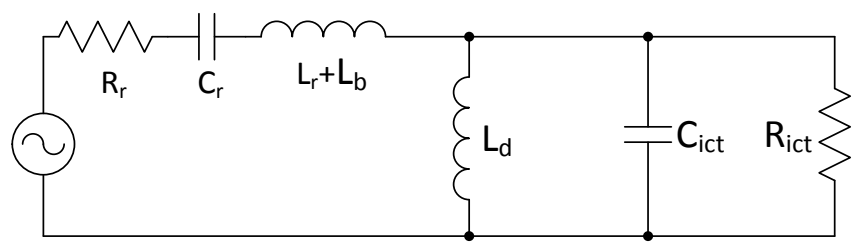

Figure 3-9: Lumped Element RLC Band-Pass Filter, Broadband Match

Define coefficient $\beta$ :

$$
\beta=\frac{L_{h}}{L_{h}+L_{s}}
$$

Circuit transformations to convert the narrowband lumped element tag design (Figure 3-6) into a broadband lumped element tag design (Figure 3-8) are [16]:

$$
\begin{gathered}
Z_{i c t}=\beta^{2} Z_{i c} \\
L_{d}=\beta^{2}\left(L_{s}+L_{h}\right) \\
L_{b}=\frac{L_{s} L_{h}}{L_{s}+L_{h}}
\end{gathered}
$$

and are derived in Appendix E. Applying (3-11) to the parallel RC load (Figure 3-9), the shunt resistance and capacitance are:

$$
\begin{gathered}
R_{i c t}=\beta^{2} R_{i c} \\
C_{i c t}=\frac{C_{i c}}{\beta^{2}}
\end{gathered}
$$

The parallel shunt inductor $L_{d}$ and capacitor $C_{\text {ict }}$ resonant frequency is: 


$$
f=\frac{1}{2 \pi \sqrt{L_{d} C_{i c t}}}
$$

Inserting (3-12) and (3-15) into (3-16), the resonant frequency is:

$$
f=\frac{1}{2 \pi \sqrt{C_{i c t}\left(L_{s}+L_{h}\right)}}
$$

Maximum bandwidth occurs at minimum frequency difference $\omega_{2}-\omega_{1}$ :

$$
\Delta \omega=\omega_{2}-\omega_{1}
$$

The center angular frequency $\omega_{0}$ is the minimum and maximum geometric mean:

$$
\omega_{o}=\sqrt{\omega_{1} \omega_{2}}
$$

The resistance mismatch between $R_{r}$ and $R_{i c t}$ determines the maximum center band reflection coefficient. The transformed circuit's target resistance $R_{\text {ict }}$ is:

$$
R_{i c t}=R_{r} \frac{1+\Gamma}{1-\Gamma}
$$

where $\Gamma=10^{-\left|S_{11}\right| / 20}$. To complete the design, solve for either $C_{r}$ or $L_{r}$. The transformed series RLC circuit resonant frequency is:

$$
\omega_{o}^{2}=\frac{1}{C_{r}\left(L_{r}+L_{b}\right)}
$$

Rearranging (3-21):

$$
\omega_{o}^{2} C_{r} L_{r}+\omega_{o}^{2} C_{r} L_{b}-1=0
$$

RLC quality factor $Q_{r}$ is:

$$
Q_{r}=\frac{\omega_{o}}{\Delta \omega_{r}}=\frac{1}{R_{r}} \sqrt{\frac{L_{r}}{C_{r}}}
$$

Forming a quadratic equation in $Q_{r}$ and substituting into (3-22) yields: 


$$
L_{r}^{2}+L_{r} L_{b}-\left(\frac{Q_{r} R_{r}}{\omega_{o}}\right)^{2}=0
$$

Solving the quadratic equation for $L_{r}$, positive values only:

$$
L_{r}=\frac{1}{2}\left(\sqrt{L_{b}^{2}+4\left(\frac{Q_{r} R_{r}}{\omega_{o}}\right)^{2}}-L_{b}\right)
$$

which is expressed as [16]:

$$
L_{r}=\sqrt{+\left(\frac{Q_{r} R_{r}}{\omega_{o}}\right)^{2}+\left(\frac{(1-\beta)\left(L_{s}+L_{h}\right)}{2 \sqrt{2}}\right)^{2}}-\frac{(1-\beta)\left(L_{s}+L_{h}\right)}{2 \sqrt{2}}
$$

$L_{r}$ yields $C_{r}$ by $L C$ resonance (3-2). Antenna quality $Q_{r}$ factor is approximated as [22]:

$$
Q_{r} \approx \frac{\omega_{o}}{2 R_{r}} \frac{\Delta\left|X_{r}\left(\omega_{o}\right)\right|}{\Delta \omega_{o}}
$$

where $\mathrm{D}\left|\mathrm{X}\left(\mathrm{w}_{\mathrm{o}}\right)\right| / \mathrm{Dw_{0 }}$ is evaluated by computing the slope of (3-7) over the range $0.3<\lambda<0.6\left(w_{0}=2 \pi^{*} 3 \times 10^{8} / \lambda\right)$.

Design procedure:

1) Choose antenna length based on package size limitations. Solve $R_{r}$ (3-3), (3-4).

2) Set $\left|S_{11}\right|$ to $-10 d B$ (0.316). Calculate $R_{\text {ict }}(3-20)$.

3) Find the center angular frequency (3-19).

4) The IC load shunt resistance $R_{i c}$ is the stated shunt resistance on the RFIC datasheet. Find $\beta$ (3-14).

5) Calculate $L_{s}+L_{h}$ using (3-17); $L_{s}$ and $L_{h}$ from (3-10). Microstrip lengths are calculated from (3-9) by solving for $l$.

6) Find antenna quality factor $Q_{r}(3-27)$.

Finally, find $L_{r}$ 
7) (3-26). The dipole resonant frequency is determined from $L_{r}$ and $C_{r}$. The dipole is designed to resonate at this frequency.

A method to design Meander Line Antennas to resonate at a specific frequency is shown in the next section.

\section{4: Meander Line Antenna}

RFID antennas are often size-limited to small packages; a $915 \mathrm{MHz}$ half-wave dipole $(\sim 16 \mathrm{~cm})$ exceeds the maximum footprint for many applications. One solution is decreased antenna length; however, electrically short dipoles exhibit large capacitive input impedances. This increases required matching network shunt and series resistance lengths. A method for reducing dipole size, while maintaining positive reactance, is to meander the dipole length. A Meander Line Antenna (MLA) [23] is a dipole with vertical and parallel elements to add inductive reactance. The meander sections carry currents traveling in opposite directions and are electrically close $(<\lambda / 10)$. Hence, meander element radiation is not seen in the far-field. The antenna, similar to a straight dipole, does not radiate on the z-axis (Figure 3-10). The MLA includes meander elements with width $w$ and height $h$. Conductor radius is $a$, total length is $s$ and $M$ is the number of meander elements.

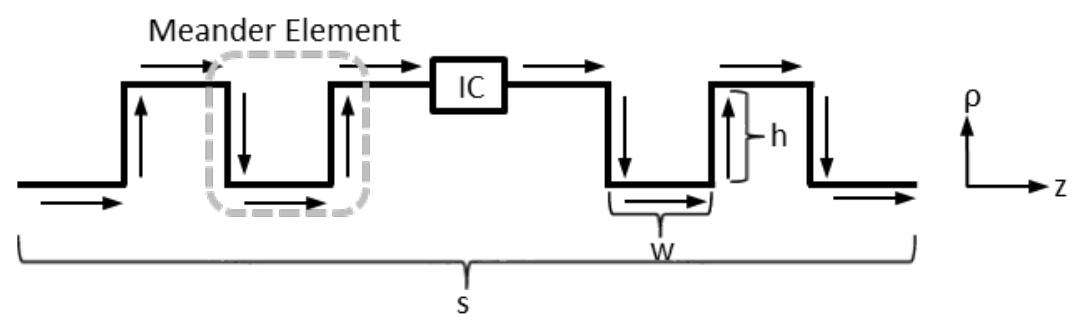

Figure 3-10: Current Distributions and Geometry, Meander Line Dipole

The meander elements $M$ are approximated as short circuits. This approximation is valid if current magnitude deviates less than $5 \%$ over each meander element, which is satisfied when $M \geq 14$ [24]. The reactance added by each meander section is:

$$
X_{m}=2 \pi f L_{m}=Z_{\text {char }} \tan (\beta h)
$$

Expanding the $\tan (\beta \mathrm{h})$ MacLaurin Series in (3-28) to third order: 


$$
\tan (\beta h) \approx \beta h+\frac{1}{3}(\beta h)^{3} \quad \text { for }(\beta h \ll 1)
$$

The characteristic impedance $Z_{\text {char }}$ of parallel cylindrical conductors is [23]:

$$
Z_{\text {char }}=\frac{\eta_{o}}{\pi} \ln \left(\frac{2 w}{a}\right)
$$

where $\eta_{\mathrm{o}}$ is the intrinsic impedance of free-space. Substituting (3-29) and (3-30) into (3-28) yields the inductance of a single meander section:

$$
L_{m}=\frac{\mu_{o} h}{\pi} \ln \left(\frac{2 w}{a}\right)\left[1+\frac{1}{3}(\beta h)^{2}\right]
$$

The self-inductance of a straight conductor of length $s$ is approximated as [23]:

$$
L_{s} \approx \frac{\mu_{o}}{2 \pi} s\left[\ln \frac{4 s}{a}-1\right]
$$

The total MLA inductance is:

$$
L_{T}=L_{s}+M L_{m}
$$

where $M$ is the number of meander elements. To determine the self-inductance of a half-wave dipole, substitute $s=\lambda / 2$ into (3-32):

$$
L_{\lambda / 2}=\frac{\mu_{o}}{\pi} \frac{\lambda}{4}\left[\ln \frac{2 \lambda}{a}-1\right]
$$

It is assumed that the meander dipole and half-wave dipole have the same resonant frequency; hence, meander dipole $L_{T}$ inductance and half-wave dipole $L_{N / 2}$ are equal at resonance:

$$
L_{s}+M L_{m}=L_{\lambda / 2}
$$

Substituting (3-31), (3-32) and (3-34) for the inductance terms in (3-35):

$$
\frac{\mu_{o}}{2 \pi} s\left[\ln \frac{4 s}{a}-1\right]+M \frac{\mu_{o} h}{\pi} \ln \left(\frac{2 w}{a}\right)\left[1+\frac{1}{3}(\beta h)^{2}\right]-\frac{\mu_{o}}{\pi} \frac{\lambda}{4}\left[\ln \frac{2 \lambda}{a}-1\right]=0
$$


Given known antenna geometry values, the wavelength is determined using MATLAB. For a meander antenna with $s=10 \mathrm{~cm}, w=2 \mathrm{~mm}, M=14$ and $h=6 \mathrm{~mm}$, the resonant frequency is $910 \mathrm{MHz}$. ADS simulation indicates $934 \mathrm{MHz}$; a $2.5 \%$ error. 


\section{MEASUREMENT TECHNIQUES}

4.1: Patch Antennas for Range Testing and Sleeve Balun Verification

Air dielectric, probe-fed patch antennas (geometry shown in Figure 4-1) are used as RFID reader transmit and receive antennas and for sleeve balun verification (discussed in Section 4.2), due to simple construction and low cost. An approximation for patch antenna width $W$ is [25]:

$$
W=\frac{c}{2 f \sqrt{\varepsilon_{r}}}
$$

where $c$ is the speed of light $\left(3 \times 10^{8} \mathrm{~m} / \mathrm{s}\right)$ in vacuum, $f$ is the patch antenna center frequency and $\varepsilon_{r}$ is the effective dielectric constant. The physical patch antenna length $L$ is [25]:

$$
L=\frac{c}{2 f \sqrt{\varepsilon_{r}}}+2 \Delta L
$$

where $\Delta L$ accounts for electric fields radiating from edge to ground plane (Figure 4-2). An approximation for $\Delta L$ is [25]:

$$
\Delta L=0.412 h \frac{\left(\varepsilon_{r}+0.3\right)\left(\frac{W}{h}+0.264\right)}{\left(\varepsilon_{r}-0.258\right)\left(\frac{W}{h}+0.8\right)}
$$

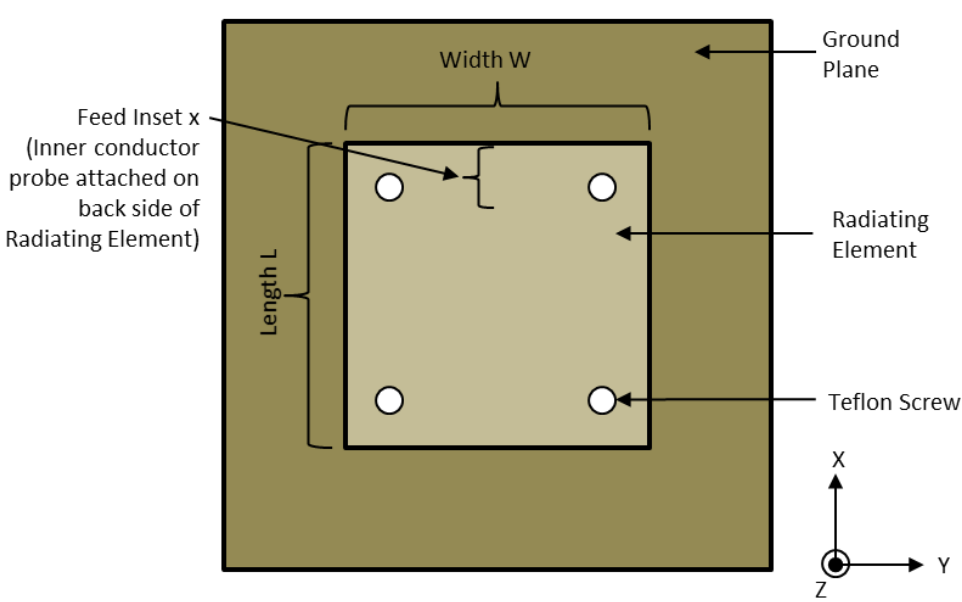

(a) Front View of Patch Antenna

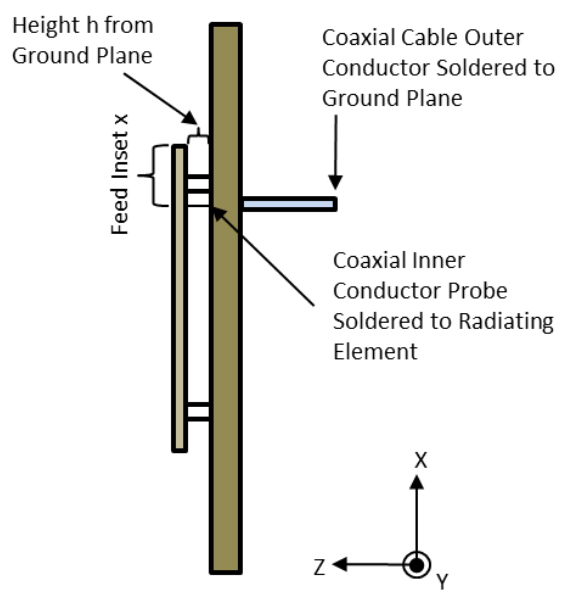

(b) Side View of Patch Antenna

Figure 4-1: Air Dielectric, Probe Fed Patch Antenna Geometry: (a) Patch Antenna Front View, (b) Patch Antenna Side View 


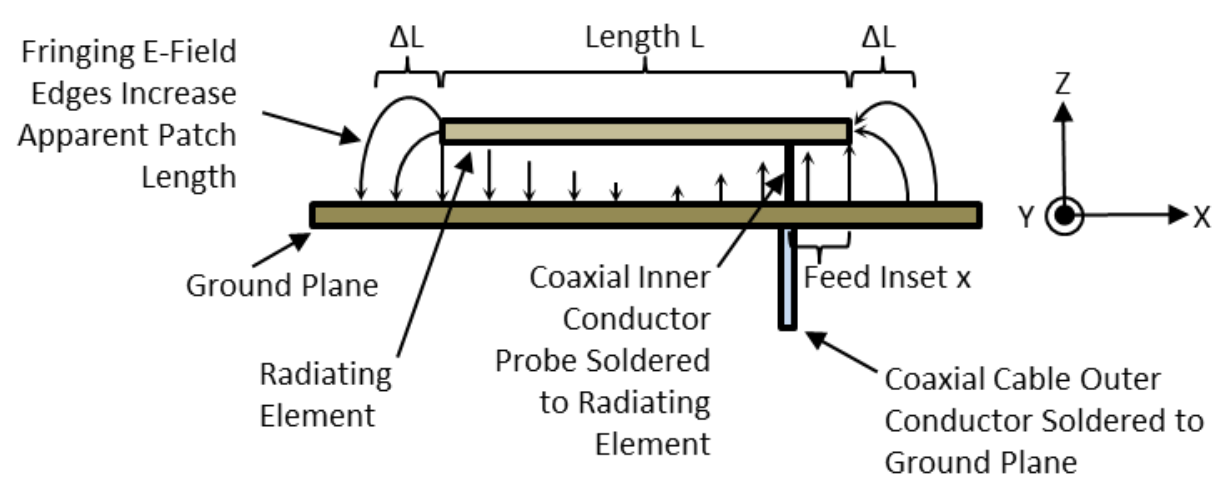

Figure 4-2: Patch Antenna to Ground Electric Fields and Fringing Areas

Two $915 \mathrm{MHz}$ air dielectric $\left(\varepsilon_{\mathrm{r}}=1\right)$, probe-fed patch antennas were fabricated (Figure 4-3) for RFID reader transmission and reception. Dimensions are defined in Table 4-1 and $50 \Omega$ matching data $\left|S_{11}\right|$ is shown Figure 4-4.

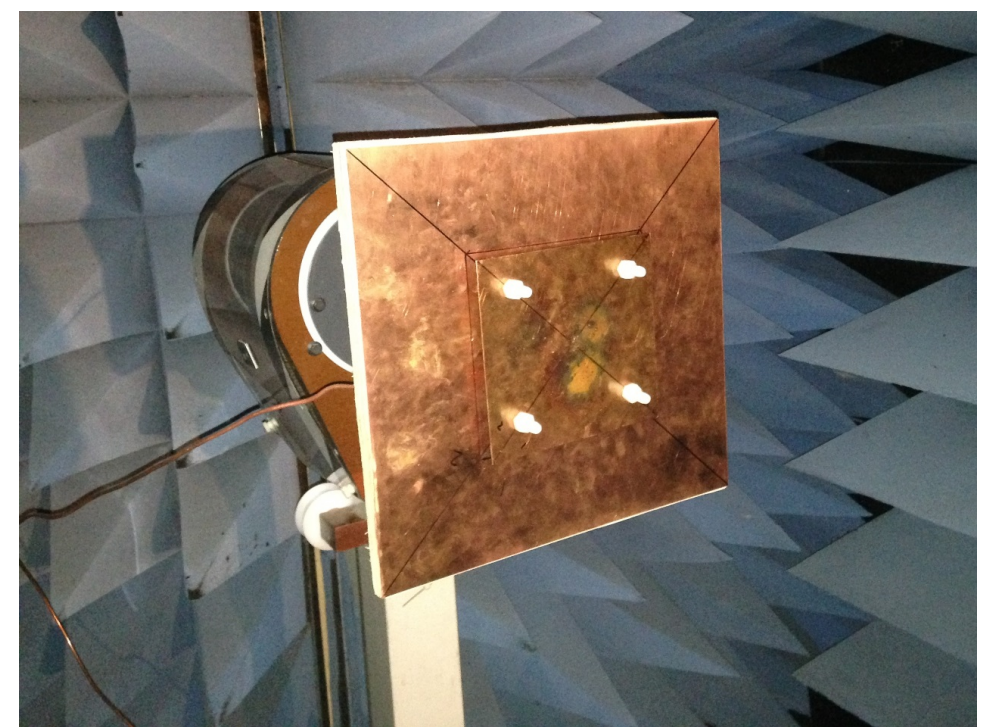

Figure 4-3: Air Dielectric Patch Antenna, $902 \mathrm{MHz}-928 \mathrm{MHz}$

Table 4-1: Air Dielectric Patch Antenna (902MHz-928MHz) Dimensions

\begin{tabular}{|l|r|l|}
\hline \multicolumn{3}{|c|}{$915 \mathrm{MHz}$ Air Dielectric Patch Antenna } \\
Dimensions
\end{tabular}




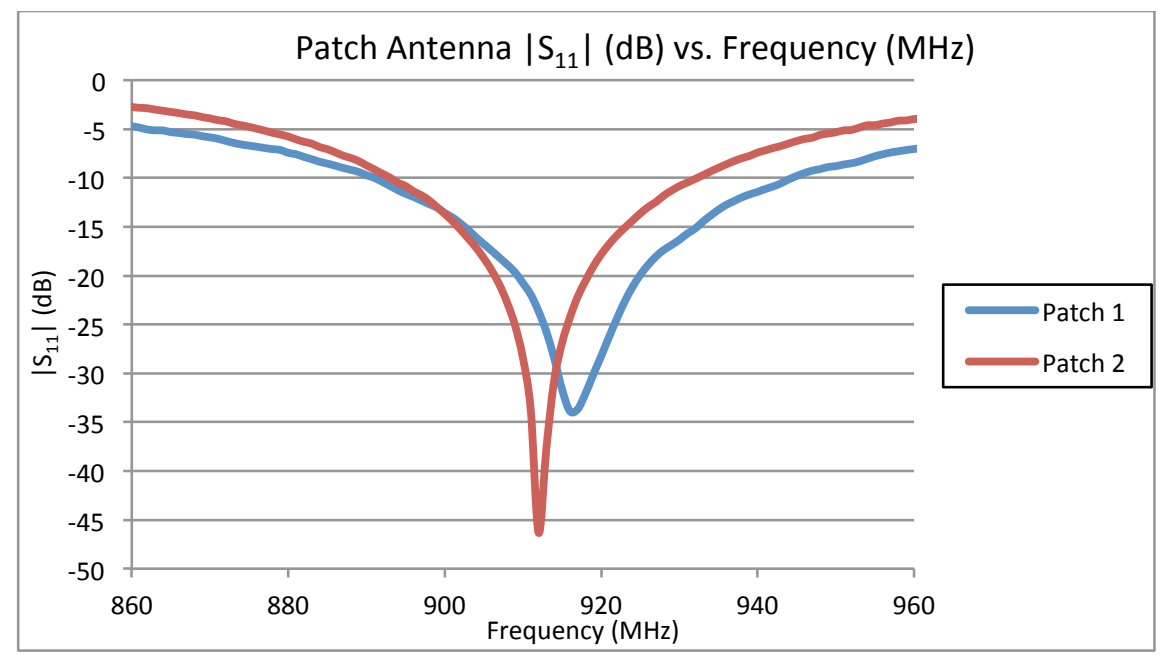

Figure 4-4: Air Dielectric Patch Antenna $\left|\mathrm{S}_{11}\right|(\mathrm{dB})$ vs. Frequency $(\mathrm{MHz}), 902 \mathrm{MHz}-928 \mathrm{MHz}$

The Friis equation in decibels $(\mathrm{dB}, \mathrm{dBm})$ is [20]:

$$
P_{R}=P_{T}+G_{T}+G_{R}+20 \log _{10}\left(\frac{c}{4 \pi R f}\right)
$$

where $P_{R}$ is received power $(d B m), P_{T}$ is transmit power $(d B m), G_{T}$ is transmit gain $(d B)$, $G_{R}$ is receive gain $(\mathrm{dB}), c$ is the speed of light in vacuum $\left(3 \times 10^{8} \mathrm{~m} / \mathrm{s}\right), R$ is antenna separation and $f$ is the operating frequency. Antenna gain calculations assume the two patch antennas are identical; therefore, equal gains. Receive minus transmit power $(d B m)$ is the transmission scattering parameter $(d B):\left|S_{21}\right|=P_{R}-P_{T}$. Solving for $\left|S_{21}\right|$ in $(4-4)$ :

$$
\left|S_{21}\right|=2 G+20 \log _{10}\left(\frac{c}{4 \pi R f}\right)
$$

where gain $G$ is equal to $G_{T}$ and $G_{R}$. Antenna gain is:

$$
G=\frac{1}{2}\left[\left|S_{21}\right|-20 \log _{10}\left(\frac{c}{4 \pi R f}\right)\right]
$$

Figure 4-5 shows the patch antenna gain over frequency. Expected patch antenna gain is $7 \mathrm{~dB}$ to $9 \mathrm{~dB}[26]$. 


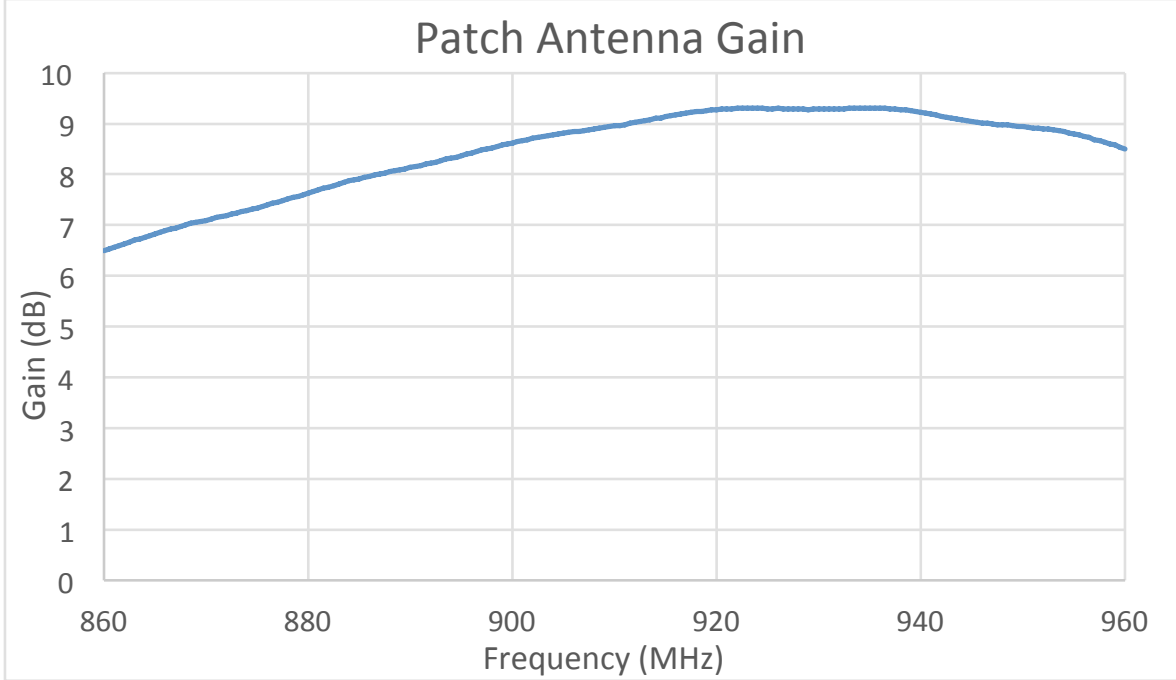

Figure 4-5: Measured Air Dielectric Patch Antenna Gain (dB) vs. Frequency (MHz), 902MHz-928MHz

\section{2: RFID Antenna Input Impedance Measurement Methods}

\subsection{1: Sleeve Balun Probe}

Antenna input impedance is calculated by measuring input reflection coefficient $\Gamma_{\text {in }}$, on a Vector Network (VNA), and solving for impedance $Z_{\text {in }}[1]$ :

$$
Z_{\text {in }}=Z_{o} \frac{1+\Gamma_{\text {in }}}{1-\Gamma_{\text {in }}}
$$

where $Z_{o}$ is the transmission line characteristic impedance. Dipole currents on the two antenna feeds form a differential signal (equal, out-of-phase amplitudes) at the probe (Figure 4-6). Current loc flows inside the outer conductor and current $I_{I C}$ flows on the inner conductor. However, current also flows on the outer conductor's outer surface, parasitic current $I_{p}$, which is included in the impedance measurement. An unbalanced line (coaxial cable) is a single ended line with a ground plane current return path. A balanced line includes two conductors which transmit anti-phase signals. A balun (BALanced-UNbalanced) converts an unbalanced line to a balanced line (or vice-versa) and attenuates the parasitic current. Baluns can also be used to transform transmission line impedances. 


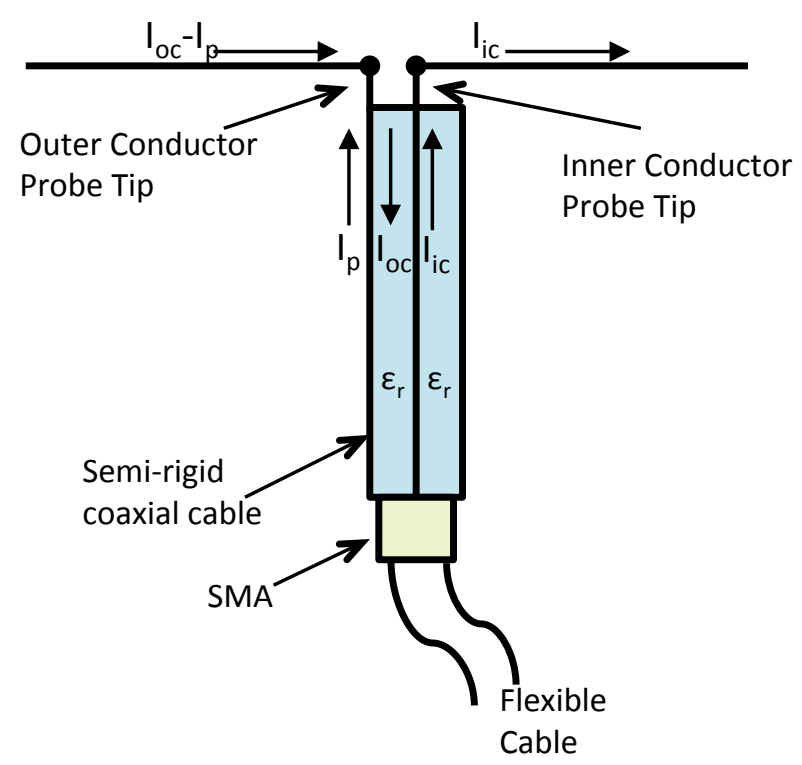

Figure 4-6: Dipole and Cable without Balun

A sleeve (or bazooka) balun is selected for a one-to-one impedance ratio between the balanced and unbalanced lines. The sleeve balun (Figure 4-7 and 4-8) is a quarterwave $(\lambda / 4)$ brass tube soldered to the semi-rigid coaxial cable's outer conductor. The two probe tips extend from the inner and outer conductors. Both probe tips connect to a balanced device. At the desired frequency $(\mathrm{c} / \lambda)$, the short circuit termination creates an open termination at the probe tip outer conductor (Figure 4-9), which blocks current flow on the outer conductor's outer surface. This enables accurate one-to-one impedance measurements. 


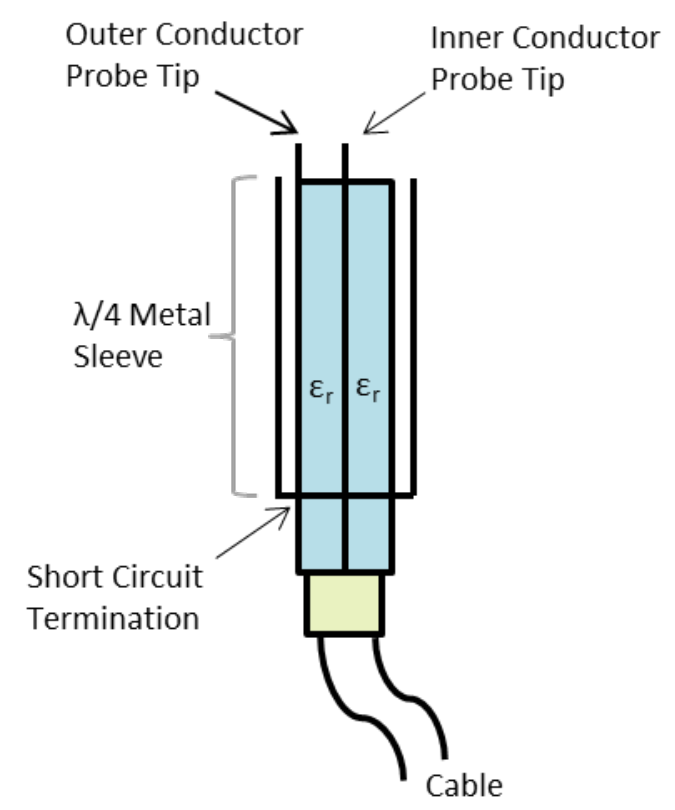

Figure 4-7: Sleeve Balun, N/4 Metal Sleeve Soldered to Outside of Outer Conductor

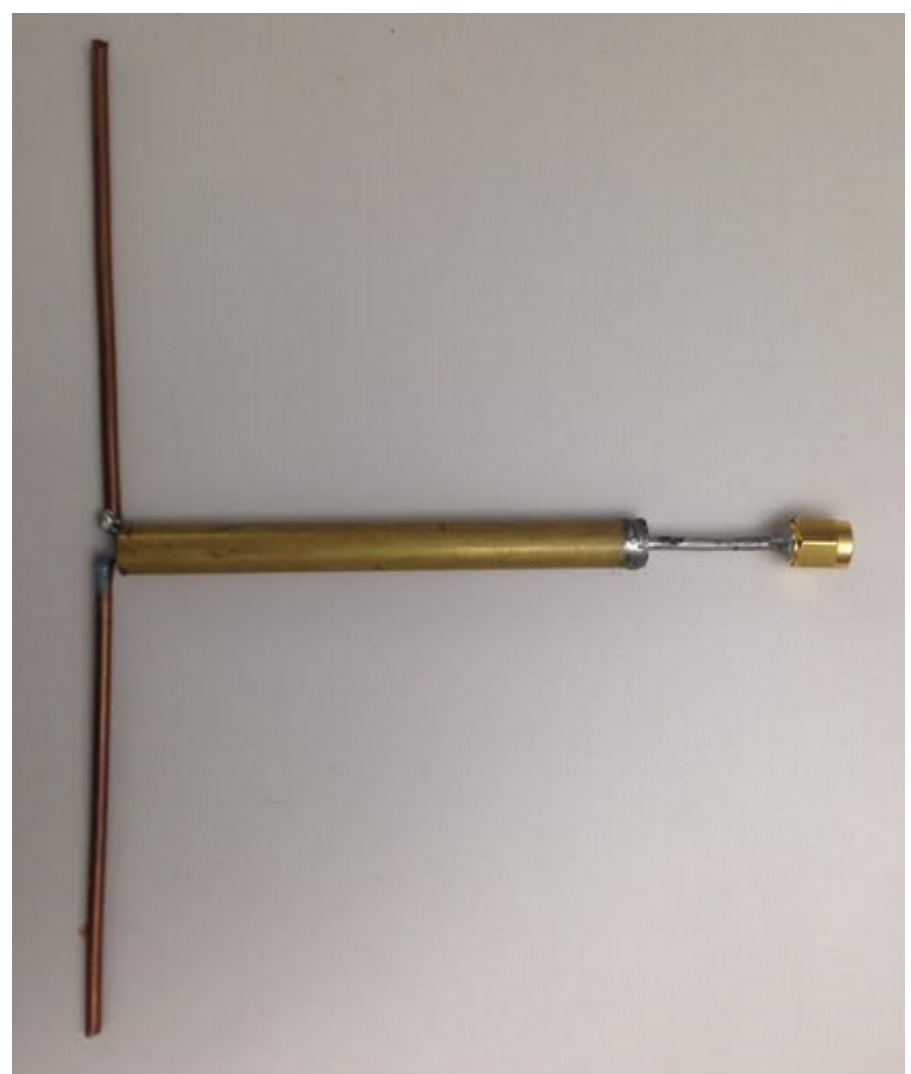

Figure 4-8: Constructed Sleeve Balun 


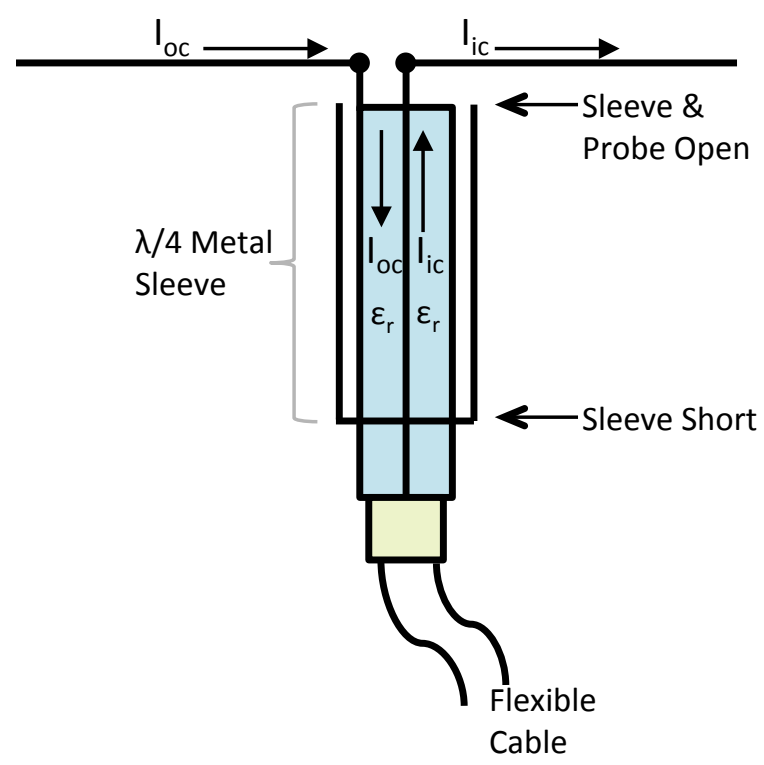

Figure 4-9: Dipole with Sleeve Balun

To test the sleeve balun, $915 \mathrm{MHz}$ half-wave dipole leads are soldered to the inner and outer conductor probe tips. The dipole radiation pattern is measured in the E-Plane (Figure 4-10). The half-wave dipole E-field radiation pattern is [20]:

$$
\boldsymbol{F}=\frac{E}{E_{M A X}} \sin (\theta) \widehat{\boldsymbol{\theta}}
$$

where $E$ is the electric field and $E_{M A X}$ is the maximum electric field. If the sleeve balun prevents current flow on the probe's outer shielding, no E-field radiates in the dipole null directions $\left(\Theta=90^{\circ}, 270^{\circ}\right.$ : see Fig. $\left.4-10\right) .915 \mathrm{MHz}$ half-wave dipole E-plane radiation patterns are measured with and without a sleeve balun (Figure 4-11). The $\Theta=90^{\circ}$ and $\Theta=270^{\circ}$ sleeve balun/dipole nulls are attenuated $14 \mathrm{~dB}$ and $12 \mathrm{~dB}$, respectively, compared to 'no balun' measurements. Hence, the sleeve balun effectively attenuates the probe's outer conductor current flow. 


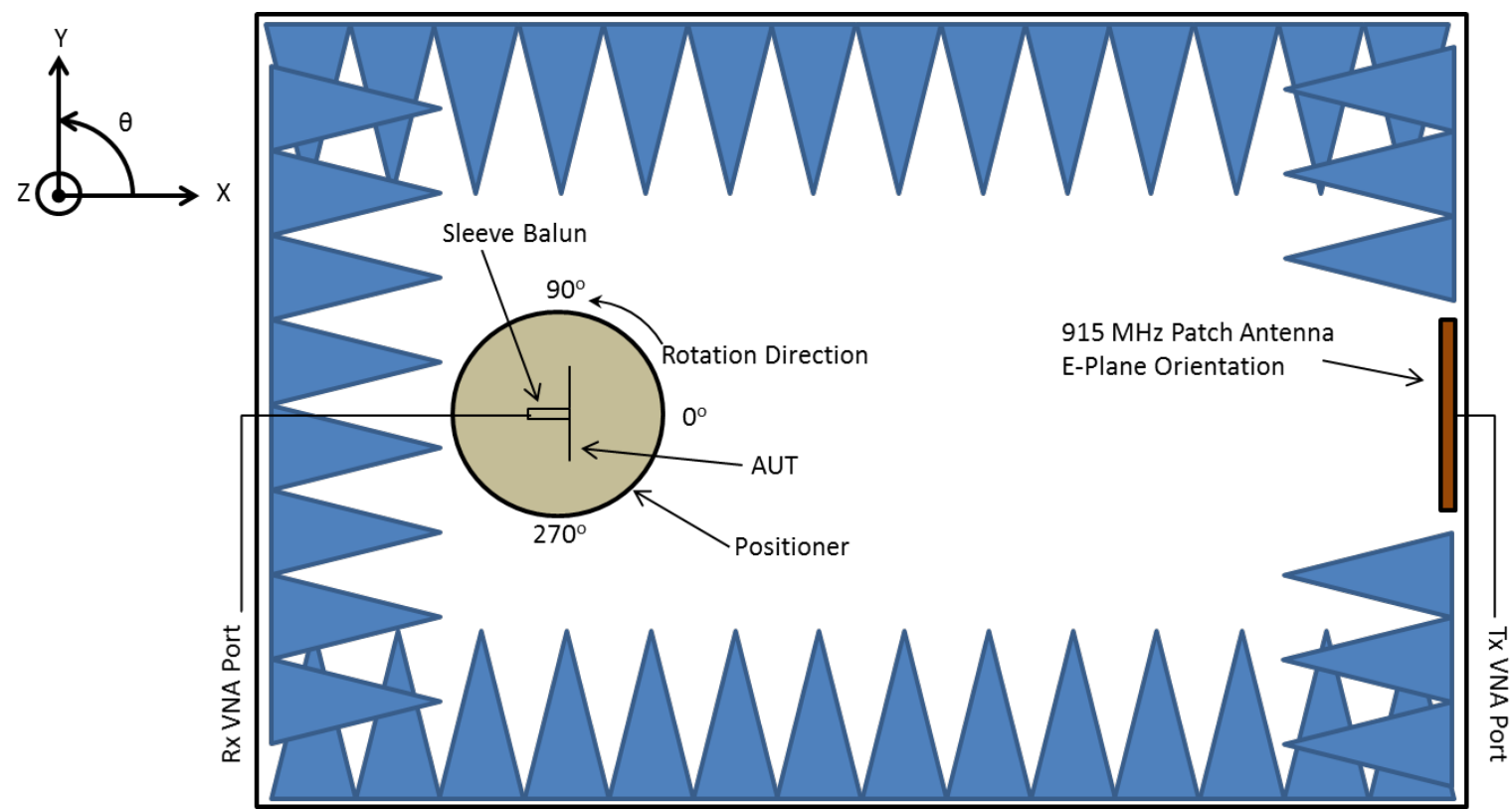

Figure 4-10: Anechoic Chamber Pattern Measurement Setup, Top View

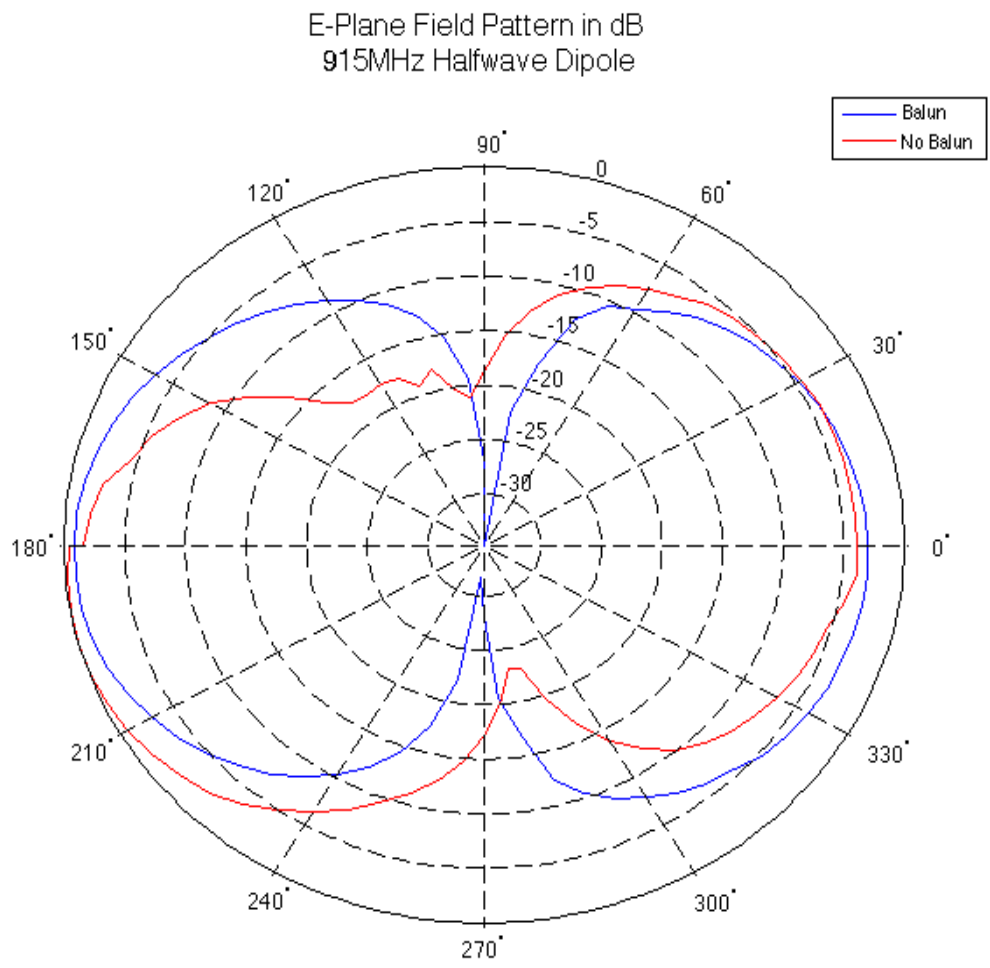

Figure 4-11: Dipole With and Without Sleeve Balun, E-Plane ( $\theta)$ Field Pattern, dB 


\subsection{2: Differential Impedance Probe}

Antenna input impedance is also VNA-measured with a differential probe (Figure 4-12) [27] by converting two-port S-parameter measurements to input impedance.

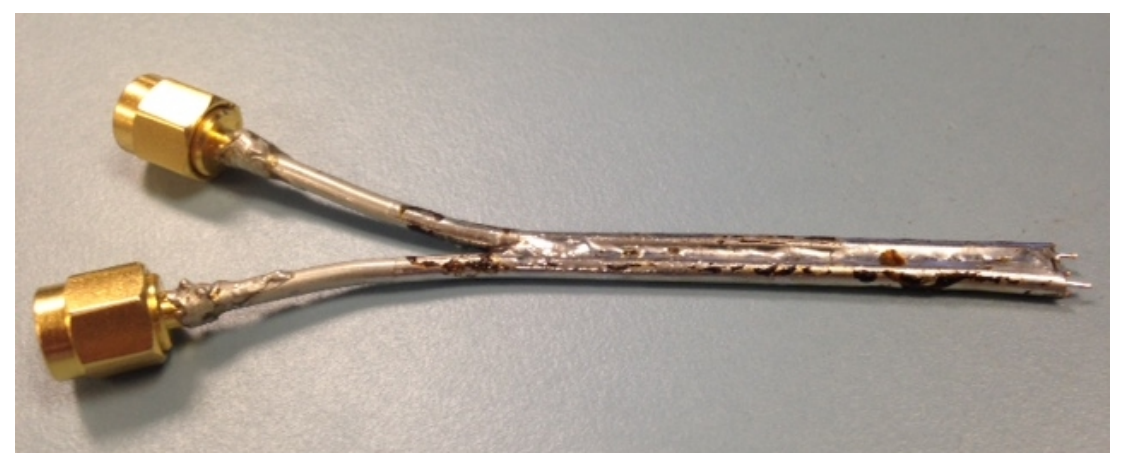

Figure 4-12: Differential Probe, Tag Antenna Input Impedance Measurements

To derive input impedance, consider the two-port network in Figure 4-13. The network's Z-parameter matrix is [1]:

$$
\left[\begin{array}{l}
V_{1} \\
V_{2}
\end{array}\right]=\left[\begin{array}{ll}
Z_{11} & Z_{12} \\
Z_{21} & Z_{22}
\end{array}\right]\left[\begin{array}{l}
I_{1} \\
I_{2}
\end{array}\right]
$$

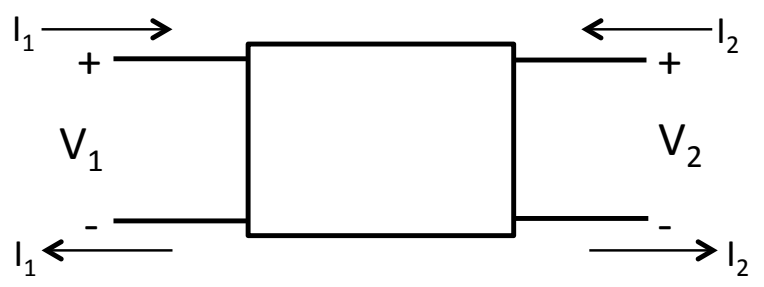

Figure 4-13: Two-Port Network

A dipole antenna is modeled as a current source with source currents $I_{1}$ and $I_{2}$ exciting a two-port network (Figure 4-14). The input voltage across the feed, $V_{\mathbb{I N}}$, is the difference between $V_{1}$ and $V_{2}$ :

$$
V_{I N}=V_{1}-V_{2}
$$

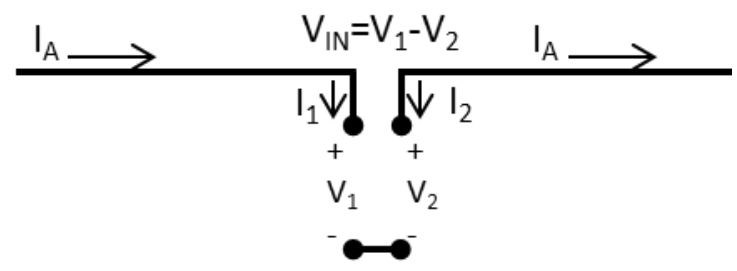

Figure 4-14: Two-Port Network with Dipole Currents 
Antenna current ' $\mathrm{I}_{A}$ ' flows in a single direction along the antenna; hence, $\mathrm{I}_{1}=\mathrm{I}_{\mathrm{A}}$ and $\mathrm{I}_{2}=-\mathrm{I}_{\mathrm{A}}$. Substituting (4-9) into (4-10), $V_{I N}$ is written in terms of Z-Parameters and $I_{A}$ :

$$
V_{I N}=\left(Z_{11}-Z_{12}-Z_{21}+Z_{22}\right) I_{A}
$$

The input impedance $Z_{\mathbb{N}}$ is:

$$
Z_{I N}=\frac{V_{I N}}{I_{A}}=Z_{11}-Z_{12}-Z_{21}+Z_{22}
$$

Using Z-to-S parameter conversions [1], the input impedance is written in terms of the S-parameters:

$$
Z_{I N}=2 Z_{o} \frac{1-S_{11} S_{22}+S_{12} S_{21}-S_{12}-S_{21}}{\left(1-S_{11}\right)\left(1-S_{22}\right)-S_{12} S_{21}}
$$

If the antenna is symmetric, $S_{21}=S_{12}$ and $S_{11}=S_{22}$. Input impedance reduces to:

$$
Z_{I N}=2 Z_{o} \frac{1-S_{11}^{2}+S_{21}^{2}-2 S_{12}}{\left(1-S_{11}\right)^{2}-2 S_{21}}
$$

To construct a differential probe, cut two equal length semi-rigid coaxial cables. In this example, the lengths are $10 \mathrm{~cm}$. Attach male SMA connectors to one side of each coaxial cable. Expose $0.5 \mathrm{~mm}$ inner conductor lengths on the other side (antenna probes). Connect the exposed inner conductor probes to the Antenna Under Test (AUT). Align the probes lengthwise. Solder the probes' outer shielding together, leaving $2-3 \mathrm{~cm}$ on the SMA side unsoldered.

The differential probe extends beyond the calibration plane (Figure 4-15). S-parameter phase changes along the probe length; the active ports' calibration planes must be transferred to the probe tips (port extension plane, Figure 4-15). Time Domain Reflectometry (TDR) methods determine electrical delay to the port extension plane. The active ports' reference planes are adjusted to the port extension plane. 


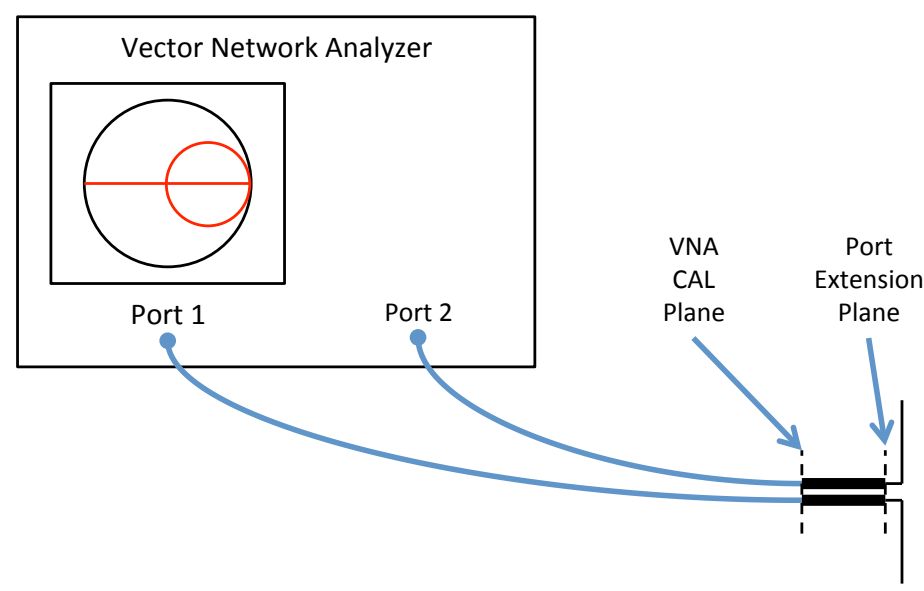

Figure 4-15: VNA Port Extension

\subsection{3: Sleeve Balun and Differential Probe Verification}

RFID antennas are printed on Dupont Melinex® ST504 polyethylene terephthalate (PET) film (dielectric thickness $\mathrm{t}_{\varepsilon}=150 \mu \mathrm{m}$ and dielectric constant $\varepsilon_{\mathrm{r}}=2.9$ ) and bounded by air dielectric $\left(\varepsilon_{\mathrm{r}}=1\right)$ above and below the substrate (Figure 4-16). The structure is defined in Keysight's Advanced Design System (ADS) Momentum Electromagnetic Simulator. A $15.6 \mathrm{~cm}$ length (s dimension in Figure 4-17) planar dipole is simulated in ADS from $860 \mathrm{MHz}$ to $960 \mathrm{MHz}$. Antenna dimensions include microstrip thickness $t_{\mathrm{Ag}}=25 \mu \mathrm{m}$, microstrip width $\mathrm{W}=1 \mathrm{~mm}$ and $\mathrm{g}=1 \mathrm{~mm}$ feed gap. The antenna is measured in an anechoic chamber with the sleeve balun and differential probe. Impedance results are shown in Figure 4-18 and Figure 4-19. The sleeve balun antenna resistance is within $\pm 5 \Omega$ of simulations from $880 \mathrm{MHz}$ to $940 \mathrm{MHz}$. The differential probe antenna resistance is within $\pm 5 \Omega$ of simulated values over the $860 \mathrm{MHz}-960 \mathrm{MHz}$ band. Both the sleeve balun and differential probe reactances are within $\pm 5 \Omega$ over the $860 \mathrm{MHz}-$ $960 \mathrm{MHz}$ band. Sleeve baluns are narrowband devices within a $\pm 3.5 \%$ bandwidth around the $915 \mathrm{MHz}$ center frequency [20]. The differential probe is a broadband (greater than $\pm 3.5 \%$ bandwidth) measurement configuration; bandwidth is limited by the semi-rigid coax and VNA bandwidth. The differential probe measurement configuration is used to measure RFID antennas in Chapter 5. 


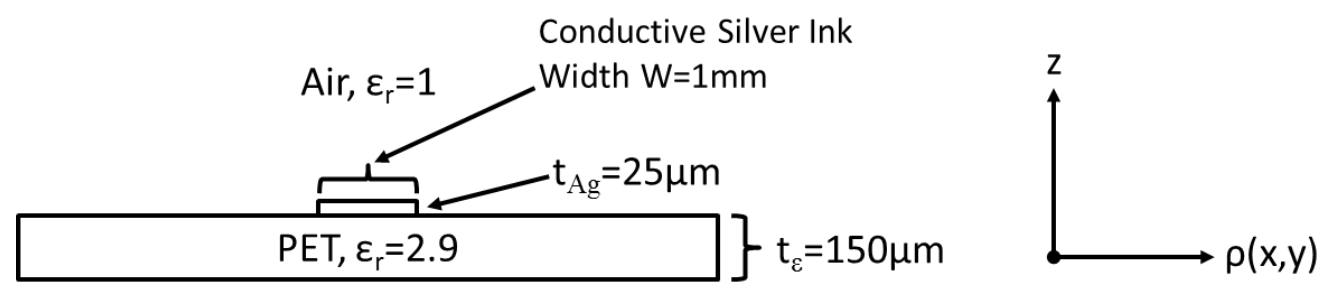

Air, $\varepsilon_{\mathrm{r}}=1$

Figure 4-16: PET Substrate Bounded Above and Below by Air Dielectric, Side View

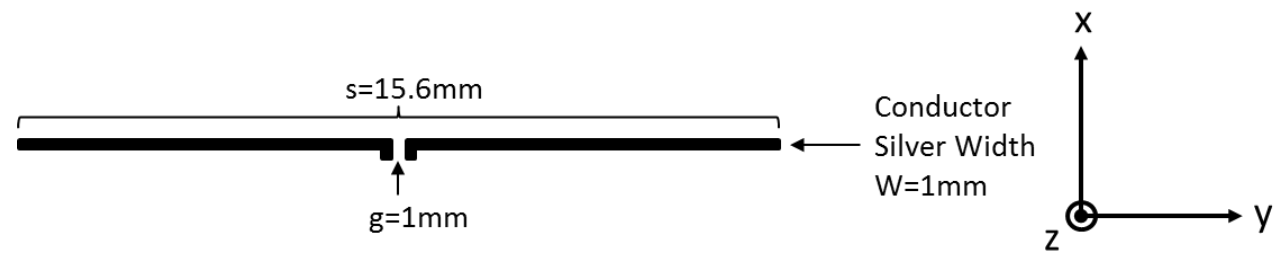

Figure 4-17: Planar Dipole Design, Top View

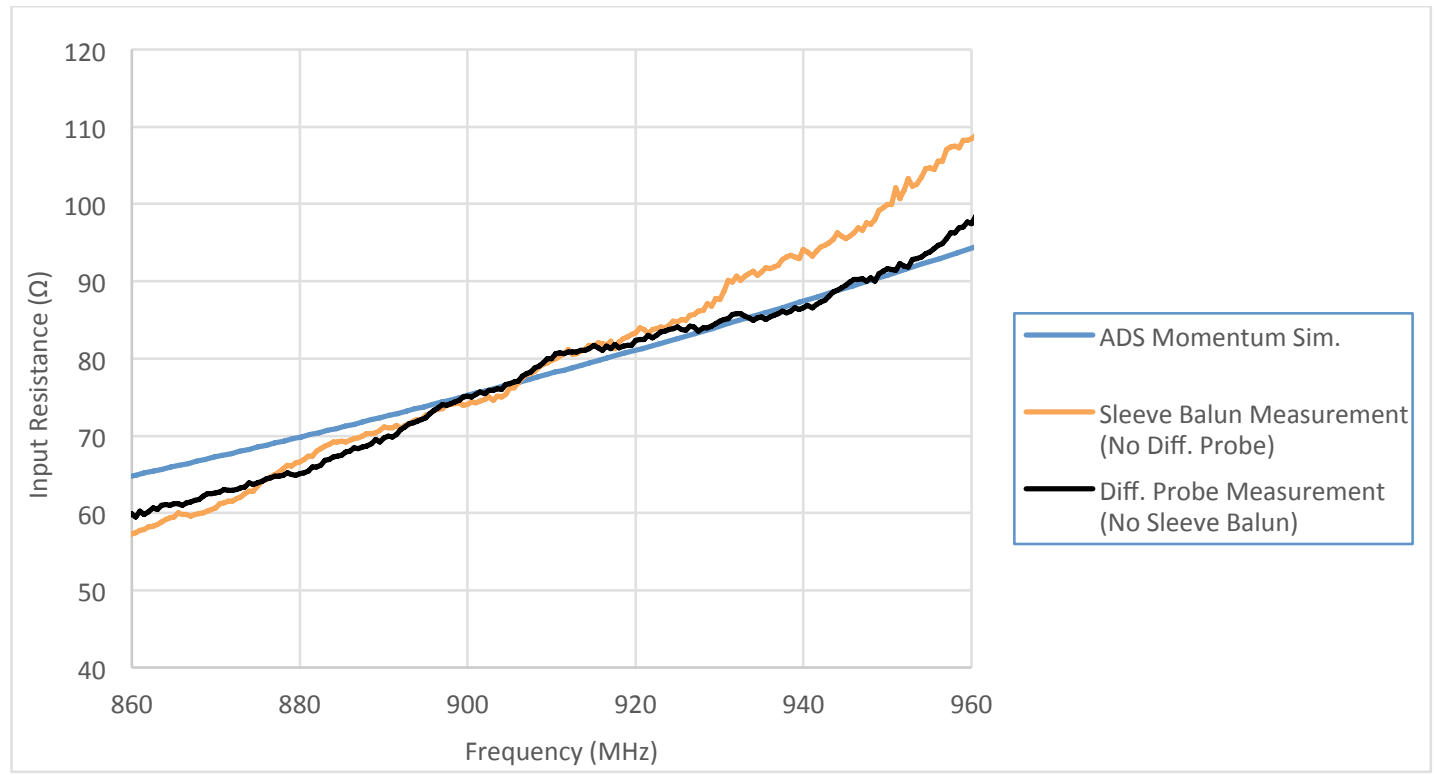

Figure 4-18: Printed Planar Dipole Input Resistance $(\Omega)$ vs. Frequency $(\mathrm{MHz})$ 


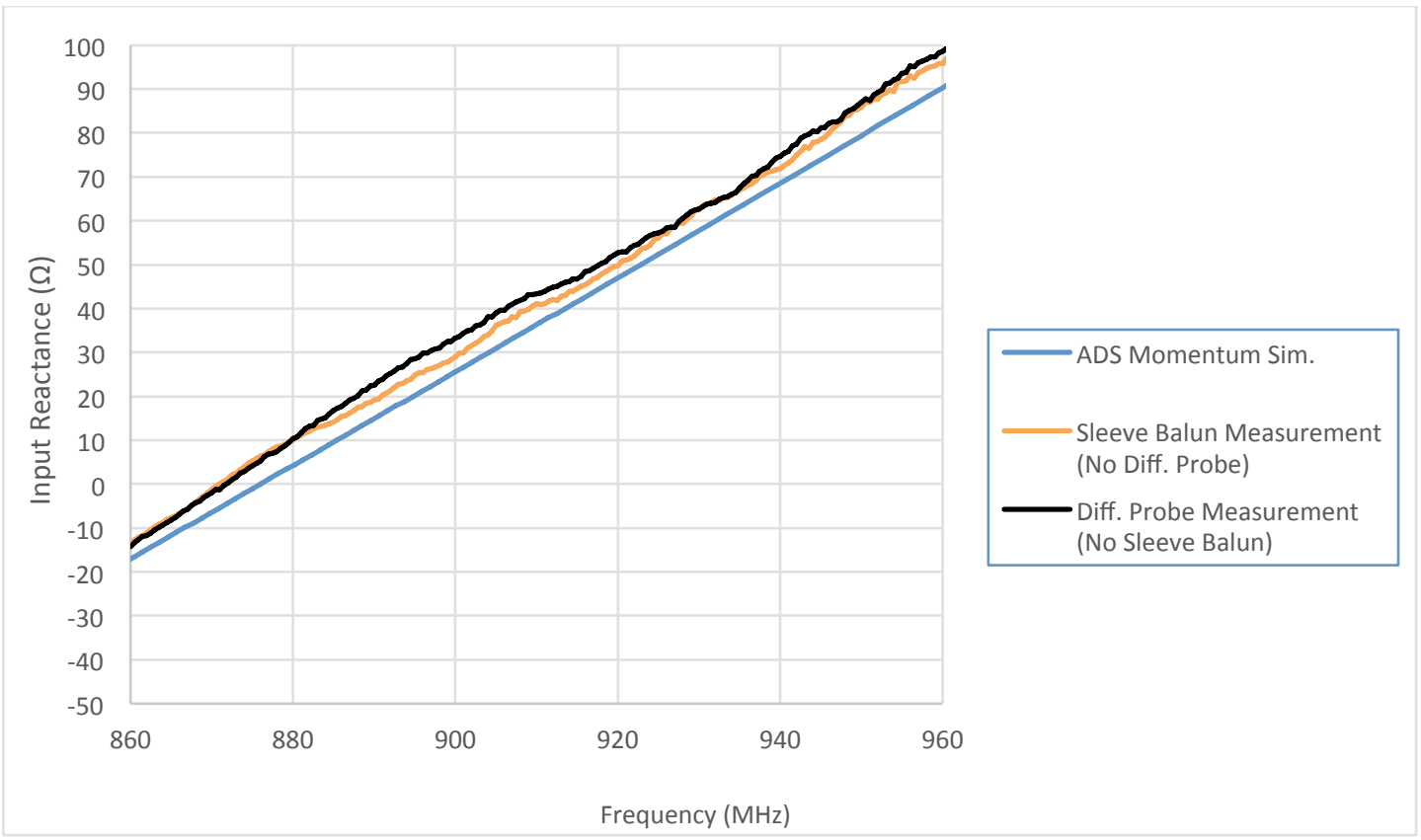

Figure 4-19: Printed Planar Dipole Input Reactance $(\Omega)$ vs. Frequency $(\mathrm{MHz})$ 


\section{ANTENNA DESIGNS AND RESULTS}

\section{1: Load Characterization}

Alien Technology's Higgs-4 Radio Frequency Integrated Circuits (RFICs) are used to range test antenna designs. The Higgs- 4 RFIC package size is $600 \times 600 \mu \mathrm{m}$. Alien Technology distributes sample RFICs on straps (Figure 5-1), which include two copper traces $(3.5 \times 2.5 \mathrm{~mm})$ connected to the RFIC inputs. The RFIC and traces are affixed to a dielectric substrate, called an inlay. Straps increase surface area and facilitate RFIC connection to tag antennas.

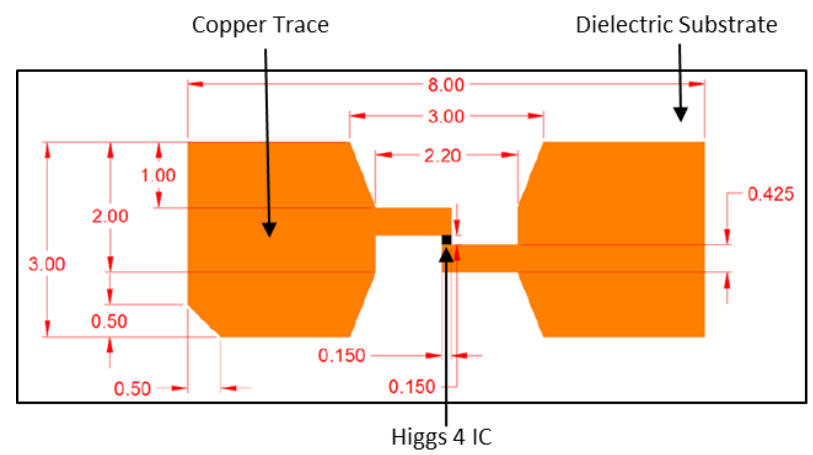

Figure 5-1: Higgs-4 Strap Dimensions (Millimeters) [9]

Manufacturers typically define RFIC input impedance as a parallel shunt resistor and capacitor (Figure 5-2). The Higgs-4 strap datasheet specifies shunt resistance $R_{L}=1800 \Omega$ and shunt capacitance $C_{L}=0.95 p F$ at minimum operating power, $-18.5 \mathrm{dBm}$ $(860 \mathrm{MHz}-960 \mathrm{MHz})$. The Higgs-4 series impedance response (parallel $C_{L}$ and $R_{L}$ ) is shown in Figure 5-3 and Figure 5-4. The RFIC's $915 \mathrm{MHz}$ center frequency input impedance $Z_{I C}$ is $18.43-j 181.2 \Omega$. Measuring RFIC input impedance has been the focus of several studies including [28] [29] and is not a trivial task. The RFIC has several circuit blocks at the input (discussed in Chapter 1), and input impedance is power dependent. Furthermore, some RFIC designs include a wake-up sequence. The manufacturer specifies only a "best" compensation point at a specific power to simplify design procedures. A direct VNA measurement of RFIC input impedance yields incorrect results $\left(Z_{I C}=9-140 j \Omega\right)$. For this thesis the manufacturer's stated input impedance $\left(Z_{I C}=18.43-j 181.2 \Omega\right)$ is used. 


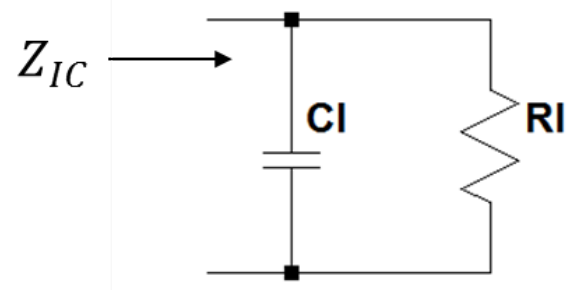

Figure 5-2: RFIC Input Shunt Capacitance and Resistance

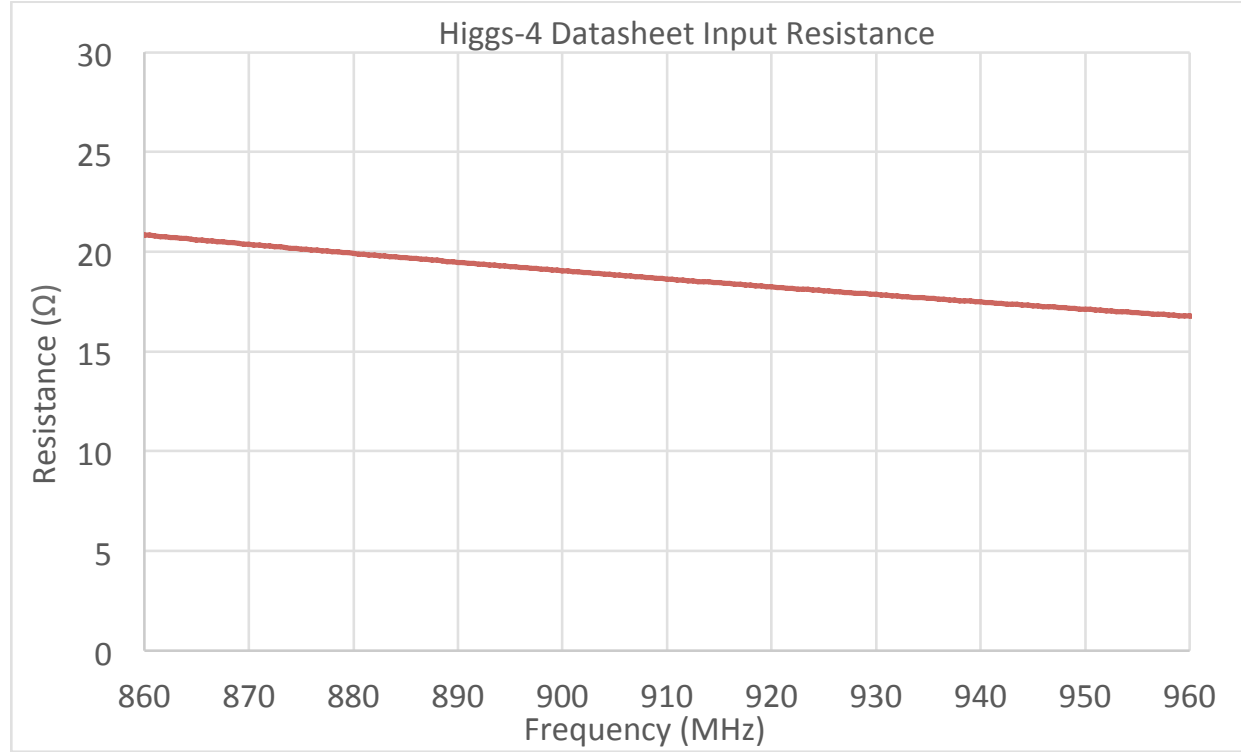

Figure 5-3: Higgs-4 $Z_{\mathrm{IC}}$ Input Resistance $(\Omega)$ vs. Frequency $(\mathrm{MHz})$

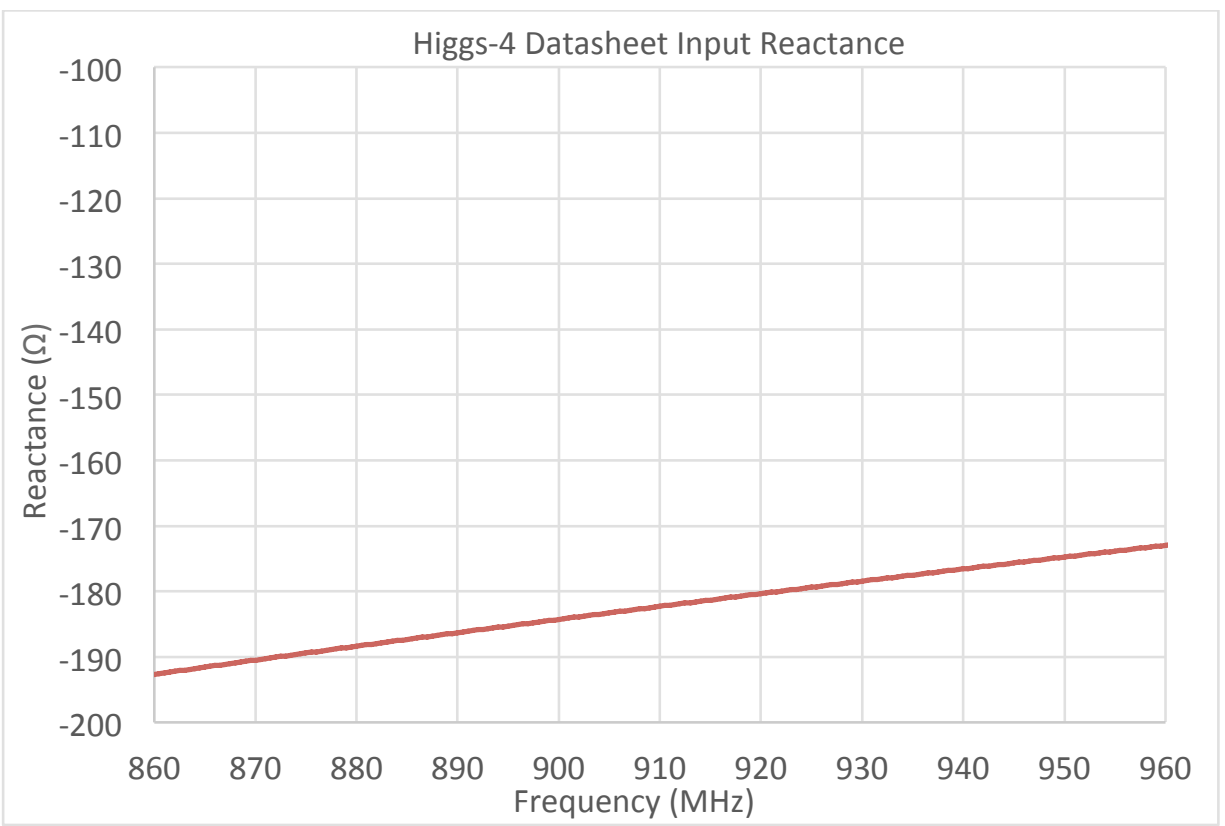

Figure 5-4: Higgs-4 $\mathrm{Z}_{\mathrm{IC}}$ Input Reactance $(\Omega)$ vs. Frequency $(\mathrm{MHz})$ 
5.2: Narrowband 902-928MHz Design, Measurement and Range Testing

The Higgs- 4 complex conjugate impedance at $915 \mathrm{MHz}$ is $Z_{I N}^{*}=18.43+\mathrm{j} 181.2 \Omega$.

Following Section 3.2's narrowband matching design, an $s=11.3 \mathrm{~cm}, 14$ meander element antenna is defined in Advanced Design System (ADS) (Figure 5-5) to match the $Z_{I N}^{*}$ target. Antenna dimensions are listed in Table 5-1. Gap $g$ allows space for mounting the Higgs-4 strap between the two Is series inductors. The simulation indicates the antenna's $915 \mathrm{MHz}$ input resistance (Figure 5-6) is $5 \Omega$ less than the Higgs-4 resistance. The antenna's $915 \mathrm{MHz}$ inductive reactance (Figure $5-7$ ) is $35 \Omega$ less than the IC's input conjugate reactance.

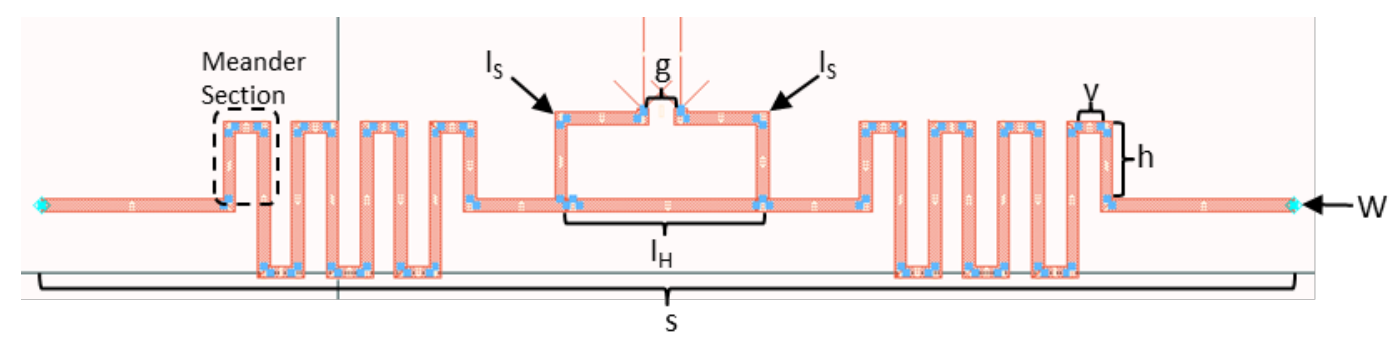

Figure 5-5: Narrowband Antenna Dimensions

Table 5-1: Narrowband Antenna Dimensions

\begin{tabular}{|c|c|}
\hline \multicolumn{2}{|c|}{$\begin{array}{c}\text { Narrowband Antenna } \\
\text { Dimensions }\end{array}$} \\
\hline Conductor Width (W) & $1.1 \mathrm{~mm}$ \\
\hline Antenna Length (s) & $113.0 \mathrm{~mm}$ \\
\hline Meander Sections (M) & 14 \\
\hline Meander Spacing (v) & $2.0 \mathrm{~mm}$ \\
\hline Meander Height (h) & $6.0 \mathrm{~mm}$ \\
\hline Shunt Inductor $\left(\mathrm{I}_{H}\right)$ & $17.0 \mathrm{~mm}$ \\
\hline Series Inductor $\left(I_{S}\right)$ & $17.0 \mathrm{~mm}$ \\
\hline Gap (g) & $2.3 \mathrm{~mm}$ \\
\hline
\end{tabular}




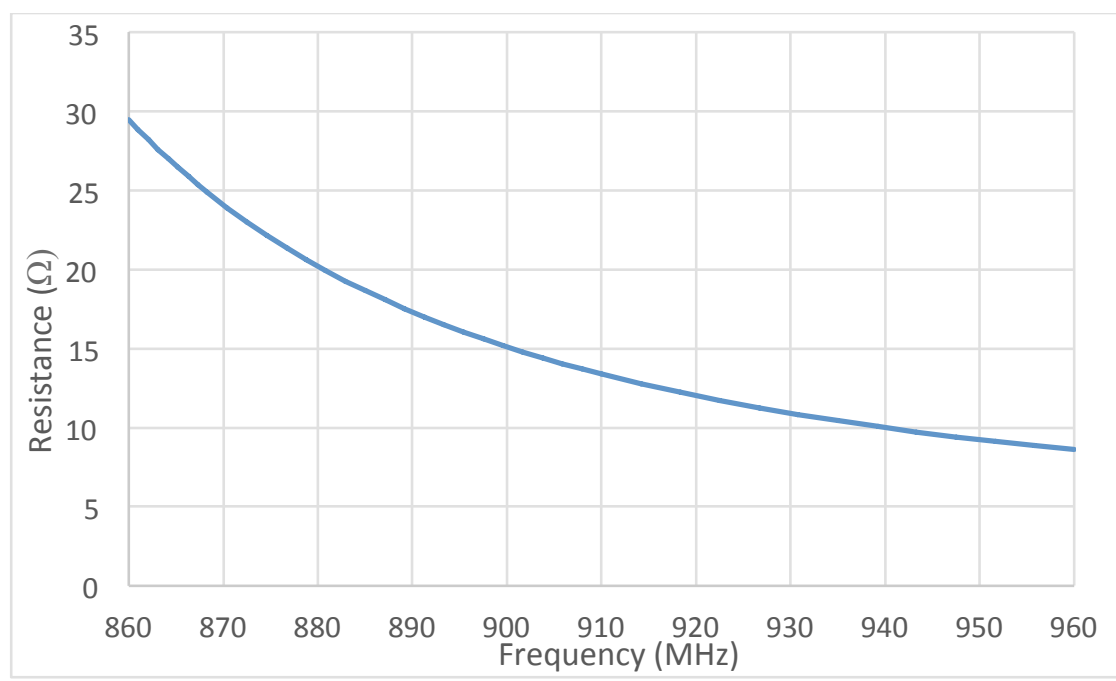

Figure 5-6: Simulated Narrowband Input Resistance $(\Omega)$ vs. Frequency $(\mathrm{MHz})$

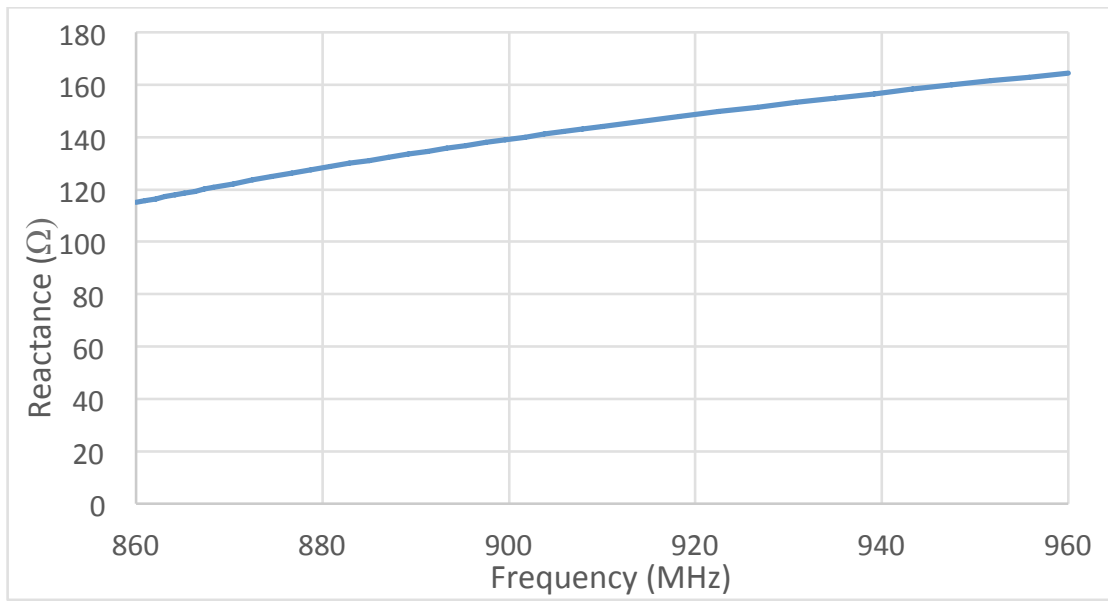

Figure 5-7: Simulated Narrowband Input Reactance $(\Omega)$ vs. Frequency $(\mathrm{MHz})$

$I_{H}$ is lengthened by $1 \mathrm{~mm}$ to increase resistance and $I_{S}$ strips are lengthened in steps $(18.0 \mathrm{~mm}, 18.5 \mathrm{~mm}$ and $19.5 \mathrm{~mm})$ and simulated to show series inductance effects (results in Figure 5-8 and 5-9). At center frequency the input resistance increases by $2 \Omega / \mathrm{mm}$ and inductive reactance increases by $12 \Omega / \mathrm{mm}$. The three simulated antennas are fabricated and measured (Figure 5-10 and 5-11). Measured resistances are 8-9 $\Omega$ greater than simulated resistances and measured reactance is within 3-6 $\Omega$ simulated reactance. Sources of error are discussed in Section 5.3. 


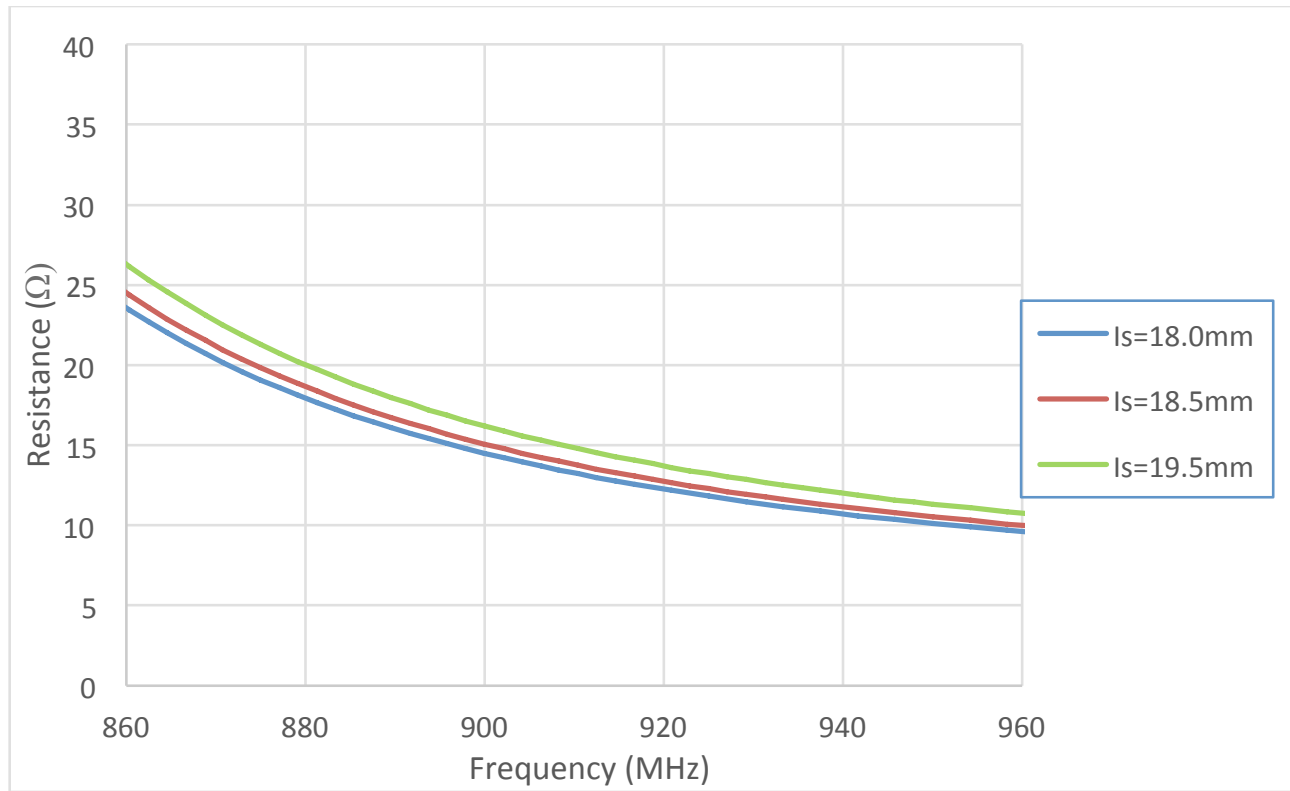

Figure 5-8: Simulated Narrowband Input Resistance $(\Omega)$ vs. Frequency $(\mathrm{MHz})$

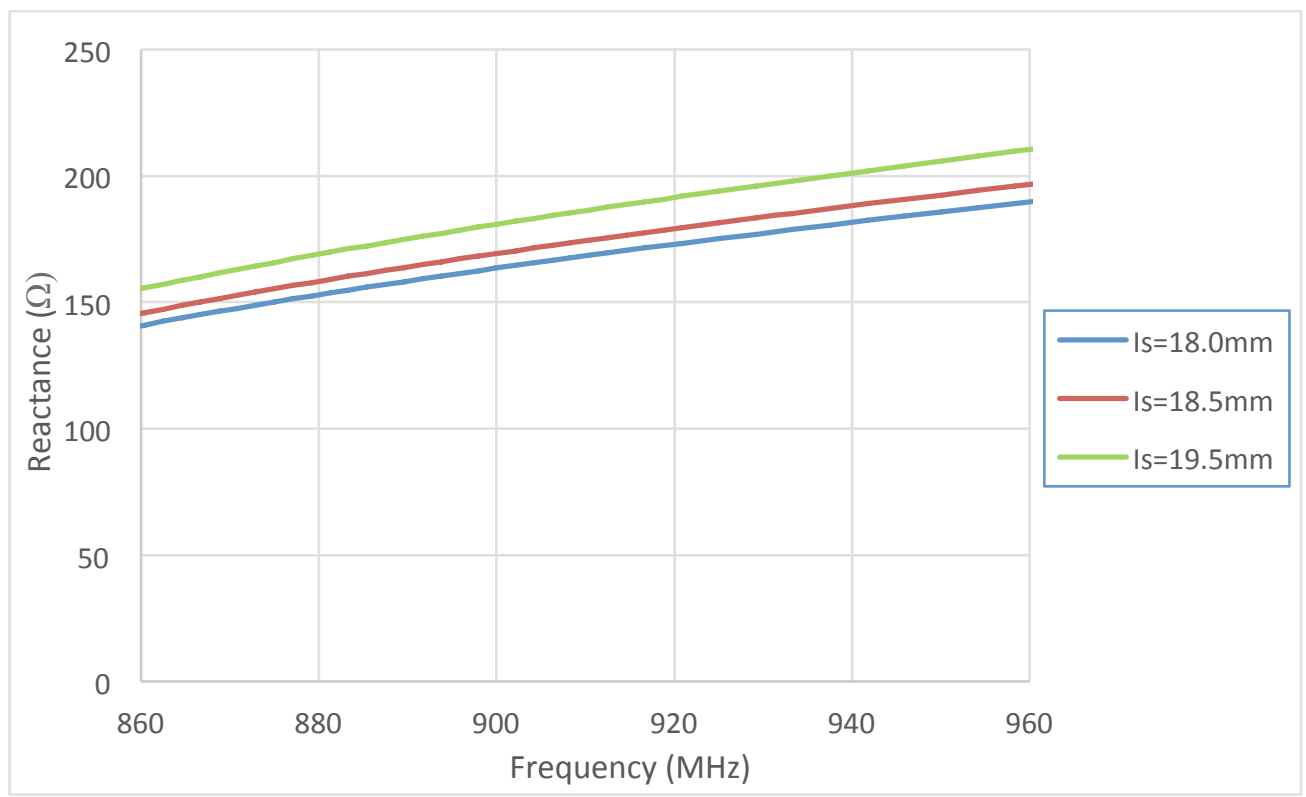

Figure 5-9: Simulated Narrowband Input Reactance $(\Omega)$ vs. Frequency $(\mathrm{MHz})$ 


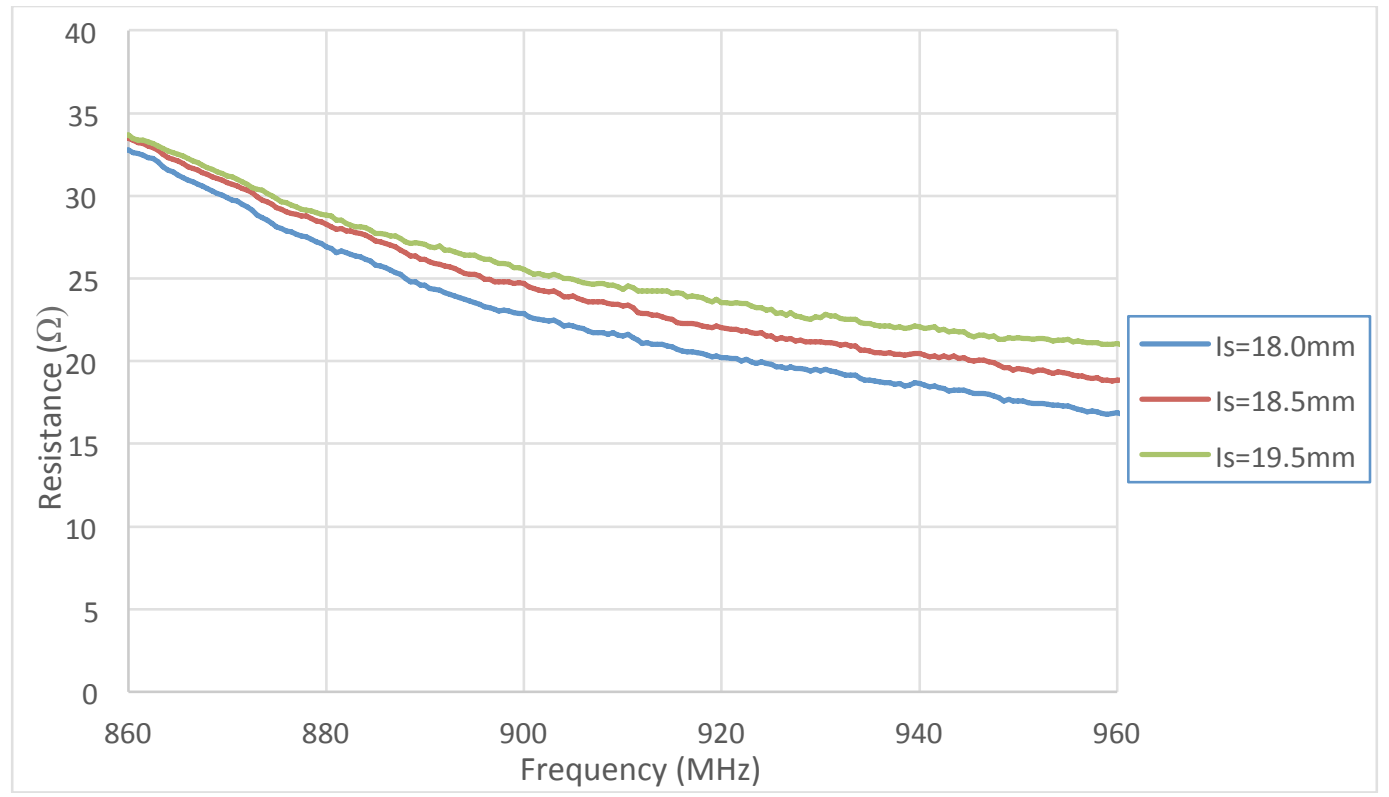

Figure 5-10: Measured Narrowband Input Resistance $(\Omega)$ vs. Frequency $(\mathrm{MHz})$

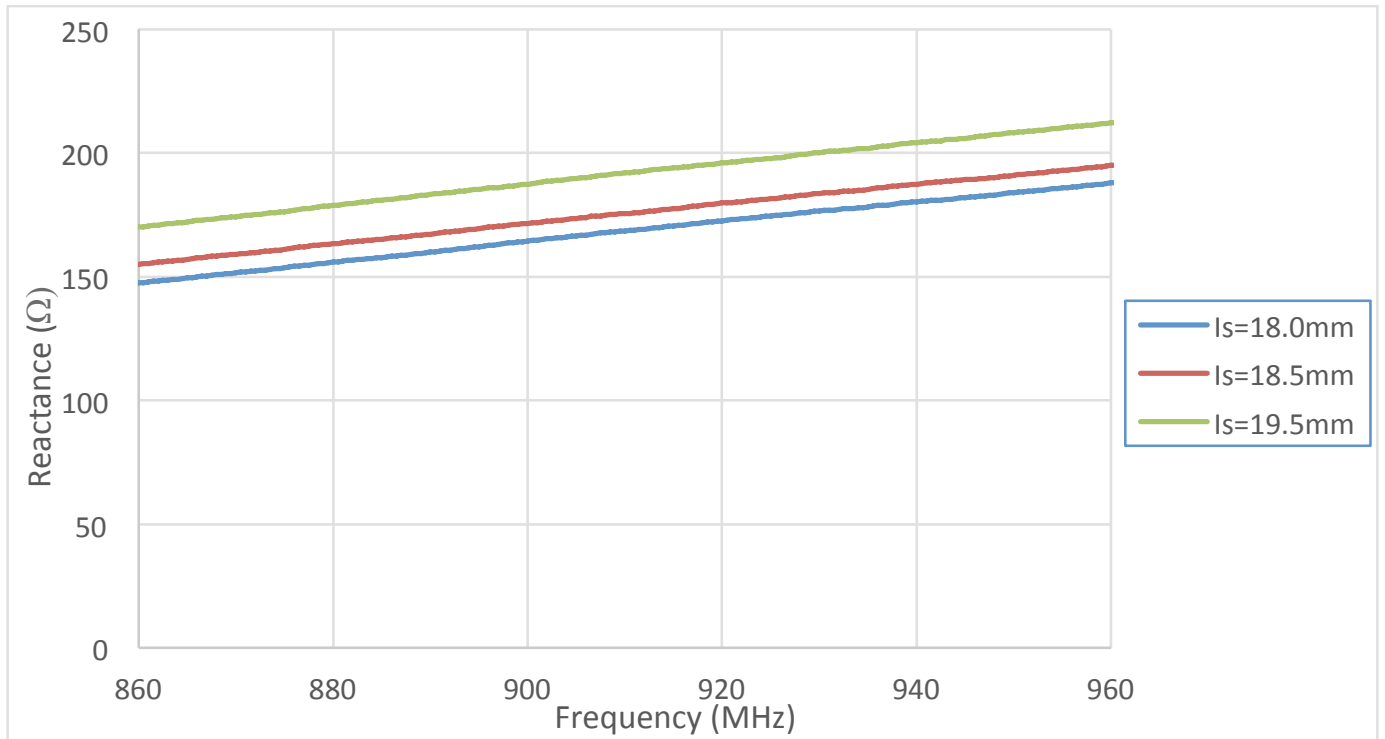

Figure 5-11: Measured Narrowband Input Reactance $(\Omega)$ vs. Frequency $(\mathrm{MHz})$

Voltage reflection coefficient ' $s_{r}$ ' from RFIC to antenna is [1]:

$$
s_{r}=\frac{Z_{I C}-Z_{A}^{*}}{Z_{I C}+Z_{A}}
$$

where $Z_{A}$ is antenna input impedance and $Z_{I C}$ is RFIC input impedance. Reflection parameter $\left|S_{11}\right|$ from RFIC to antenna is then [16]:

$$
\left|S_{11}\right|=20 * \log _{10}\left|S_{r}\right|
$$


Antenna|S ${ }_{11} \mid$ responses are calculated (Figure 5-12).

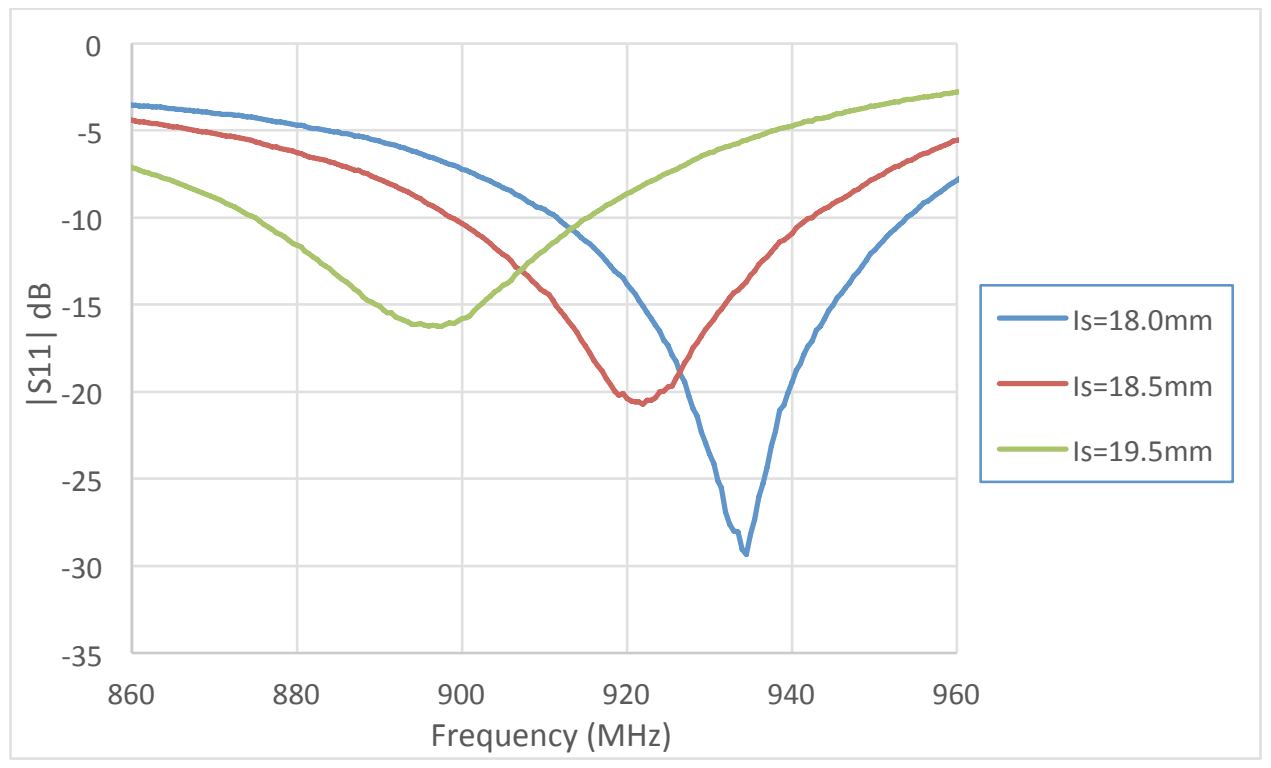

Figure 5-12: Simulated Narrowband $\left|\mathrm{S}_{11}\right|(\mathrm{dB})$ vs. Frequency $(\mathrm{MHz})$

The Friis Transmission Equation is [30]:

$$
P_{R}=P_{T} G_{T} G_{R} L\left(\frac{\lambda}{4 \pi R}\right)^{2}\left(1-\left|\Gamma_{t}\right|^{2}\right)\left(1-\left|s_{r}\right|^{2}\right)
$$

where $P_{T}$ and $P_{R}$ are transmit and receive power, $G_{T}$ and $G_{R}$ are transmit and receive antenna gain, $L$ is transmit antenna cable attenuation, $\lambda$ is wavelength, $R$ is transmit to receive antenna distance, and $\Gamma_{\mathrm{T}}$ and $\mathrm{s}_{\mathrm{r}}$ are the transmit antenna and receive antenna voltage reflection coefficients. Find $\mathrm{R}$ to determine maximum transmit range:

$$
R=\frac{\lambda}{4 \pi} \sqrt{\frac{P_{T} L G_{T} G_{R}\left(1-\left|\Gamma_{T}\right|^{2}\right)\left(1-\left|\mathrm{s}_{R}\right|^{2}\right)}{P_{R}}}
$$

Straps are attached to the printed narrowband antennas (Figure 5-13). The transmit antenna (reader patch antenna) and receive antenna (RFID tag) are separated by fixed distance $R=4.0 \mathrm{~m}$ (Figure $5-14$ ). At $915 \mathrm{MHz}$, transmit patch antenna gain $\mathrm{G}_{\mathrm{T}}$ is $9.1 \mathrm{~dB}$ (Chapter 4 ) and reflection coefficient $\Gamma_{\mathrm{T}}$ is $-30 \mathrm{~dB}$. Cable (length $=1 \mathrm{~m}$ ) attenuation $L$ is 1.1dB. Measuring receive antenna gain $G_{R}$ on a Vector Network Analyzer (VNA) requires a matching network between the antenna feed and $50 \Omega$ VNA port. Instead, ADS is used to simulate the field pattern (Figure 5-15) to derive receive antenna gain $G_{R}$. Simulated receive gain $G_{R}$ is $1.6 \mathrm{~dB}$. Voltage reflection coefficient for conjugate 
matching, $\mathrm{S}_{\mathrm{r}}$, is derived from antenna impedance measurements and the Higgs-4 input impedance datasheet value. The minimum receive power to activate the Higgs-4 IC $P_{R}$ is $-18.5 \mathrm{dBm}$ (from product datasheet [9]). Range testing conditions are shown in Table 5-2.

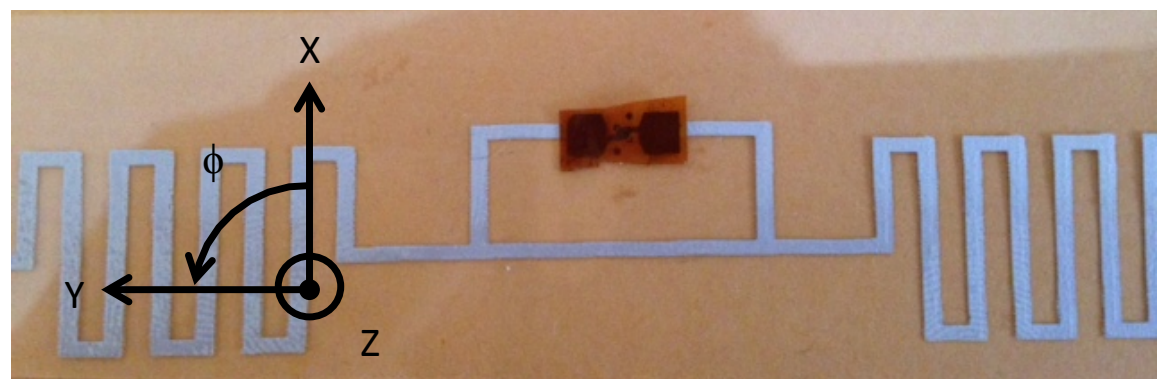

Figure 5-13: Higgs-4 RFIC Strap Attached to Narrow Band Antenna

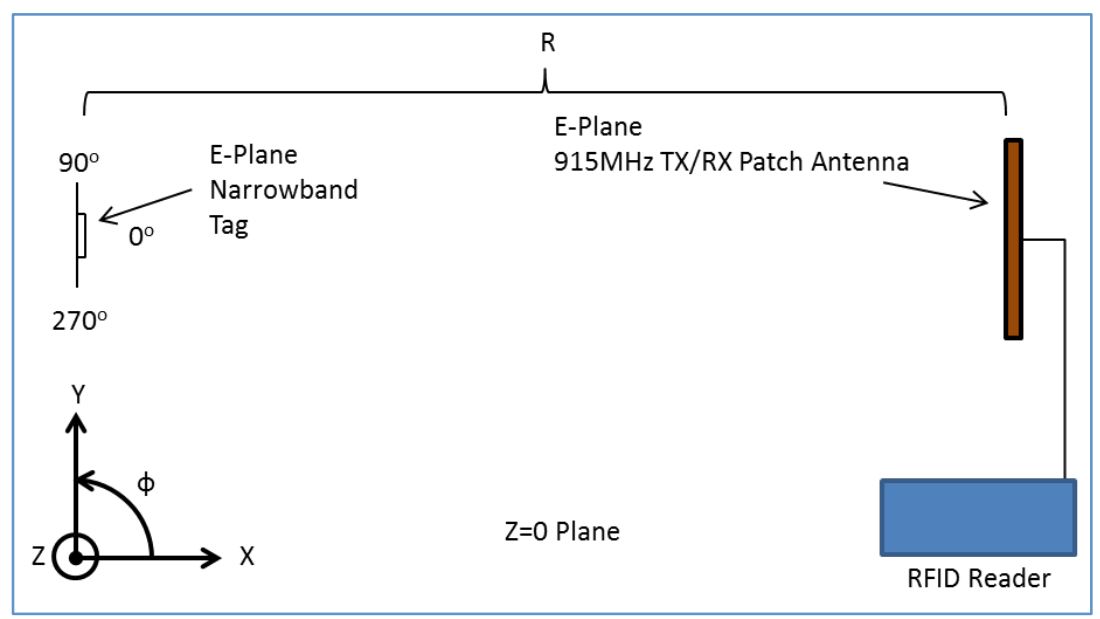

Figure 5-14: RFID Tag Range Testing Setup, E-Plane aligned with $\mathrm{f}$

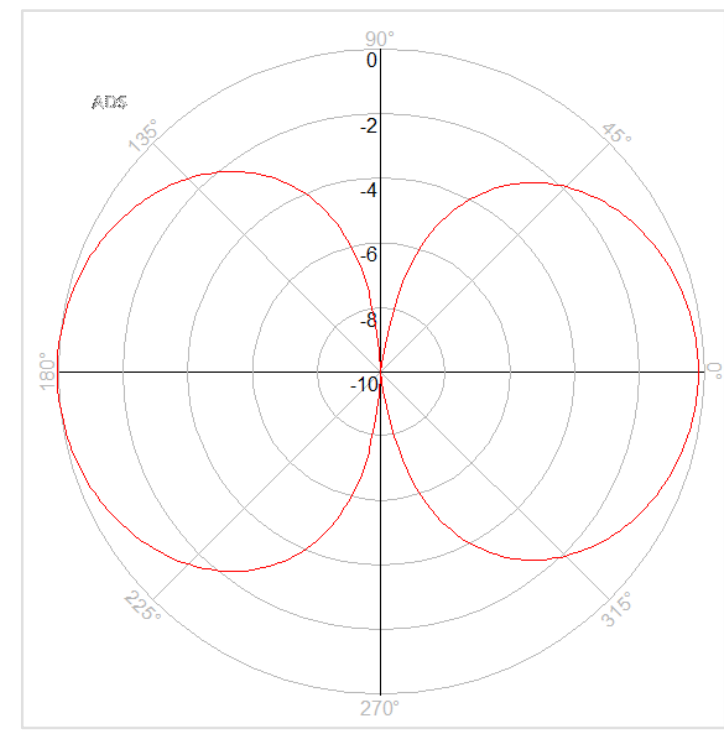

Figure 5-15: Simulated Narrowband 915MHz Antenna E-Field Pattern (f) in dB 
Table 5-2: Narrowband Antenna Range Testing Conditions at $915 \mathrm{MHz}^{*}$

\begin{tabular}{|c|c|c|}
\hline \multicolumn{3}{|c|}{$\begin{array}{c}\text { Narrowband Antenna Range } \\
\text { Testing Conditions at 915 MHz }\end{array}$} \\
\hline \hline$R$ & 4.0 & $\mathrm{~m}$ \\
\hline $\mathrm{P}_{\mathrm{R}}$ & -18.5 & $\mathrm{dBm}$ \\
\hline $\mathrm{G}_{\mathrm{T}}$ & 9.1 & $\mathrm{~dB}$ \\
\hline $\mathrm{L}$ & 1.1 & $\mathrm{~dB}$ \\
\hline $\mathrm{G}_{\mathrm{R}}$ & 1.6 & $\mathrm{~dB}$ \\
\hline$\Gamma_{\mathrm{T}}$ & -30 & $\mathrm{~dB}$ \\
\hline$\lambda$ & 0.328 & $\mathrm{~m}$ \\
\hline \multicolumn{3}{|c|}{${ }^{*} \mathrm{~S}_{\mathrm{r}}\left(\left|\mathrm{S}_{11}\right|\right)$ listed in Table 5-3 }
\end{tabular}

Tag transmit distance is evaluated by decreasing transmit power $\mathrm{P}_{\mathrm{T}}$ until the reader no longer communicates with the tag. The reader frequency hops every $0.4 \mathrm{~ms}$ within the $902 \mathrm{MHz}-928 \mathrm{MHz}$ band; the minimum power required for a read is not necessarily at the center frequency. The three length $I_{S}$ antennas are range tested. $R_{F R I I S}$ is the Friis Equation predicted antenna transmit distance with measured $\mathrm{s}_{\mathrm{r}}$ and reader transmit power $\mathrm{P}_{\mathrm{T}}$. Range testing results are shown in Table 5-3. The $\mathrm{I}_{\mathrm{S}}=18.0 \mathrm{~mm}$ antenna correlates most closely to $R_{F R I I S}$ and requires the least amount of power for a read.

Table 5-3: Narrowband Antenna/ Higgs-4 RFIC Range

\begin{tabular}{|c|c|c|c|c|}
\hline \multicolumn{5}{|c|}{ Narrowband Antenna/Higgs-4 RFIC Read Range } \\
\hline \hline $\mathrm{I}_{\mathrm{S}}(\mathrm{mm})$ & $\mathrm{P}_{\mathrm{T}}(\mathrm{dBm})$ & $\left|\mathrm{S}_{11}\right|(\mathrm{dB})$ & $\mathrm{R}_{\mathrm{FRIIS}}(\mathrm{m})$ & $\begin{array}{c}\mathrm{R}_{\mathrm{FR} I I S}-\mathrm{R} \\
(\mathrm{m})\end{array}$ \\
\hline 18.0 & 16.6 & -11.3 & 4.3 & 0.3 \\
\hline 18.5 & 16.7 & -17.4 & 4.5 & 0.5 \\
\hline 19.5 & 18.0 & -10.0 & 5.0 & 1.0 \\
\hline
\end{tabular}

\section{3: Broadband $865-955 \mathrm{MHz}$ Design, Measurement and Range Testing}

The broadband match procedure, discussed in Section 3.4, overlays antenna input impedance on the RFIC's complex conjugate impedance for a best fit over the 865$955 \mathrm{MHz}$ band (shown for Impinj's Monza-4 IC load in Figure 5-16 and 5-17). The matching technique yields the broadband $\left|S_{11}\right|$ simulated response in Figure 5-18. 


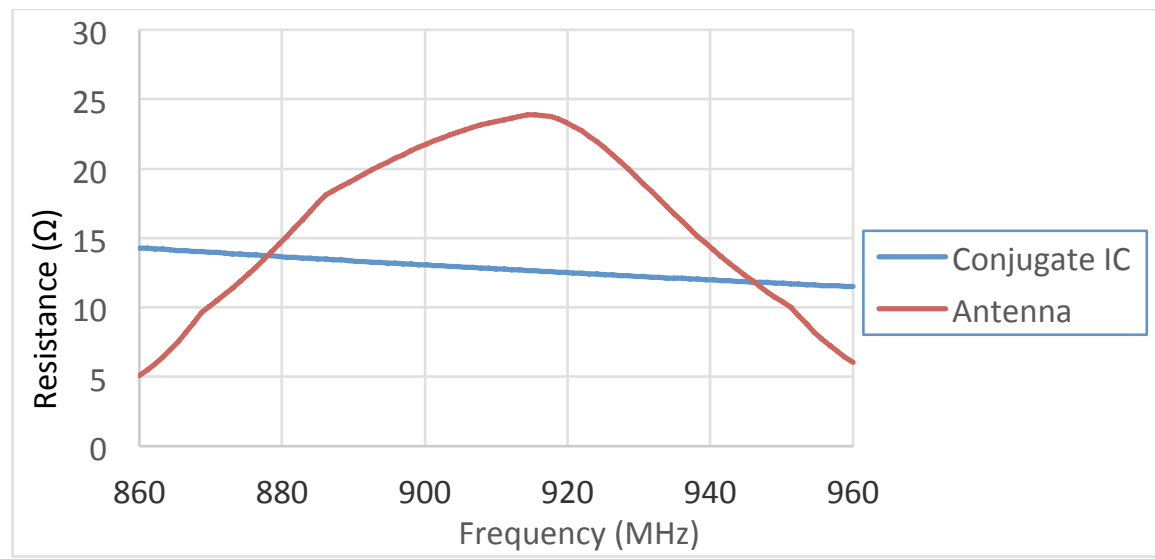

Figure 5-16: Broadband Simulated Input Resistance $(\Omega)$ vs. Frequency $(\mathrm{MHz})$

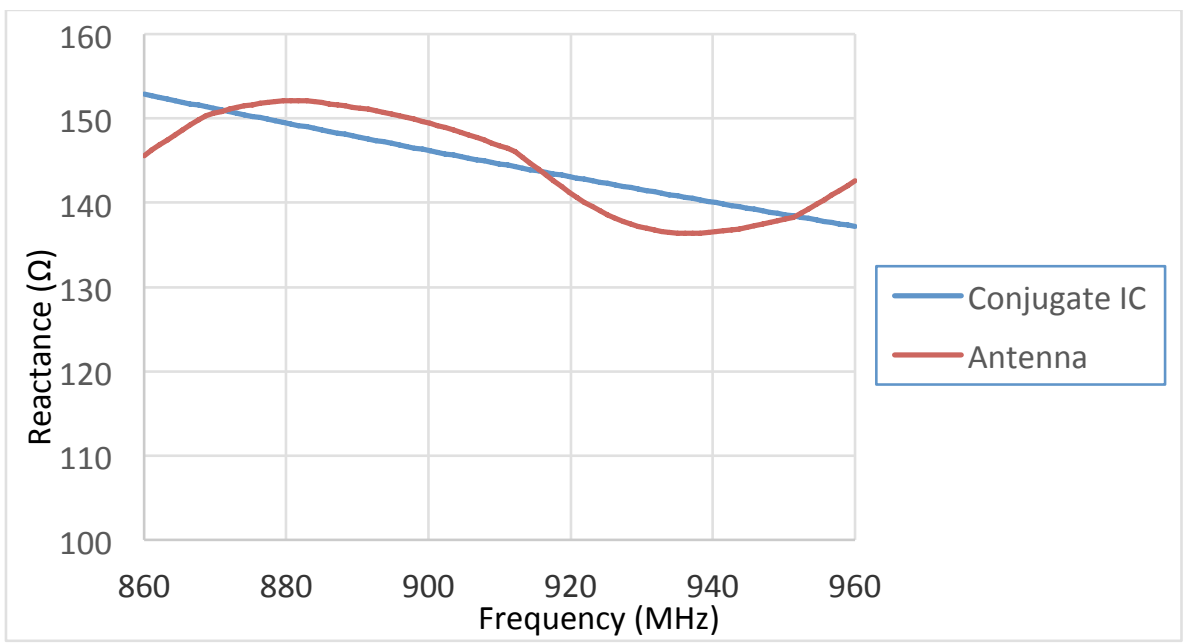

Figure 5-17: Broadband Simulated Reactance $(\Omega)$ vs. Frequency $(\mathrm{MHz})$

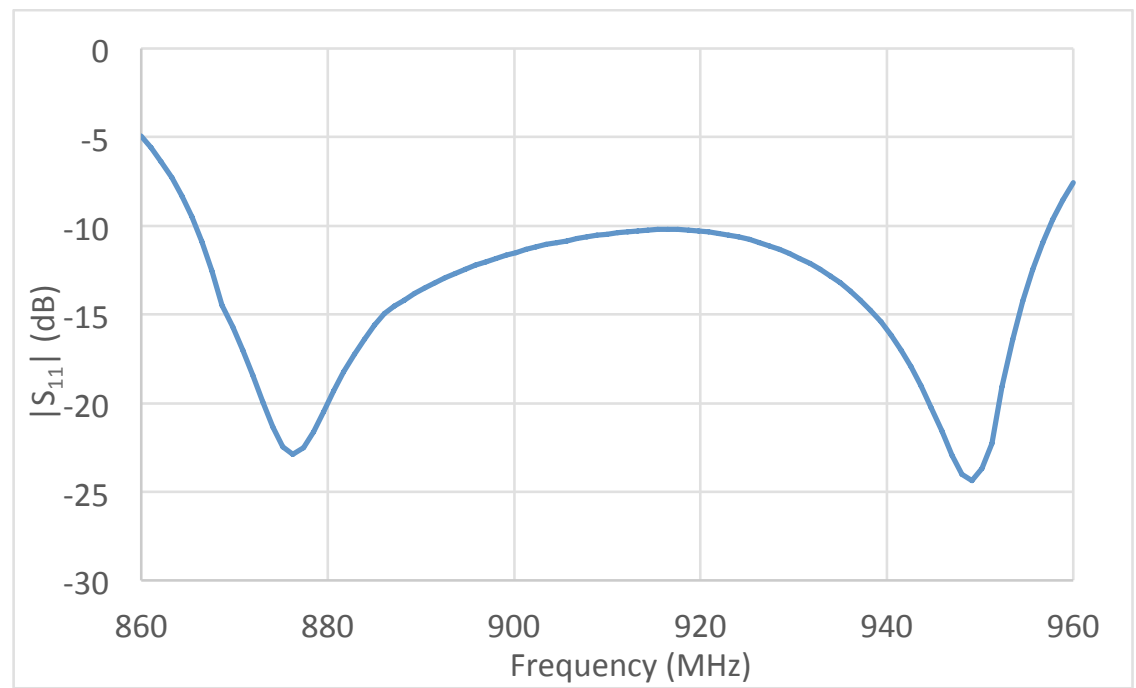

Figure 5-18: Broadband Simulated $\left|\mathrm{S}_{11}\right|(\mathrm{dB})$ vs. Frequency $(\mathrm{MHz})$

Following the Section 3.4 broadband matching procedure, a 14 element meander, $s=9.0 \mathrm{~cm}$ length antenna layout is designed (Figure 5-19) to match across the $865 \mathrm{MHz}-$ 
$955 \mathrm{MHz}$ band. The band's center frequency is $910 \mathrm{MHz}$. Antenna geometry defined in Table 5-4. Simulated antenna impedance is shown in Figure 5-20 and 5-21.

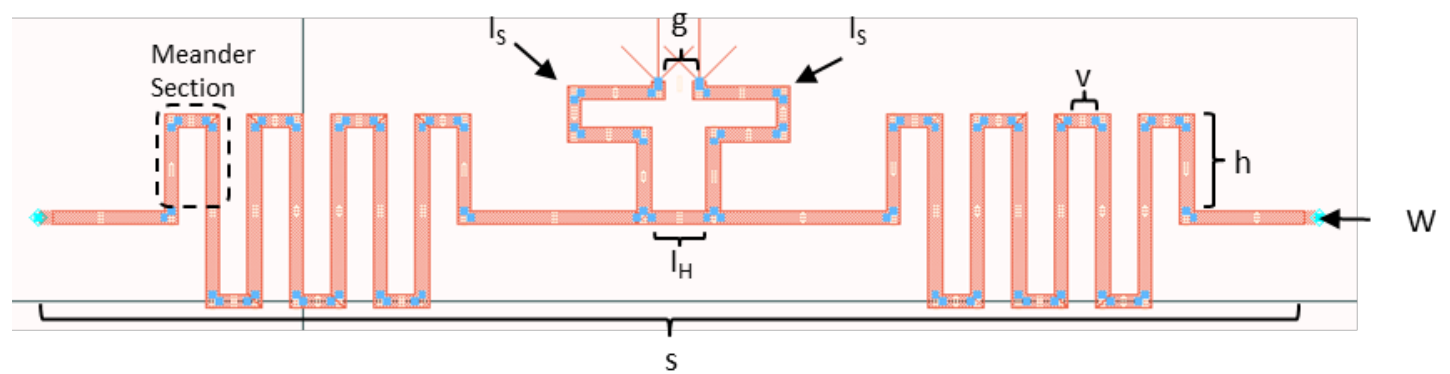

Figure 5-19: Broadband MLA Antenna Design

Table 5-4: Broadband Antenna Dimensions

\begin{tabular}{|c|c|}
\hline \multicolumn{2}{|c|}{$\begin{array}{c}\text { Broadband Antenna } \\
\text { Dimensions }\end{array}$} \\
\hline Conductor Width (W) & $1.1 \mathrm{~mm}$ \\
\hline Antenna Length (s) & $90.0 \mathrm{~mm}$ \\
\hline Meander Sections (M) & 14 \\
\hline Meander Spacing (v) & $2.0 \mathrm{~mm}$ \\
\hline Meander Height (h) & $6.0 \mathrm{~mm}$ \\
\hline Strap Gap (g) & $2.3 \mathrm{~mm}$ \\
\hline Shunt Inductor (IH) & $5.0 \mathrm{~mm}$ \\
\hline Series Inductors (Is) & $17.0 \mathrm{~mm}$ \\
\hline
\end{tabular}

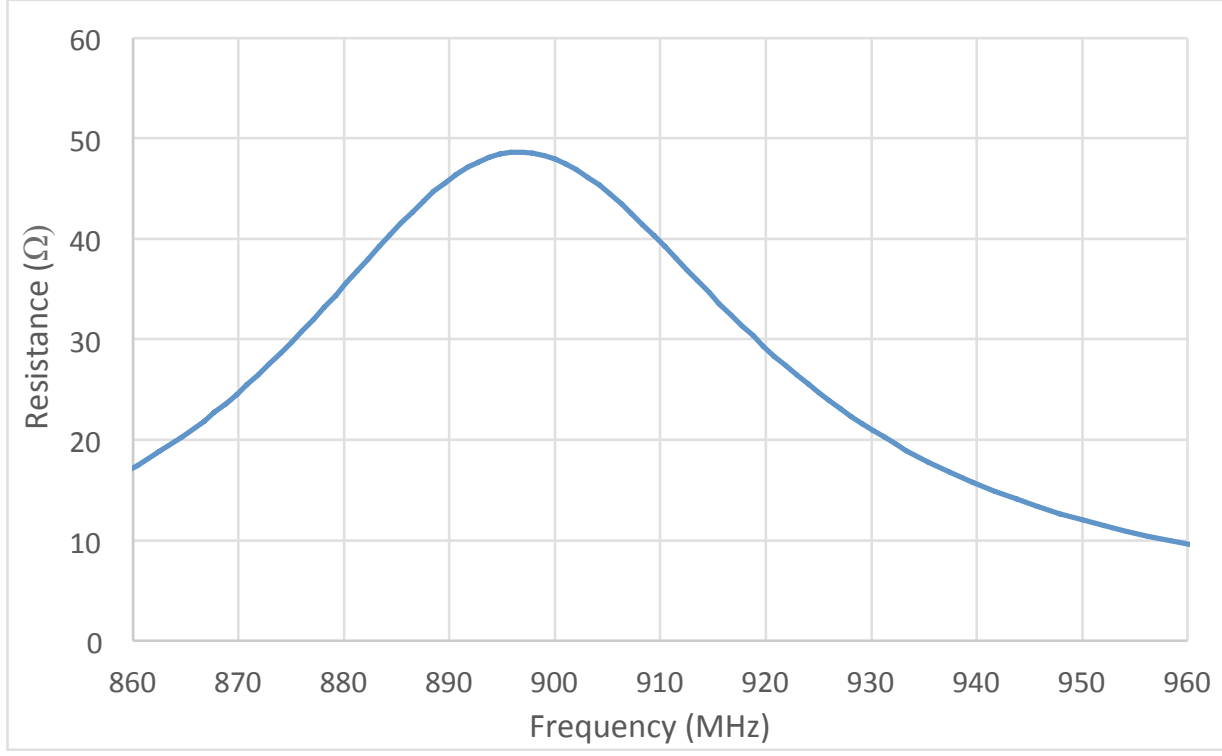

Figure 5-20: Calculated Broadband Input Resistance $(\Omega)$ vs. Frequency $(\mathrm{MHz})$ 


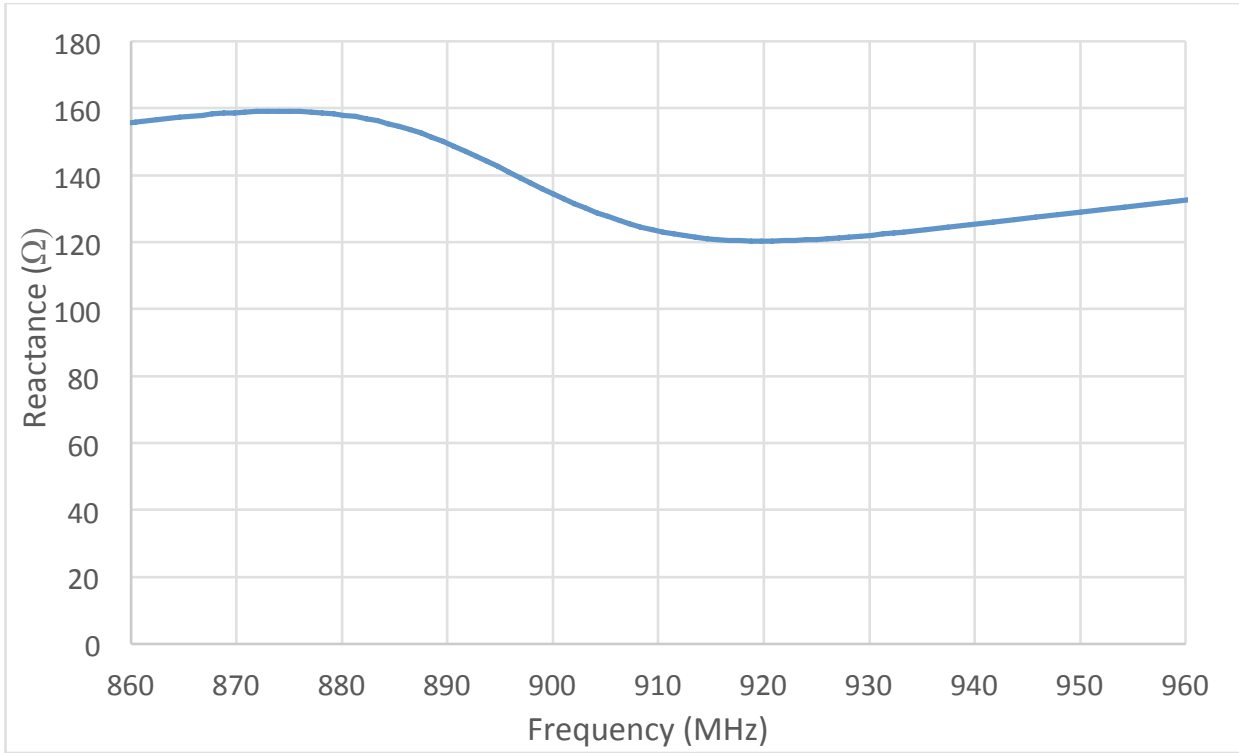

Figure 5-21: Calculated Broadband Input Reactance $(\Omega)$ vs. Frequency $(\mathrm{MHz})$

The simulated resistance maxima occurs at $898 \mathrm{MHz}$, which is $12 \mathrm{MHz}$ less than the center frequency. Simulated reactance is also $40 \Omega$ lower across the band than the conjugate Higgs-4 reactance. The antenna is shortened to $s=8.6 \mathrm{~cm}$ to center the resistance maxima at $910 \mathrm{MHz}$. The shunt inductor is shortened to $4 \mathrm{~mm}$, reducing peak resistance (discussed in Section 5.4). Series inductors $\left(I_{\mathrm{S}}\right)$ are lengthened in $1 \mathrm{~mm}$ steps to $22-24 \mathrm{~mm}$, to increase series inductance. Simulated impedance results are shown in Figure 5-22 and 5-23. The series inductance does not affect peak resistance but increases reactance $9 \Omega / \mathrm{mm}$. 


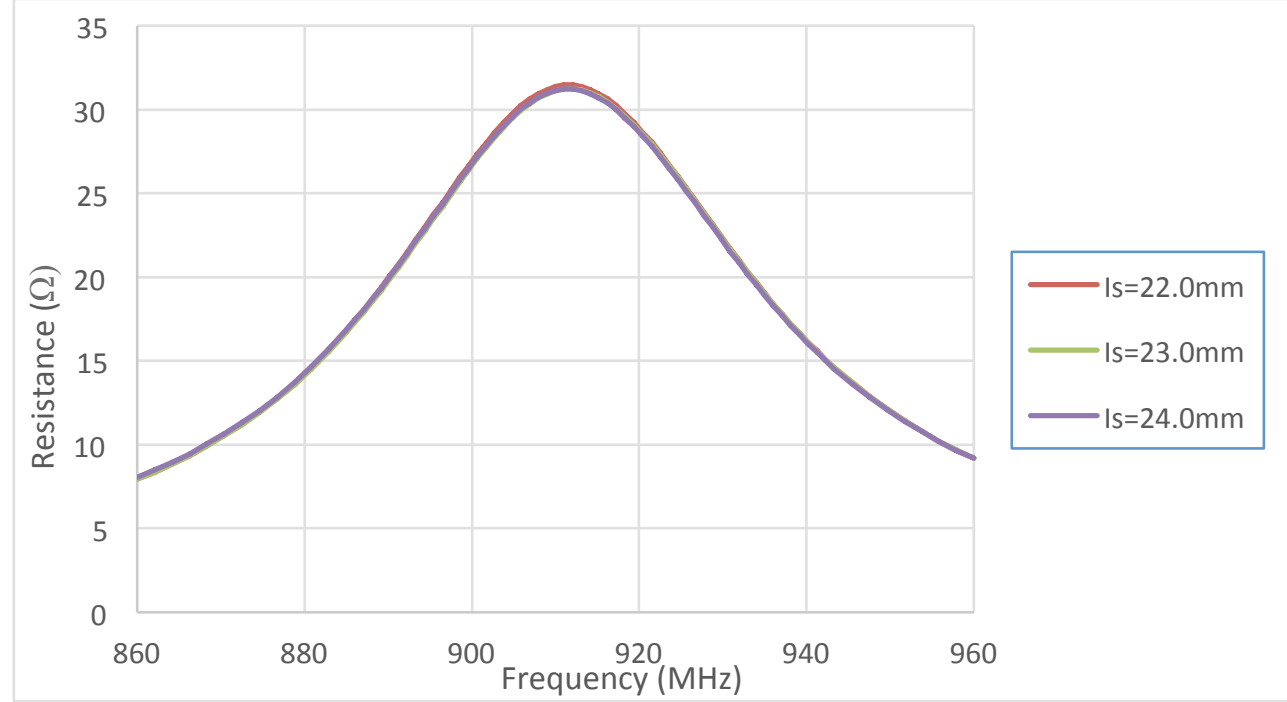

Figure 5-22: Simulated Broadband Input Resistance $(\Omega)$ vs. Frequency $(\mathrm{MHz})$

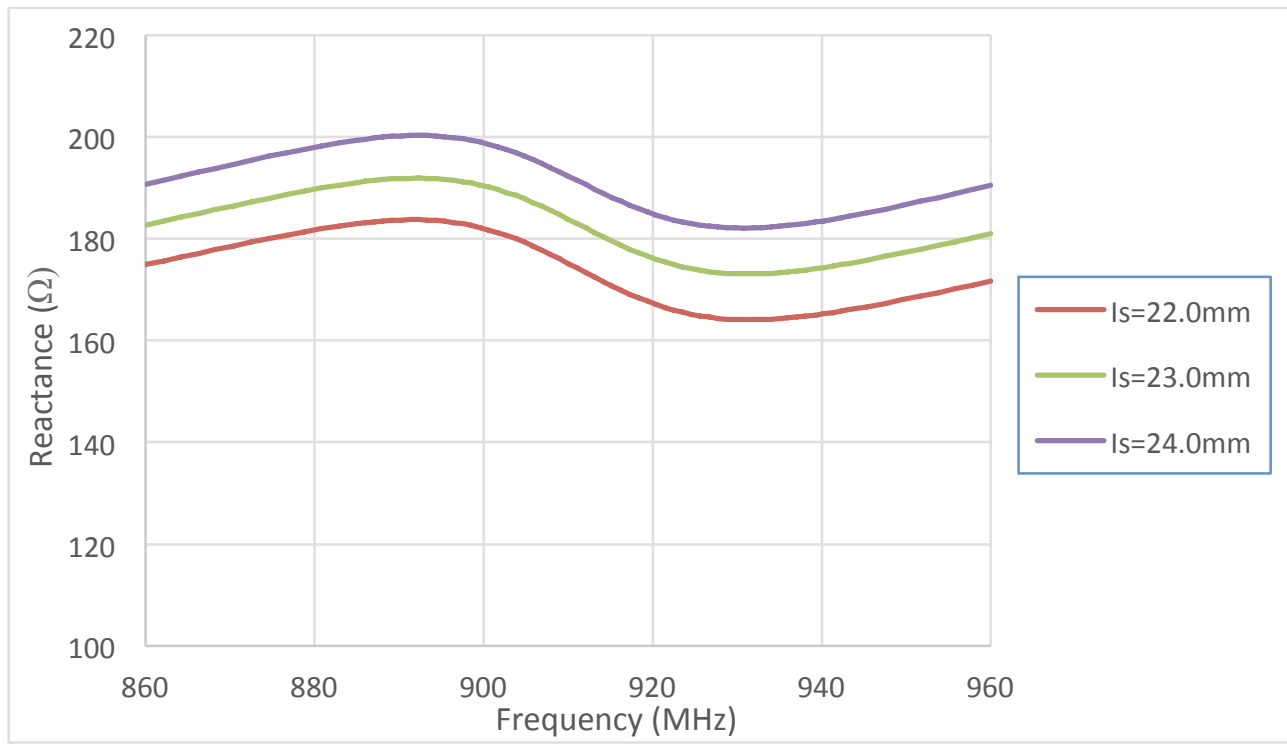

Figure 5-23: Simulated Broadband Input Reactance $(\Omega)$ vs. Frequency $(\mathrm{MHz})$

Input impedances for three fixed antennas with increased $I_{S}$ lengths are shown in Figure 5-24 and 5-25. The peak resistance for simulated and measured antennas both occur at $910 \mathrm{MHz}$. Simulated resistance is $5-7 \Omega$ greater than measured resistance and simulated reactance is $4 \Omega$ greater than measured reactance at $910 \mathrm{MHz}$. Simulated reactance variance over the band is $18 \Omega$ but only $7 \Omega$ across the measured band. 


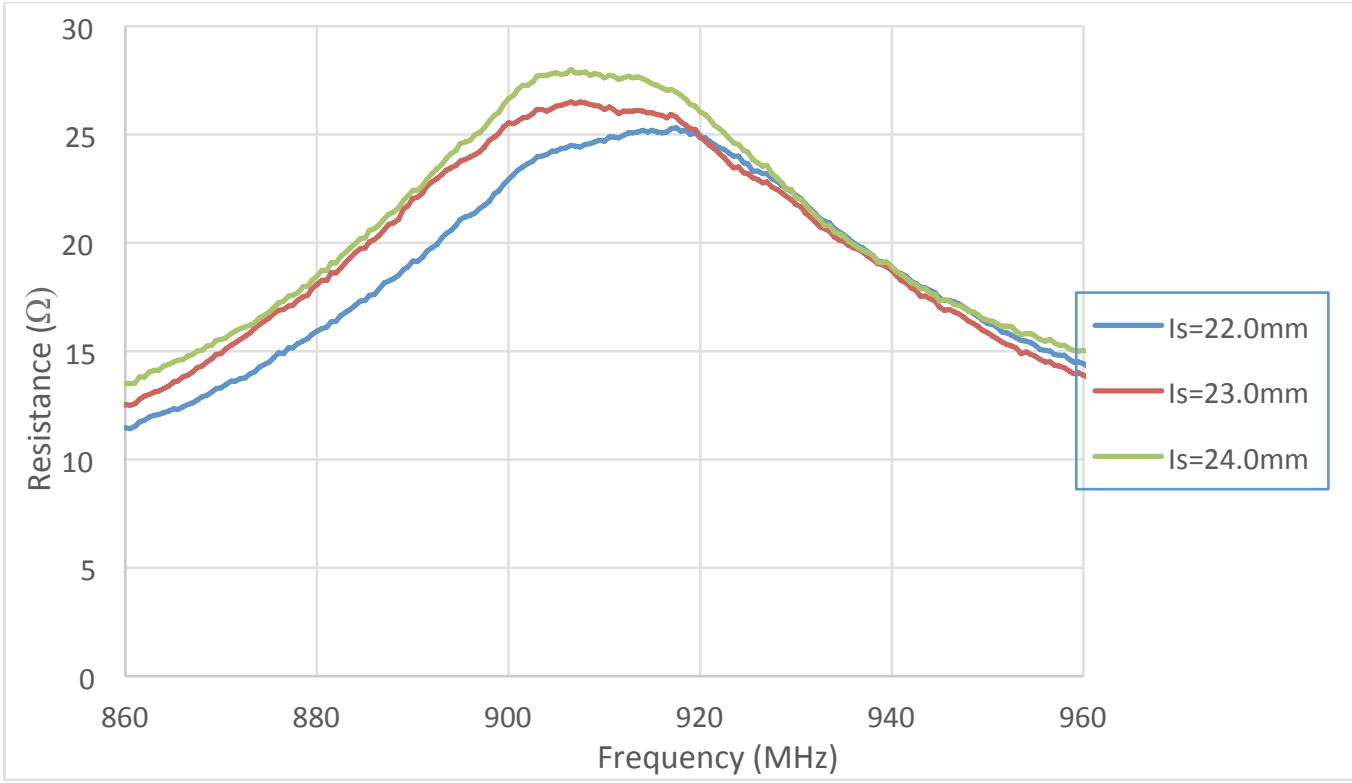

Figure 5-24: Measured Broadband Feed Input Resistance $(\Omega)$ vs. Frequency $(\mathrm{MHz})$

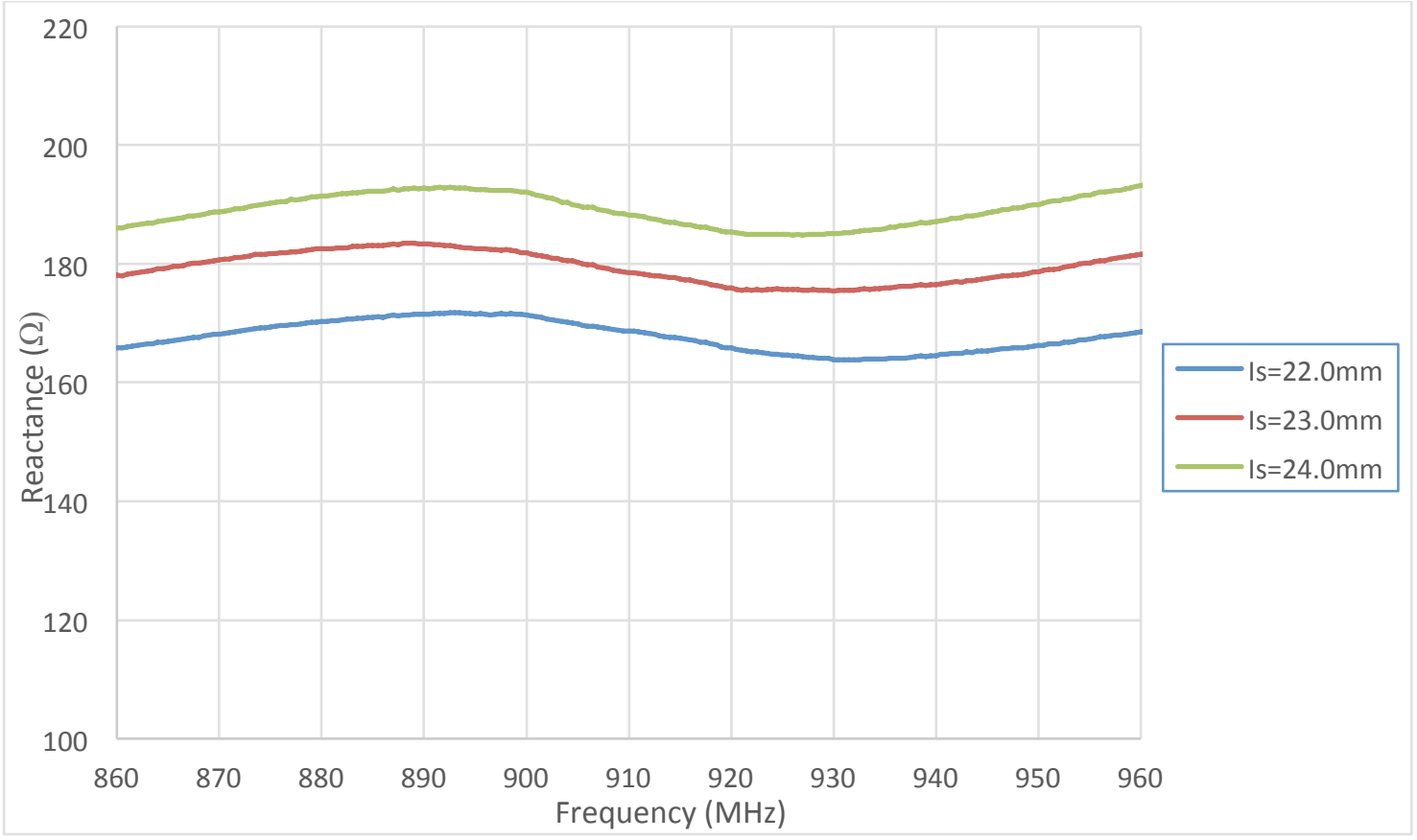

Figure 5-25: Measured Broadband Feed Input Reactance $(\Omega)$ vs. Frequency (MHz) 


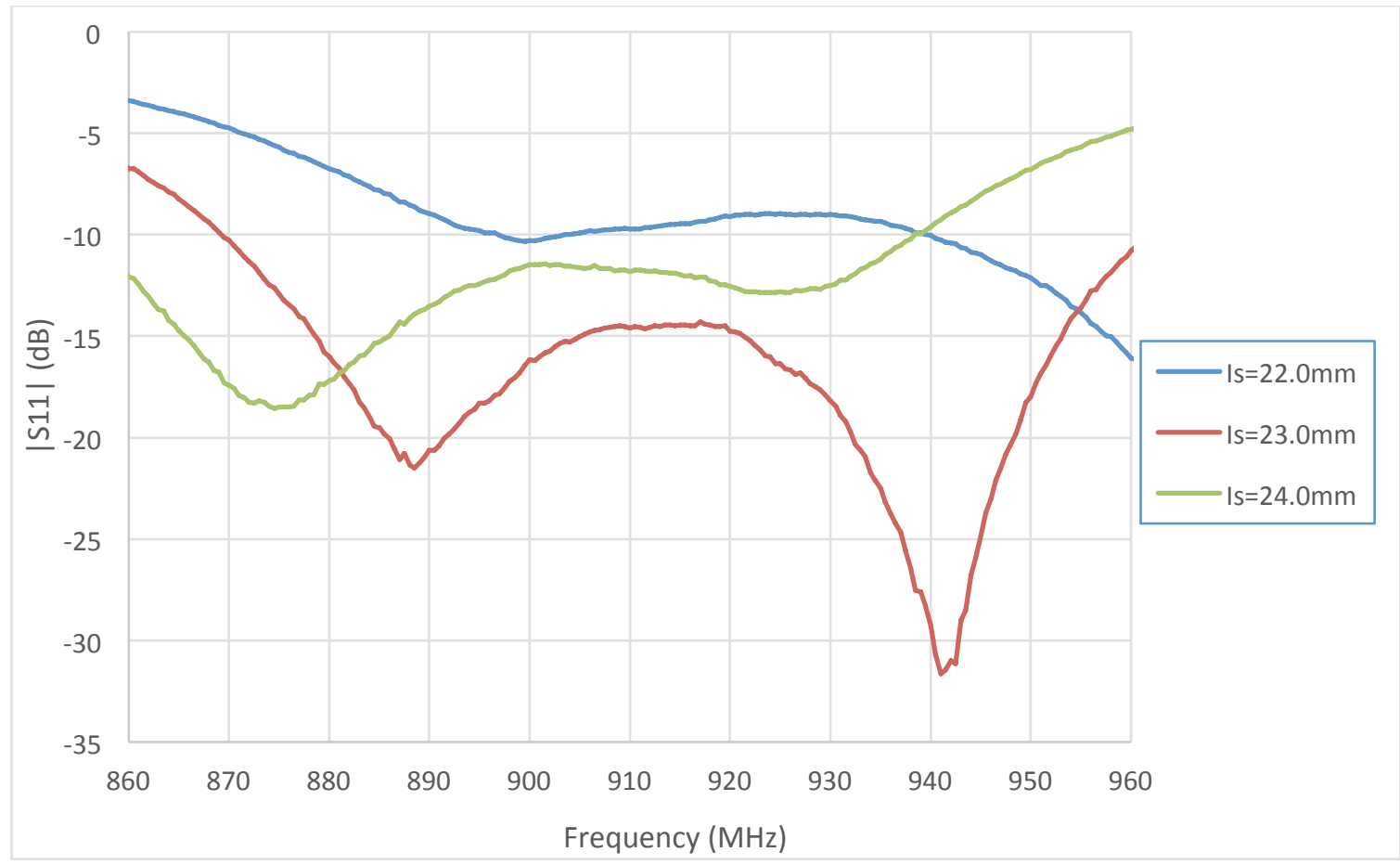

Figure 5-26: Measured Broadband Feed $\left|\mathrm{S}_{11}\right|(\mathrm{dB})$ vs. Frequency $(\mathrm{MHz})$

Conjugate match reflection parameters are shown in Figure 5-26. The broadband antennas are shorter than the narrowband antennas; hence, have decreased radiation resistance and gain. ADS simulation predicts a $1.0 \mathrm{~dB}$ broadband antenna receive gain $\mathrm{G}_{\mathrm{R}}$. Range testing parameters are listed in Table 5-5. Range testing results are shown Table 5-6. The $I_{S}=22 \mathrm{~mm}$ antenna performed the best and is closest to the predictive value. 


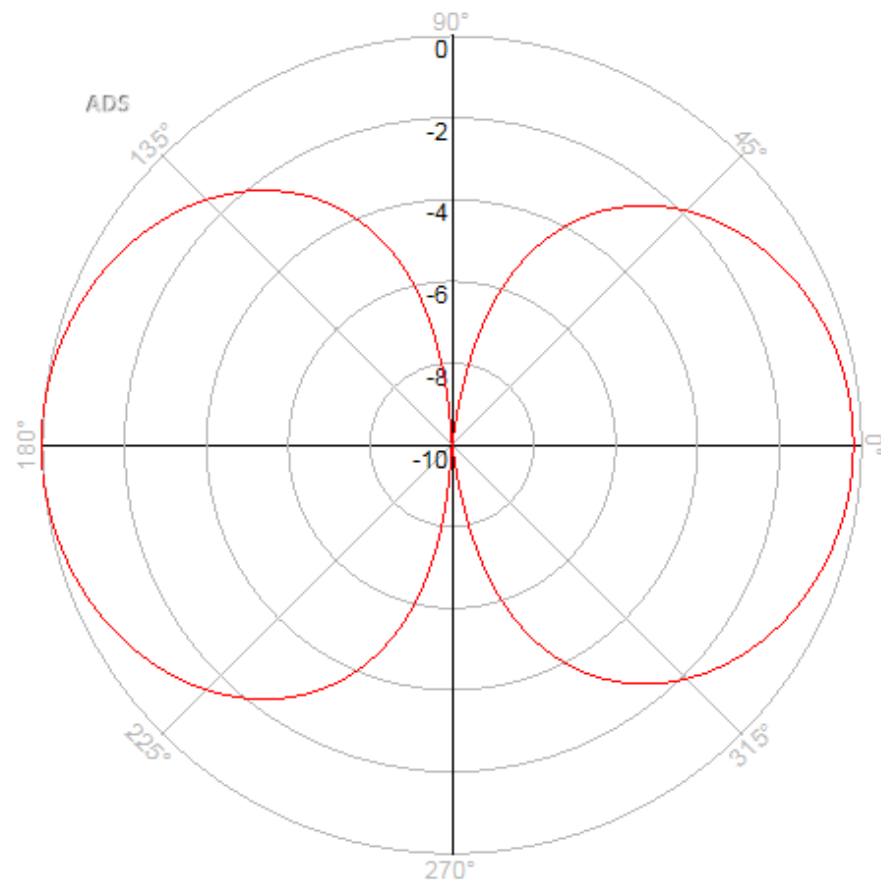

Figure 5-27: $915 \mathrm{MHz}$ Simulated Broadband Antenna E-Field Pattern $(\phi)$ in dB

Table 5-5: Broadband Antenna Range Test Conditions at $910 \mathrm{MHz}$

\begin{tabular}{|c|c|c|}
\hline \multicolumn{3}{|c|}{$\begin{array}{c}\text { Broadband Antenna Range } \\
\text { Testing Conditions at } \\
\text { 910MHz* }\end{array}$} \\
\hline \hline$R$ & 4.0 & $\mathrm{~m}$ \\
\hline $\mathrm{P}_{\mathrm{R}}$ & -18.5 & $\mathrm{dBm}$ \\
\hline $\mathrm{G}_{\mathrm{T}}$ & 9.1 & $\mathrm{~dB}$ \\
\hline $\mathrm{L}$ & 1.1 & $\mathrm{~dB}$ \\
\hline $\mathrm{G}_{\mathrm{R}}$ & 1.0 & $\mathrm{~dB}$ \\
\hline$\Gamma_{\mathrm{T}}$ & -30 & $\mathrm{~dB}$ \\
\hline$\lambda$ & 0.328 & $\mathrm{~m}$ \\
\hline \multicolumn{2}{|c|}{${ }^{*} \mathrm{~S}_{\mathrm{r}}\left(\left|\mathrm{S}_{11}\right|\right)$ values listed in Table 5-6 }
\end{tabular}

Table 5-6: Broadband Antenna/RFIC Range Read Range

\begin{tabular}{|c|c|c|c|c|}
\hline \multicolumn{5}{|c|}{ Broadband Antenna/Higgs-4 IC Range } \\
\hline \hline $\mathrm{I}_{\mathrm{S}}(\mathrm{mm})$ & $\mathrm{P}_{\mathrm{T}}(\mathrm{dBm})$ & $\left|\mathrm{S}_{11}\right|(\mathrm{dB})$ & $\mathrm{R}_{\mathrm{FRIIS}}(\mathrm{m})$ & $\mathrm{R}_{\mathrm{FRIIS}}-\mathrm{R}(\mathrm{m})$ \\
\hline 22.0 & 16.8 & -9.5 & 4.0 & 0.0 \\
\hline 23.0 & 17.0 & -14.5 & 4.3 & 0.3 \\
\hline 24.0 & 18.1 & -12.0 & 5.0 & 0.8 \\
\hline
\end{tabular}

For simulations, the silkscreened silver ink vertical thickness theoretical approximation is $1 \mathrm{mil}$ based on silk-screen mesh and emulsion used. Sheet resistivity is $12-$ 
$15 \mathrm{~m} \Omega / \mathrm{sq} / \mathrm{mil}$; exact values are affected by antenna curing temperature. Also, the conductor's surface roughness is not specified in the product datasheet. Adding a surface roughness parameter to the simulation reduces both the simulation's resistance peaking and reactance variance over the band.

\section{4: Narrowband vs. Broadband Frequency Response}

Narrow and broadband antennas have similar structures but distinct shunt inductor length $I_{H}$ and antenna length $s$. Antenna frequency responses with varied shunt inductor lengths $I_{H}$ are plotted (Figure 5-28 and 5-29) to illustrate input impedance effects. Series inductor length $I_{S}$ remains constant. Lengthening $I_{H}$ increases antenna reactance and maximum resistance across the band. It also increases reactance variance vs. frequency. The narrowband antenna uses a large shunt inductor $\left(\mathrm{I}_{\mathrm{H}}=18.0 \mathrm{~mm}\right)$ to adjust the resistance peak's falling edge to match the RFIC input impedance at the center frequency. The broadband design uses a short shunt inductor $\left(\mathrm{I}_{\mathrm{H}}=4 \mathrm{~mm}\right)$ to compress the resistance peak and minimize reactance frequency response ripple. The broadband design dipole length must be decreased to center the resistance peak at the center frequency. Decreasing antenna length reduces gain; hence, bandwidth is exchanged for increased transmit range. This is an acceptable trade-off for RFIC applications; reducing gain yields a more omni-directional antenna. Also, commercially viable antennas are often restricted to small $(s<10 \mathrm{~cm})$ package sizes. 


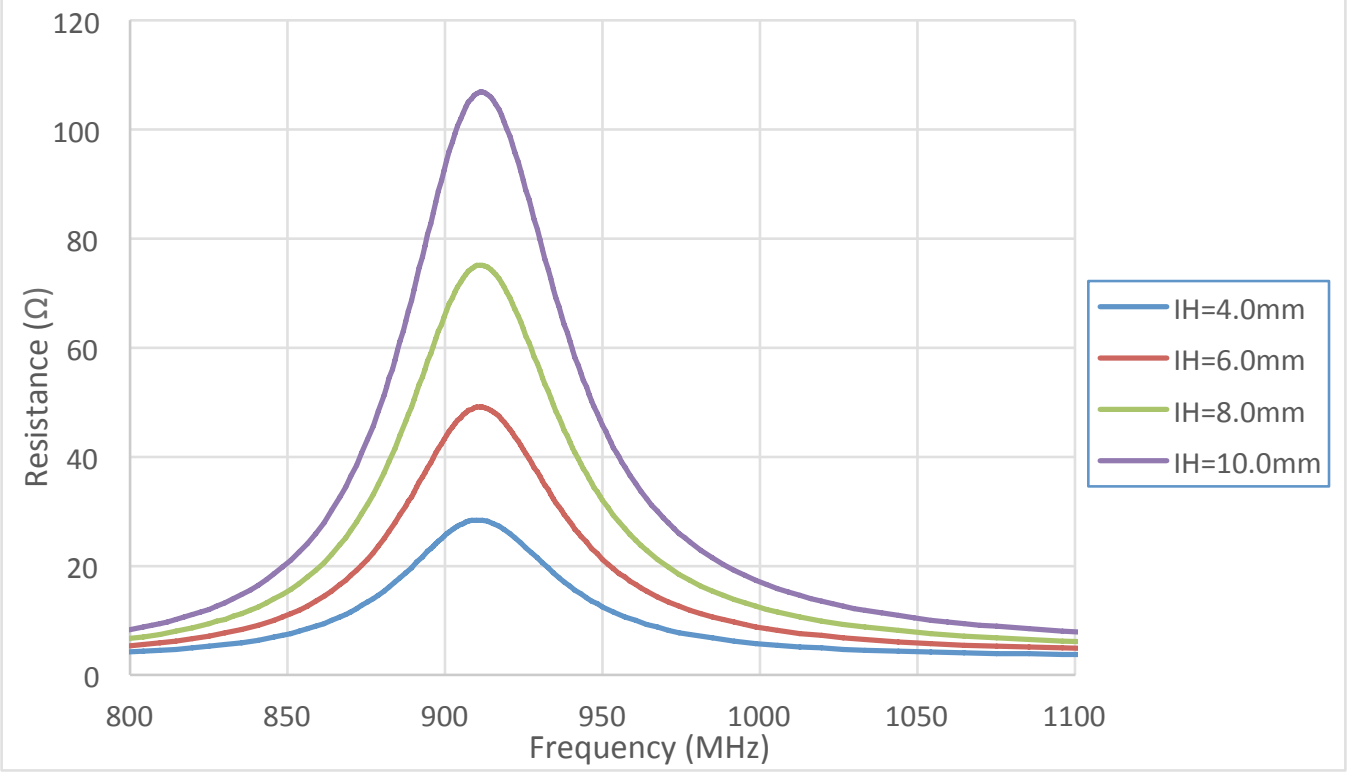

Figure 5-28: Simulated Antenna Resistance $(\Omega)$ vs. Frequency $(\mathrm{MHz})$ for Varying Shunt Inductor $\mathrm{I}_{\mathrm{H}}$ Lengths

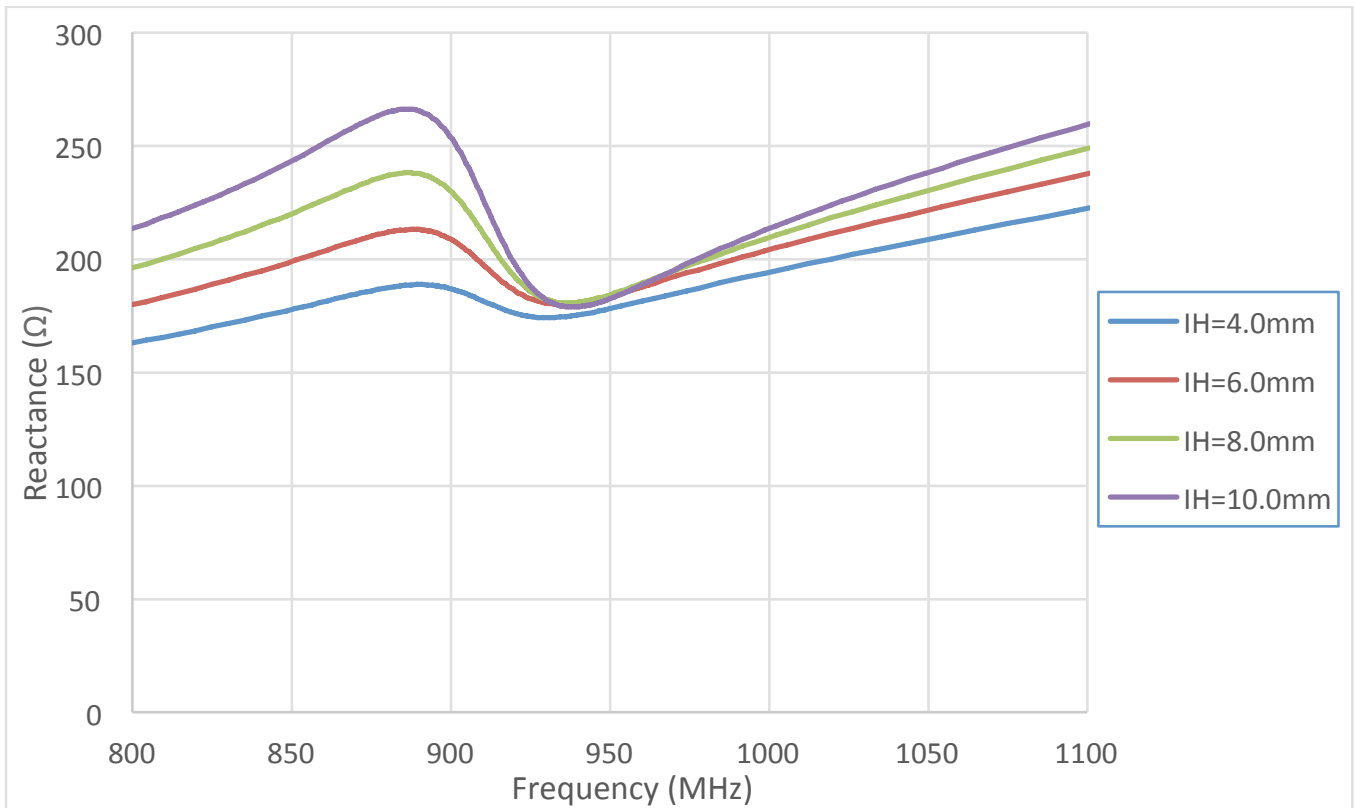

Figure 5-29: Simulated Antenna Resistance $(\Omega)$ vs. Frequency $(\mathrm{MHz})$ for Varying Shunt Inductor $\mathrm{I}_{\mathrm{H}}$ Lengths 


\section{5: Conclusion}

This thesis demonstrates a start-to-finish design process for narrow and broadband planar RFID antennas and illustrates element sizing effects on antenna input impedance. The narrow and broadband antenna's input impedances are conjugate matched to a passive RFIC load (Alien Technology's Higgs-4) to maximize RFID tag transmit range. Antenna designs are simulated and refined in Keysight's Advanced Design System (ADS) Momentum electro-magnetic simulator, and then silk-screened at Cal Poly's Graphic Communication Department. Input impedance is measured differentially with a two-port method on a Vector Network Analyzer (VNA) to maximize bandwidth over a 1-port narrowband balun measurement. Antenna impedances are manually tuned by adjusting element dimensions. Impedance simulations, fabricated antenna impedance measurements and range testing results are compared for accuracy.

Antenna element sizes are parametrically swept to demonstrate effects on input impedance. Lengthening series inductor $I_{S}$ increases input reactance and has minimal effects on input resistance. Lengthening shunt inductor $I_{H}$ increases the input resistance peak and increases input reactance ripple over the band. Lengthening dipole length increases input resistance and reactance. The broadband dipole antenna has a short shunt inductor $\left(I_{H}<5 \mathrm{~mm}\right)$ to set the antenna's input resistance peak at the RFIC input resistance level and to limit the antenna's input reactance ripple. Inductor Is length is then adjusted to conjugate match the RFIC input reactance. The broadband dipole length is set to approximately a quarter wave-length to center the resistance peak at center frequency. Dipole gain is largest at a half wave-length, and decreases when shortened. A broadband antenna can match over the GS1 EPC ${ }^{\mathrm{TM}}$ Global Gen2 $860 \mathrm{MHz}-960 \mathrm{MHz}$ band; however, gain and range are reduced. The narrowband antenna can match only over the ISM $902 \mathrm{MHz}-928 \mathrm{MHz}$ band but also exhibits increased length, gain, and read range. 


\section{BIBLIOGRAPHY}

[1] G. Gonzalez, Microwave Transistor Amplifiers: Analysis and Design, Upper Saddle River, NJ.: Prentice Hall, 1997.

[2] S. Uda and Y. Mushiake, Yagi-Uda Antenna, Sendai, Japan: Research Institute of Electrical Communication, Tohoku University, 1954.

[3] D. Deavours, "Analysis and Design of Wideband Passive UHF RFID Tags Using a Circuit Model," IEEE International Conference on RFID, pp. 283-290, 2009.

[4] J. O. Sophocles, Electromagnetic Waves and Antennas, Piscataway, NJ: Rutgers University, 2008.

[5] P. Cole, Z. Hu and Y. Wang, "Operating Range Evaluation of RFID Systems," in Advanced Radio Frequency Identification Design and Applications, Intech, 2011.

[6] P. Penfield, "Noise in negative resistance amplifiers," IEEE Trans. Circuit Theory, Vols. CT-7, no. 2, pp. 166-170, 1960.

[7] "Monza 4 Datasheet," Impinj, Seattle, WA, 2014.

[8] "Higgs 3 IC Datasheet," Alien Technology, Morgan Hill, CA, 2014.

[9] "Higgs 4 IC Datasheet," Alien Technology, Morgan Hill, CA, 2012.

[10] "The Global Language of Business," 4 July 2016. [Online]. Available: http://www.gs1.org/docs/epc/UHF_Regulations.pdf.

[11] R. Hansen, "Folded and T-Match Dipole Transformation Ratio," IEEE Trans. Antenna Propagat., Vols. AP-30, no. 1, pp. 161-162, 1982.

[12] W. Smythe, Static and Dynamic Electricity, New York: McGraw-Hill Book Company, Inc., 1950.

[13] R. W. Lampe, "Design Formulas for an Asymmetrical, Coplanar Strip, Folded Dipole," IEEE Trans. Antenna Propagat., Vols. Ap-33, no. 9, pp. 1028-1031, 1985.

[14] K. Demarest, "Limitations of the Uda Model for T-Match Antennas," Progress In Electromagnetics Research, vol. 113, pp. 1-15, 2011. 
[15] M. T. Reich and C. Bauer-Reich, "UHF RFID Impedance Matching: When is a TMatch Not a T-Match?," in IEEE International Conference on RFID, Orlando, 2014.

[16] D. Deavours, "Analysis and Design of Wideband Passive UHF RFID Tags Using a Circuit Model," in IEEE International Conference on RFID, 2009.

[17] D. M. Dobkins, The RF in RFID: UHF RFID in Practice, Burlington, MA: Newnes, 2007.

[18] M. Hamid and R. Hamid, "Equivalent Circuit of Dipole Antenna of Arbitrary Length," IEEE Trans. Antennas Propogat., vol. 45, no. 11, pp. 1695-1696, 1997.

[19] D. Miron, Small Antenna Design, Burlington, MA: Elsevier, Inc., 2006.

[20] C. A. Balanis, Antenna Theory: Analysis and Design, 3rd Edition, Hoboken, NJ: Wiley-Interscience, 2005.

[21] D. Deavours and D. Dobkin, "UHF Passive RFID Tag Antennas," in Microstrip and Printed Antennas: New Trends, Techniques and Applications, John Wiley \& Sons, Ltd., 2010, pp. 263-303.

[22] A. Yaghjian and S. Best, "Impedance, Bandwidth, and Q of Antennas," IEEE Trans. on Antennas and Propagat., vol. 53, no. 4, pp. 1298-1324, 2005.

[23] T. Endo, Y. Sunahara, S. Satoh and T. Katagi, "Resonant Frequency and Radiation Efficiency of Meander Line Antennas," Electronics and Communications in Japan, Part 2, vol. 83, no. 1, pp. 52-58, 2000.

[24] X. Hu, P. Cole and L. Zhang, "A Method for Calculating the Resonant Frequency of Meander-line Dipole Antenna," in IEEE Conference on Industrial Electronics and Applications, Xi'an, China, 2009.

[25] W. L. Stutzman and G. Thiele, Antenna Theory and Design, Third Edition, Hoboken, NJ: Wiley, 2013.

[26] G. Breed, "The Fundamentals of Patch Antenna Design and Performance," High Frequency Electronics, pp. 48-51, March 2009.

[27] R. Meys and F. Janssens, "Measuring the Impedance of Balanced Antennas by an S-Parameter Method," IEEE Antennas Propagat. Magazine, vol. 40, no. 6, pp. 6265, 1998. 
[28] P. Nikitin, S. Rao, R. Martinez and S. Lam, "Sensitivity and Impedance Measurements," IEEE Trans. Microwave Theory and Techniques, vol. 57, no. 5, pp. 1297-1302, 2009.

[29] T. Björninen, M. Lauri, L. Ukkonen, R. Ritala, A. Elsherbeni and L. Sydänheimo, "Wireless Measurement of RFID IC Impedance," IEEE Trans. Instrumentation and Measurement, vol. 60, no. 9, pp. 9194-3206, 2011.

[30] N. L. Rao, "Antenna Design for UHF RFID Tags: A Review and a Practical Application," IEEE Trans. Antennas Propagat., vol. 53, no. 12, pp. 3870-3876, Decemeber 2005.

[31] B. C. Wadell, Transmission Line Design Handbook, Boston, Massachusetts: Artech House, 1991.

[32] M. Iskander, Electromagnetic Fields and Waves, Long Grove, Illinois: Waveland Press, Inc., 2013. 


\section{APPENDICES}

APPENDIX A: Characteristic Impedance $Z_{\text {char }}$

Characteristic impedance for two coplanar strips on a dielectric slab of finite thickness

(Figure A1) [31] is required to evaluate the T-match odd mode impedance.

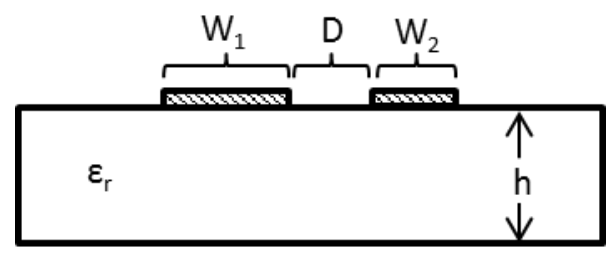

Figure A1: Asymmetric Coplanar Strip Cross-Section on Dielectric Slab of Finite Height and no Ground Plane

Characteristic impedance for asymmetric coplanar strips on a dielectric slab of finite height is [31]:

$$
Z_{\text {char }}=\frac{60 \pi}{\sqrt{\varepsilon_{e f f}}} \frac{K(k)}{K(k)},
$$

$\mathrm{K}(\mathrm{k})$ and $\mathrm{K}\left(\mathrm{k}^{\prime}\right)$ are complete elliptic integrals of the first kind. $\mathrm{K}(\mathrm{k}) / \mathrm{K}\left(\mathrm{k}^{\prime}\right)$ is approximated to an accuracy of $10^{-11}$ as [31]:

$$
\begin{aligned}
& \frac{K(k)}{K\left(k^{\prime}\right)} \cong \begin{cases}2 \pi \ln \left(2 \frac{\sqrt{1+k}+\sqrt[4]{4 k}}{\sqrt{1+k}-\sqrt[4]{4 k}}\right)^{-1}, & 0 \leq k \leq \frac{1}{\sqrt{2}} \\
\frac{1}{2 \pi} \ln \left(2 \frac{\sqrt{1+k^{\prime}}+\sqrt[4]{4 k^{\prime}}}{\sqrt{1+k^{\prime}}-\sqrt[4]{4 k^{\prime}}}\right), & \frac{1}{\sqrt{2}} \leq k \leq 1\end{cases} \\
& \varepsilon_{e f f}=1-\frac{\left(\varepsilon_{r}-1\right)}{2} \frac{K(k)}{K\left(k^{\prime}\right)} \frac{K\left(k_{1}\right)}{K\left(k_{1}^{\prime}\right)}, \\
& k=\sqrt{\frac{D}{b}\left(1+\frac{b}{d}-\frac{D}{d}\right)}, \\
& k_{1}=\sqrt{\frac{\left(t_{1}-t_{2}\right)\left(t_{3}-t_{2}\right)}{\left(t_{1}+t_{2}\right)\left(t_{3}+t_{2}\right)}},
\end{aligned}
$$




$$
\begin{gathered}
t_{n}=\frac{e^{\lambda_{n}-1}}{e^{\lambda_{n}+1}} \text { where } \mathrm{n}=1,2,3, \\
\lambda_{1}=\frac{\pi}{2}\left(\frac{2 W_{2}}{h}+\frac{D}{h}\right), \\
\lambda_{2}=\frac{\pi D}{2 h} \\
\lambda_{3}=\frac{\pi}{2}\left(\frac{2 W_{1}}{h}+\frac{D}{h}\right), \\
k^{\prime}=\sqrt{1-k^{2}}, \\
k_{1}^{\prime}=\sqrt{1-k_{1}^{2}}, \\
b=W_{2}+D
\end{gathered}
$$

The characteristic impedance of coplanar strips is used to derive the T-match odd mode impedance. 
APPENDIX B: Capacitance Per Unit Length for Two Cylindrical Conductors

A line of point charges $-q$ is parallel to the $z$-axis at $x=y=0$ (Figure B1), and a line of positive point charges $q$ is parallel to the z-axis at location $\vec{R}$. Potential $\varphi(\vec{x})$ per unit length at location $\vec{x}$ is found by using Coulomb's Law [32] and adding potentials from the two charges:

$$
\emptyset(\vec{x})=\frac{-q}{2 \pi \varepsilon_{o}}[\ln |\vec{x}-\vec{R}|-\ln |\vec{x}|]=\frac{q}{2 \pi \varepsilon_{o}} \ln \frac{|\vec{x}|}{|\vec{x}-\vec{R}|}
$$

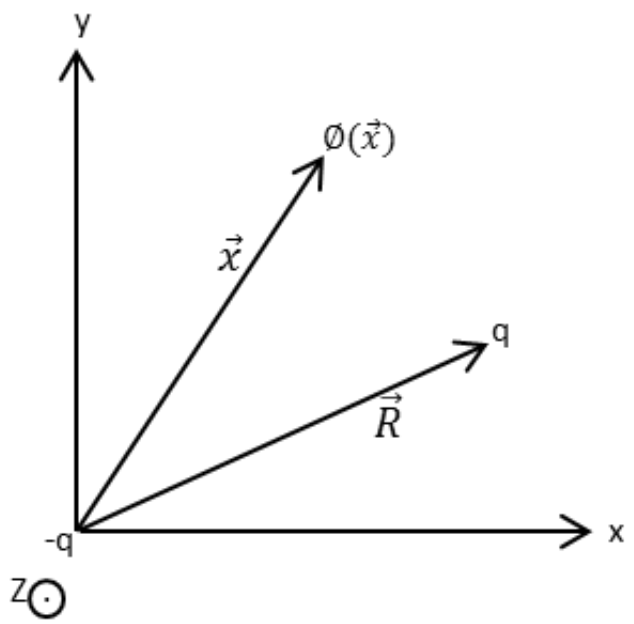

Figure B1: Z-axis Cross-section Positive and Negative Line Charges

Define equipotential surface $\varphi=V$. Rearranging (B.1):

$$
e^{\left(2 \pi \varepsilon_{o} V / q\right)}=\frac{|\vec{x}|}{|\vec{x}-\vec{R}|}
$$

Substituting $\zeta=e^{\left(2 \pi \varepsilon_{0} V / q\right)}$ in (B.2) yields:

$$
|\vec{x}-\vec{R}|=\zeta|\vec{x}|
$$

Squaring both sides of (B.3) and rearranging terms:

$$
\left(1-\zeta^{2}\right) x^{2}-2 \vec{x} \cdot \vec{R}+R^{2}=0
$$

Completing the square, the circle equation is: 


$$
\left|\vec{x}-\frac{\vec{R}}{1-\zeta^{2}}\right|^{2}=\frac{\zeta^{2} R^{2}}{\left(1-\zeta^{2}\right)^{2}}
$$

A circle is represented by $\left|\vec{x}-\vec{x}_{o}\right|^{2}=\rho^{2}$. The center of the circle, $\vec{x}_{o}$ is:

$$
\vec{x}_{o}=\frac{\vec{R}}{1-\zeta^{2}}=\frac{\vec{R}}{1-e^{\left(-4 \pi \varepsilon_{o} V / q\right)}}
$$

And the radius $\rho$ is:

$$
\rho=\frac{R \zeta}{\left|1-\zeta^{2}\right|}=\frac{R}{2\left|\sinh \left(2 \pi \varepsilon_{o} V / q\right)\right|}
$$

Hence, the equipotential surface of a line charge is a circle. For two distinct line charges, the two equipotential circles (Figure B2) are represented as the surfaces of two conductors where the separation distance $d$ is greater than the sum of the two radii $a$ and $b$.

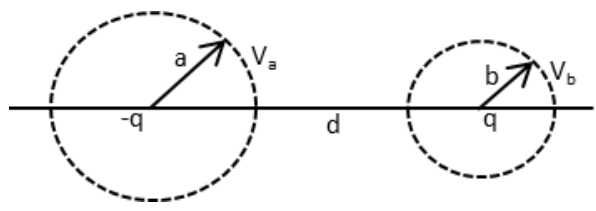

Figure B2: Two Equipotential Surfaces for Opposite Polarity Line Charges

Capacitance is the ratio of charge to voltage. The voltage between the two conductors is $V_{b}-V_{a}$. capacitance per unit length is:

$$
C=\frac{q}{V_{b}-V_{a}}
$$

To express the capacitance in terms of conductor geometry, distance $d$ is defined as the difference between the origins of the two charges:

$$
\begin{gathered}
d=\left|\vec{x}_{b o}-\vec{x}_{a o}\right|=\frac{R}{1-e^{-4 \pi \varepsilon_{o} V_{b} / q}}-\frac{R}{1-e^{-4 \pi \varepsilon_{o} V_{a} / q}} \\
=R \frac{e^{-4 \pi \varepsilon_{o} V_{b} / q}-e^{-4 \pi \varepsilon_{o} V_{a} / q}}{\left[1-e^{-4 \pi \varepsilon_{o} V_{b} / q}\right]\left[1-e^{-4 \pi \varepsilon_{o} V_{a} / q}\right]}=\frac{R}{2} \frac{\sinh \left(\frac{2 \pi \varepsilon_{o}\left(V_{a}-V_{b}\right)}{q}\right)}{\sinh \left(\frac{2 \pi \varepsilon_{o} V_{b}}{q}\right) \sinh \left(\frac{2 \pi \varepsilon_{o} V_{a}}{q}\right)} .
\end{gathered}
$$


Rewritten:

$$
\frac{2 d}{R} \sinh \left(\frac{2 \pi \varepsilon_{o} V_{b}}{q}\right) \sinh \left(\frac{2 \pi \varepsilon_{o} V_{a}}{q}\right)=\sinh \left(\frac{2 \pi \varepsilon_{o}\left(V_{a}-V_{b}\right)}{q}\right)
$$

From (B.7) when radius $\rho=a$ :

$$
\sinh \left(\frac{4 \pi \varepsilon_{o} V_{a}}{q}\right)=\frac{R}{2 a}
$$

From (B.7) when radius $\rho=b$ :

$$
\sinh \left(\frac{4 \pi \varepsilon_{0} V_{b}}{q}\right)=-\frac{R}{2 b}
$$

The following trigonometric identity is used:

$$
\cosh \left(\xi_{a}-\xi_{b}\right)=\cosh \left(\xi_{a}\right) \cosh \left(\xi_{b}\right)-\sinh \left(\xi_{a}\right) \sinh \left(\xi_{b}\right)
$$

Rearranging (B.13):

$$
\cosh \left(\xi_{a}-\xi_{b}\right)+\sinh \left(\xi_{a}\right) \sinh \left(\xi_{b}\right)=\cosh \left(\xi_{a}\right) \cosh \left(\xi_{b}\right)
$$

Squaring both sides of (B.14):

$$
\begin{gathered}
\cosh ^{2}\left(\xi_{a}-\xi_{b}\right)+2 \cosh \left(\xi_{a}-\xi_{b}\right) \sinh \left(\xi_{a}\right) \sinh \left(\xi_{b}\right)+\sinh ^{2}\left(\xi_{a}\right) \sinh ^{2}\left(\xi_{b}\right) \\
=\cosh ^{2}\left(\xi_{a}\right) \cosh ^{2}\left(\xi_{b}\right)
\end{gathered}
$$

Using the hyperbolic trigonometric identity $\cosh ^{2}(\xi)=1+\sinh ^{2}(\xi)$ on both right-hand terms of (B.15):

$$
\begin{aligned}
\cosh ^{2}\left(\xi_{a}-\xi_{b}\right) & +2 \cosh \left(\xi_{a}-\xi_{b}\right) \sinh \left(\xi_{a}\right) \sinh \left(\xi_{b}\right)+\sinh ^{2}\left(\xi_{a}\right) \sinh ^{2}\left(\xi_{b}\right) \\
= & {\left[1+\sinh ^{2}\left(\xi_{a}\right)\right]\left[1+\sinh ^{2}\left(\xi_{b}\right)\right] } \\
= & 1+\sinh ^{2}\left(\xi_{a}\right)+\sinh ^{2}\left(\xi_{b}\right)+\sinh ^{2}\left(\xi_{a}\right) \sinh ^{2}\left(\xi_{b}\right)
\end{aligned}
$$

Rearranging terms and applying $\cosh ^{2}\left(\xi_{a}-\xi_{b}\right)=1+\sinh ^{2}\left(\xi_{a}-\xi_{b}\right)$ to (B.16):

$$
2 \cosh \left(\xi_{a}-\xi_{b}\right) \sinh \left(\xi_{a}\right) \sinh \left(\xi_{b}\right)=\sinh ^{2}\left(\xi_{a}\right)+\sinh ^{2}\left(\xi_{b}\right)-\sinh ^{2}\left(\xi_{a}-\xi_{b}\right)
$$

The final form is: 


$$
\cosh \left(\xi_{a}-\xi_{b}\right)=\frac{1}{2}\left[\frac{\sinh \left(\xi_{a}\right)}{\sinh \left(\xi_{b}\right)}+\frac{\sinh \left(\xi_{b}\right)}{\sinh \left(\xi_{a}\right)}-\frac{\sinh ^{2}\left(\xi_{a}-\xi_{b}\right)}{\sinh \left(\xi_{a}\right) \sinh \left(\xi_{b}\right)}\right]
$$

Letting $\xi=4 \pi \varepsilon_{o} V / q$ and substituting (B.10), (B.11) and (B.12) into (B.18) yields:

$$
\cosh \left(\frac{2 \pi \varepsilon_{o}\left(V_{a}-V_{b}\right)}{q}\right)=\frac{1}{2}\left[-\frac{\mathrm{a}}{\mathrm{b}}-\frac{\mathrm{b}}{\mathrm{a}}+\frac{\mathrm{d}^{2}}{\mathrm{ab}}\right]=\frac{d^{2}-a^{2}-b^{2}}{2 a b}
$$

The capacitance per unit length is (B.8) is solved:

$$
C=\frac{q}{V_{b}-V_{a}}=2 \pi \varepsilon_{o}\left[\cosh ^{-1}\left(\frac{d^{2}-a^{2}-b^{2}}{2 a b}\right)\right]^{-1}
$$

If the two radii are equal, the capacitance reduces to:

$$
C=2 \pi \varepsilon_{o}\left[\cosh ^{-1}\left(\frac{d^{2}-a^{2}-b^{2}}{2 a b}\right)\right]^{-1}=2 \pi \varepsilon_{o}\left[\cosh ^{-1}\left(\frac{d^{2}-2 a^{2}}{2 a^{2}}\right)\right]^{-1}
$$

If $d>>$ a then:

$$
C=2 \pi \varepsilon_{o}\left[\cosh ^{-1}\left(\frac{d^{2}-2 a^{2}}{2 a^{2}}\right)\right]^{-1} \approx 2 \pi \varepsilon_{o}\left[\cosh ^{-1}\left(\frac{d^{2}}{2 a^{2}}\right)\right]^{-1}
$$

Applying $\cosh ^{-1}(x)=\ln \left[x+\sqrt{x^{2}-1}\right]$ yields:

$$
\begin{gathered}
C \approx 2 \pi \varepsilon_{o}\left[\cosh ^{-1}\left(\frac{d^{2}}{2 a^{2}}\right)\right]^{-1} \approx 2 \pi \varepsilon_{o} \ln \left[d^{2} / 2 a^{2}+\sqrt{\left(d^{2} / 2 a^{2}\right)^{2}-1}\right] \\
\approx \pi \varepsilon_{o} \ln (d / a)
\end{gathered}
$$


APPENDIX C: $\cosh ^{-1}(x)=\ln \left(x+\left(x^{2}-1\right)^{1 / 2}\right)$

This conversion is useful for simplifying capacitance per unit length of two cylindrical conductors.

$$
\begin{gathered}
2 x^{2}+2 x \sqrt{x^{2}-1}+1=2 x^{2}+2 x \sqrt{x^{2}-1}+1 \\
2 x^{2}+2 x \sqrt{x^{2}-1}=\left[x^{2}+2 x \sqrt{x^{2}-1}+\left(x^{2}-1\right)\right]+1 \\
2 x\left(x+\sqrt{x^{2}-1}\right)=\left(x+\sqrt{x^{2}-1}\right)\left(x+\sqrt{x^{2}-1}\right)+1 \\
2 x=\left(x+\sqrt{x^{2}-1}\right)+\frac{1}{\left(x+\sqrt{x^{2}-1}\right)} \\
2 x=e^{\ln \left(x+\sqrt{x^{2}-1}\right)}+e^{-\ln \left(x+\sqrt{x^{2}-1}\right)} \\
x=\frac{e^{\ln \left(x+\sqrt{x^{2}-1}\right)}+e^{-\ln \left(x+\sqrt{x^{2}-1}\right)}}{2} \\
x=\cosh \left[\ln \left(x+\sqrt{x^{2}-1}\right)\right]
\end{gathered}
$$

Therefore,

$$
\cosh ^{-1}(x)=\ln \left(x+\sqrt{x^{2}-1}\right)
$$


APPENDIX D: Splitting Factor in Odd Mode, Two-Port Network Analysis of T-Match Structure

The T-match is analyzed as a two-port, even and odd mode network (Figure D1). A reciprocal network has equal voltages at ports 1 and 2 when equal currents are applied to both ports. In a symmetrical network, input impedance equals output impedance. The $T$-Match network is reciprocal, but not symmetric. Hence, $Z_{12}$ equals $Z_{21}$, but $Z_{11}$ does not equal $Z_{22}$. $V_{1}$ represents source even and odd voltages, $V_{\mathrm{e} 1}$ and $V_{01}$, and $V_{2}$ represents voltages $V_{\mathrm{e} 2}$ and $V_{02}$. The generalized two-port network equation is:

$$
\begin{gathered}
\boldsymbol{V}=\boldsymbol{Z I} \\
{\left[\begin{array}{l}
V_{1} \\
V_{2}
\end{array}\right]=\left[\begin{array}{ll}
Z_{11} & Z_{12} \\
Z_{21} & Z_{22}
\end{array}\right]\left[\begin{array}{l}
I_{1} \\
I_{2}
\end{array}\right]}
\end{gathered}
$$

Applying reciprocal network conditions, $Z_{12}=Z_{21}$ :

$$
\left[\begin{array}{l}
V_{1} \\
V_{2}
\end{array}\right]=\left[\begin{array}{ll}
Z_{11} & Z_{12} \\
Z_{12} & Z_{22}
\end{array}\right]\left[\begin{array}{l}
I_{1} \\
I_{2}
\end{array}\right]
$$

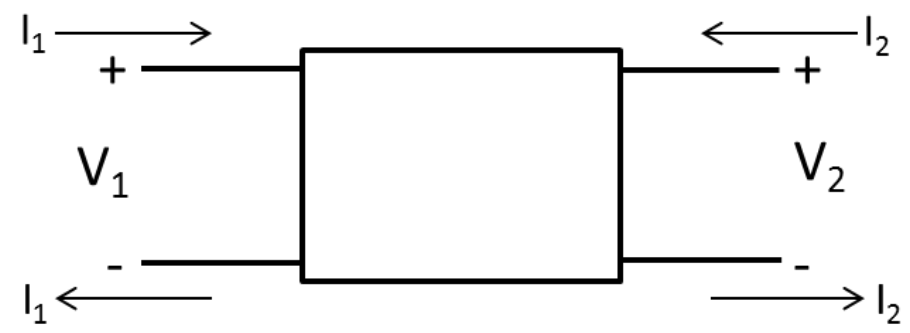

Figure D1: Two Port Network

In common mode operation, $\mathrm{V}_{1}=\mathrm{V}_{2}$ and $\mathrm{I}_{2}=\alpha \mathrm{l}_{1} ;$ (D.3) becomes:

$$
\left[\begin{array}{l}
V_{1} \\
V_{1}
\end{array}\right]=\left[\begin{array}{ll}
Z_{11} & Z_{12} \\
Z_{12} & Z_{22}
\end{array}\right]\left[\begin{array}{c}
I_{1} \\
\alpha I_{1}
\end{array}\right]
$$

Equating upper and lower rows: 


$$
V_{1}=Z_{11} I_{1}+Z_{12} \alpha I_{1}=Z_{12} I_{1}+Z_{22} \alpha I_{1}
$$

The splitting factor in terms of $Z$ parameters is:

$$
\alpha=\frac{Z_{11}-Z_{12}}{Z_{22}-Z_{12}}
$$

From Section $2.1(2-2)$, the even mode impedance is:

$$
Z_{e}=\frac{V_{e}}{(1+\alpha) I_{e}}
$$

Since $V_{e}=V_{1}$ and $I_{e}=I_{1}$, substituting $\alpha$ for the two-port network yields:

$$
Z_{e}=\frac{Z_{11} I_{1}+Z_{12} \alpha I_{1}}{I_{1}+\alpha I_{1}}=\frac{Z_{11}+\alpha Z_{12}}{1+\alpha}=\frac{Z_{11} Z_{22}-Z_{12}^{2}}{Z_{11}+Z_{22}-2 Z_{12}}
$$

For the differential mode, $\mathrm{I}_{1}=-\mathrm{I}_{2}$; equation (D.3) becomes:

$$
\left[\begin{array}{l}
V_{1} \\
V_{2}
\end{array}\right]=\left[\begin{array}{ll}
Z_{11} & Z_{12} \\
Z_{12} & Z_{22}
\end{array}\right]\left[\begin{array}{c}
I_{1} \\
-I_{1}
\end{array}\right]
$$

Defining $\mathrm{V}_{1}=\mathrm{V}_{\mathrm{o} 1}$ and $\mathrm{V}_{2}=\mathrm{V}_{\mathrm{o} 2}$ :

$$
\begin{aligned}
& V_{o 1}=Z_{11} I_{1}-Z_{12} I_{1} \\
& V_{o 2}=Z_{12} I_{1}-Z_{22} I_{1}
\end{aligned}
$$

Forming the ratio $\mathrm{V}_{\mathrm{o} 1} / \mathrm{N}_{\mathrm{o} 2}$ :

$$
\begin{gathered}
\frac{V_{o 1}}{V_{o 2}}=\frac{Z_{11}-Z_{12}}{Z_{12}-Z_{22}} \\
V_{o 1}=\frac{Z_{11}-Z_{12}}{Z_{12}-Z_{22}} V_{o 2}=-\frac{Z_{11}-Z_{12}}{Z_{22}-Z_{12}} V_{o 2}
\end{gathered}
$$

Using (D.6): 


$$
V_{o 1}=-\alpha V_{o 2}
$$

Equation (D.13) is used to solve the T-Match input impedance in Section 2.1. 
APPENDIX E: Inductive Loop Circuit Transformation
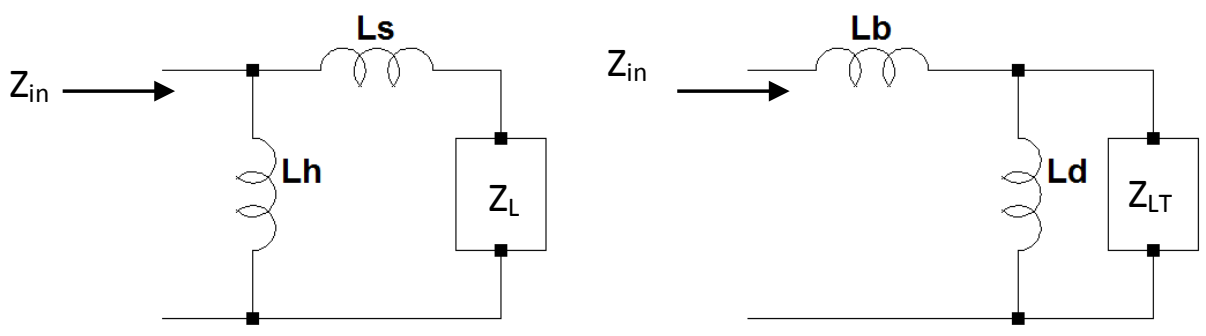

Figure E.1: (a) Original Circuit, (b) Transformed Circuit

The input impedance $Z_{\text {in }}$ from Figure $E .1 a$ is:

$$
Z_{\text {in }}=\frac{\left(Z_{L}+Z_{s}\right) Z_{h}}{Z_{L}+Z_{s}+Z_{h}}=\frac{Z_{h} Z_{L}+Z_{h} Z_{s}}{Z_{L}+Z_{s}+Z_{h}}
$$

which is re-written in the form:

$$
Z_{\text {in }}=\left[\frac{Z_{h}}{Z_{s}+Z_{h}}\right]^{2} \frac{Z_{L}\left(Z_{s}+Z_{h}\right)}{\left(Z_{L}+Z_{s}+Z_{h}\right)}+\frac{Z_{h} Z_{s}}{Z_{s}+Z_{h}}
$$

The input impedance of Figure E.1b is:

$$
Z_{\text {in }}=\frac{Z_{L T} X_{d}}{Z_{L T}+X_{d}}+X_{b}
$$

Let:

$$
\beta=\frac{X_{h}}{X_{h}+X_{s}}=\frac{L_{h}}{L_{h}+L_{s}}
$$

Equate (E.2) to (E.3) and compare similar terms to find $X_{b}, L_{b}, Z_{L T}$ and $X_{d}$ :

$$
\begin{gathered}
X_{b}=\frac{X_{h} X_{s}}{X_{S}+X_{h}} \\
L_{b}=\frac{L_{h} L_{s}}{L_{h}+L_{s}} \\
Z_{L T}=\beta^{2} Z_{L} \\
X_{d}=\beta^{2}\left(X_{h}+X_{S}\right)
\end{gathered}
$$


(E.8) reduces to:

$$
L_{d}=\beta^{2}\left(L_{h}+L_{s}\right)
$$

